\title{
Idaho Nuclear Technology and Engineering Center Sodium- Bearing Waste Treatment Research and Development FY-2002 Status Report
}

\author{
A. K. Herbst \\ J. A. DelDebbio \\ R. J. Kirkham \\ B. A. Scholes \\ T. L. Watson
}

September 2002

Idaho National Engineering and Environmental Laboratory Bechtel BWXT Idaho, LLC 


\title{
Idaho Nuclear Technology and Engineering Center Sodium-Bearing Waste Treatment Research and Development FY-2002 Status Research
}

\author{
A. K. Herbst \\ J. A. DelDebbio \\ R. J. Kirkham \\ B. A. Scholes \\ T. L. Watson \\ September 2002 \\ Idaho National Engineering and Environmental Laboratory \\ Idaho Falls, Idaho 83415 \\ Prepared for the \\ U.S. Department of Energy \\ Assistant Secretary for Environmental Management \\ Under DOE Idaho Operations Office \\ Contract DE-AC07-99ID13727
}




\begin{abstract}
The Idaho National Engineering and Environmental Laboratory (INEEL) is considering several optional processes for disposal of liquid sodium-bearing waste. During fiscal year 2002, immobilization-related research included of grout formulation development for sodium-bearing waste, absorption of the waste on silica gel, and off-gas system mercury collection and breakthrough using activated carbon. Experimental results indicate that sodium-bearing waste can be immobilized in grout at 70 weight percent and onto silica gel at 74 weight percent. Furthermore, a loading of 11 weight percent mercury in sulfur-impregnated activated carbon was achieved with $99.8 \%$ off-gas mercury removal efficiency.
\end{abstract}




\section{EXECUTIVE SUMMARY}

The Idaho National Engineering and Environmental Laboratory, specifically the Idaho Nuclear Technology and Engineering Center (INTEC) High-Level Waste Program, is to prepare the liquid sodium-bearing waste and calcined solids for eventual disposal. Several alternative treatment processes and disposal paths have been explored for these wastes. This report discusses research conducted on three process options: grouting of sodium-bearing waste following cesium removal, immobilization of sodium-bearing waste on silica gel following cesium removal, and use of activated carbon for mercury removal in the calciner or steam reformer off-gas system.

During this fiscal year, the option of grouting sodium-bearing (SBW) waste was revisited to ensure the processes were still viable based on the latest flow sheets and projected SBW compositions. It was determined that the grout formulation for 70 weight percent continued to be satisfactory. New work was started for grouting of nitric acid such as that from the Liquid Effluent Treatment and Disposal Facility. Initial findings showed that 12 molar nitric acid can be grouted at 35 weight percent.

Research continued on the absorption of SBW on silica gel. The process provides a simple method of solidifying the SBW for transportation or disposal. If the SBW is placed on silica gel at ambient temperatures, waste loadings of 74 weight percent can be achieved with a single addition. If the SBW and silica gel are heated more moisture and acid are driven off and waste loadings of 90 weight percent were found.

If thermal methods are pursued for SBW treatment, it is proposed to use activated carbon to control mercury release in the off-gas systems. The activated carbon bed's mercury removal efficiency and breakthrough loading for the New Waste Calciner Facility were researched this fiscal year. It was found that a breakthrough loading of 11 weight percent and a removal efficiency of up to $99.8 \%$ were achievable. 


\section{NOMENCLATURE}

\author{
Alkaline Grout \\ Blast Furnace Slag
}

Calcination

Cement

CsIX

Denitration

Fly Ash

GAC

Grout

HEPA Filter

Leaching
A grout formulation where the waste is rendered basic $(\mathrm{pH}>$ 12) and mixed with a 9:1 blend of blast furnace slag and portland cement.

A finely ground non-metallic waste product developed in the manufacture of pig iron, consisting basically of a mixture of lime, silica, and alumina, the same oxides that make up portland cement, but not in the same proportions or forms.

The process of converting a liquid to a solid granular product called calcine.

Refers to type I/II portland cement.

Removal of cesium from a liquid via an ion exchange media.

Thermal process to destroy the nitrate content of the waste.

A pozzolan of finely divided residue that results from the combustion of ground or powdered coal. Class C fly ash may contain $10 \%$ lime, has cementitious properties, and reacts with water to form a solid. Class F fly ash does not use water and aids in grout flow.

Granulated activated carbon.

A mixture of portland cement, other powdered additives, waste, and water. It may contain fine-grained sand and does not include large aggregate material. For this study, grouting is the process of solidifying and stabilizing low-level waste in cement-based materials.

High efficiency particulate air filter.

The process whereby a liquid agent will dissolve hazardous materials within a waste mass and transport these materials through the mass and beyond. The most widely used laboratory leaching test is the TCLP (Toxic Characteristic Leaching Procedure) specified by the EPA in several regulations. For many treated and untreated wastes, the results of this test determines whether the EPA considers the material toxic or not. 
Low-Activity Waste

NGLW

Portland Cement

Pozzolan

Solidification

Stabilization

Waste Form

Waste Loading

Vitrification
Low-level waste derived from the solvent extraction, ion exchange, and chemical extraction separation processes on the tank farm sodium-bearing waste and on the dissolved calcines.

Newly generated liquid waste -- low-level waste projected to be produced that is not part of the existing tank farm inventory. Sources are the process equipment waste system, decontamination solutions, and filter leach solutions.

The product obtained by pulverizing clinker consisting essentially of hydraulic calcium silicates.

A siliceous or siliceous and aluminous material that reacts with liquid calcium hydroxide in the cement gel to form compounds possessing cementitious properties.

The process of producing from liquid, sludge, or loose solids a more or less monolithic structure having some integrity. Occasionally, solidification may refer to the process that results in a soil-like material rather than a monolithic structure. Solidification does not necessarily reduce leaching of hazardous materials. However, when a waste is solidified, its mass and structure are altered, decreasing migration of solutions within the mass.

Generally refers to a purposeful chemical reaction that is carried out to make waste constituents less leachable. This is accomplished by chemically immobilizing hazardous materials or reducing their solubility by a chemical reaction.

The final product for long-term storage. This includes the solidified/stabilized waste as well as the container. The waste form must pass extensive qualification testing prior to release for storage.

The mass weight percent of the waste in the total mass of the final waste form.

The process of placing waste material in a glass form. This is a thermal process where the waste material is placed in a melter with glass forming material (chemicals or frit), then heated together, poured into a storage container, and cooled to a solid form. 


\section{CONTENTS}

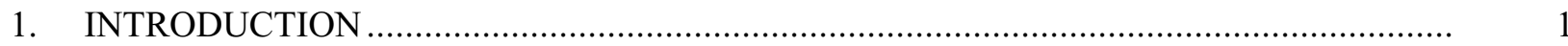

2. GROUT FORMULATION TESTING .................................................................. 2

2.1 Background and Test Method .......................................................................

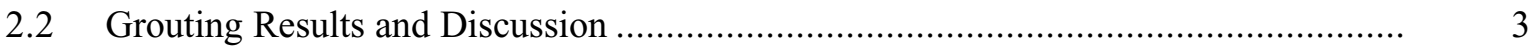

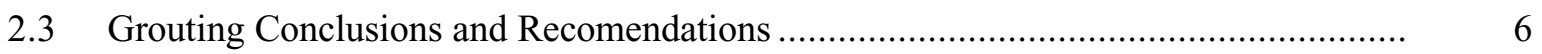

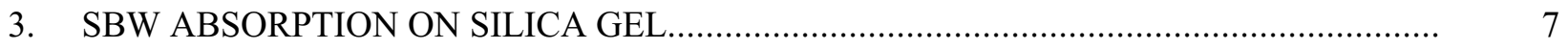

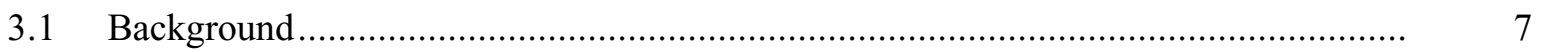

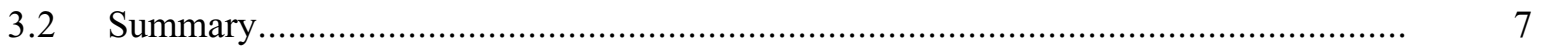

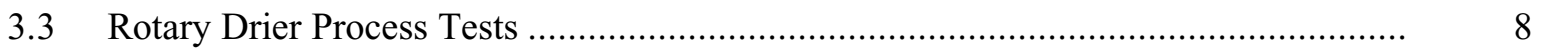

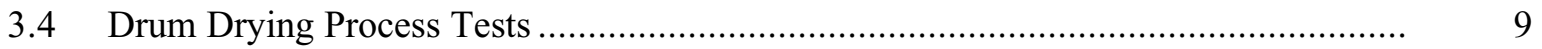

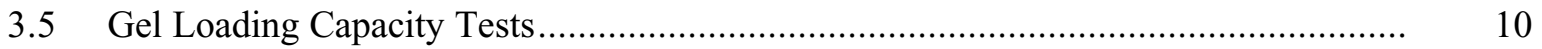

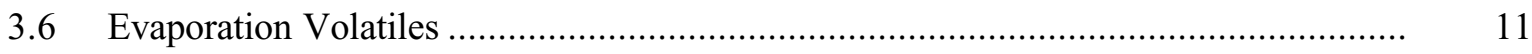

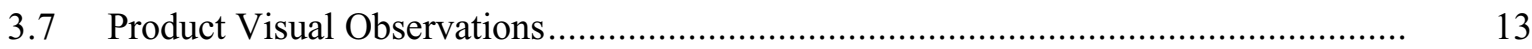

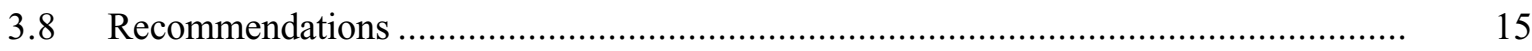

4. MERCURY REMOVAL BY ACTIVATED CARBON ...................................................... 16

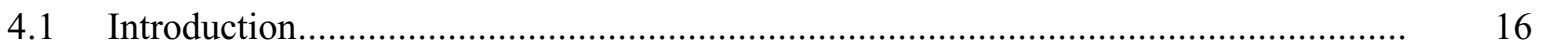

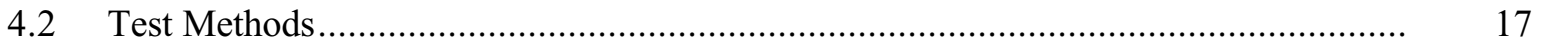

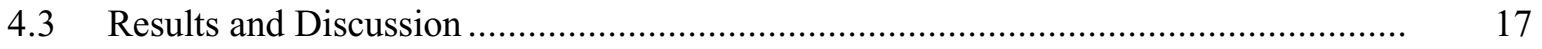

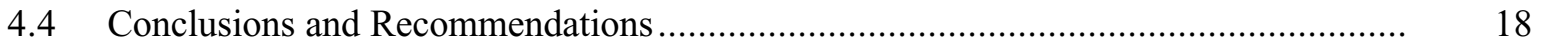

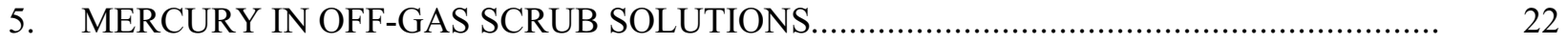

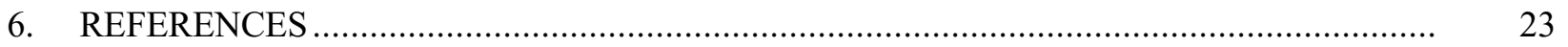




\section{FIGURES}

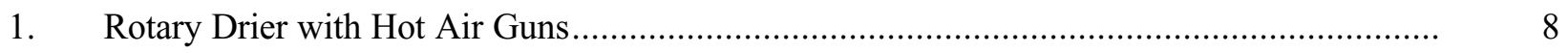

2. Mass Fraction of Volatiles Found in the Condensate vs. Temperature ............................... 12

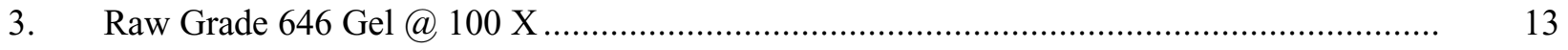

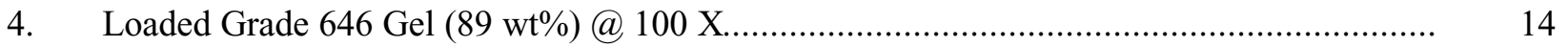

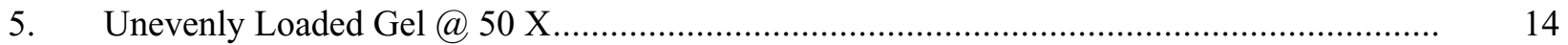

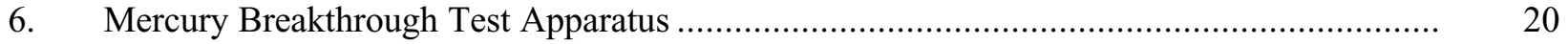

\section{TABLES}

1. Projected Sodium-Bearing Waste Compositions .............................................................. 2

2. Acid Neutralization Temperature ............................................................................

3. Recommended Grout Formulation and Waste Form Density ......................................... 3

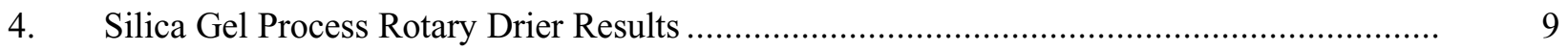

5. New Sodium-Bearing Waste Simulant Composition and Analyses ................................ 10

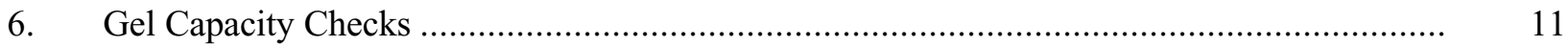

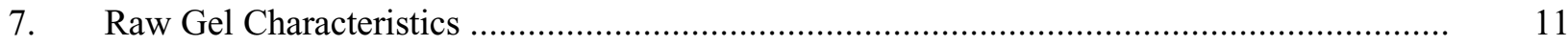

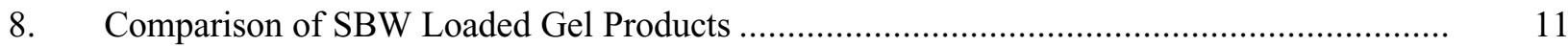

9. Mercury Removal Efficiencies, Breakthrough Loadings, and TCLP Results for

\section{APPENDICES}

A. Grouted Waste Formulation Data

B. Mercury Characterization In Off-Gas Scrub Solutions 


\section{IDAHO NUCLEAR TECHNOLOGY AND ENGINEERING CENTER SODIUM-BEARING WASTE TREATMENT RESEARCH AND DEVELOPMENT FY-2002 STATUS REPORT}

\section{INTRODUCTION}

The Idaho National Engineering and Environmental Laboratory, specifically the Idaho Nuclear Technology and Engineering Center (INTEC) High-Level Waste Program, is to prepare the liquid sodiumbearing waste and calcined solids for eventual disposal. Several alternative treatment processes and disposal paths have been explored for these wastes. During fiscal year 2002, four options were studied for the sodium-bearing waste: cesium ion exchange, ${ }^{1}$ evaporation/crystalization, ${ }^{2}$ steam reforming, ${ }^{3}$ and calcination. This report discusses three subsets of these options: grouting of sodium-bearing waste following cesium removal, immobilization of sodium-bearing waste on silica gel following cesium removal, and use of activated carbon for mercury removal in a calciner or steam reformer off-gas system.

The cesium ion exchange process (CsIX) proposes to remove the cesium from the sodium-bearing waste (SBW), immobilize the waste, and ship it to the Waste Isolation Pilot Plant (WIPP) for disposal. By this process, the cesium is removed to reduce the gamma radiation and permit contact handling of the waste form. Following CsIX, immobilization of the SBW can be accomplished by grouting or by absorption on silica gel. Both of these options were initially reported in FY-2000. During this fiscal year, the options were revisited to ensure that these immobilization processes were still viable based on the latest flow sheets and projected SBW compositions. The principal investigator for grout immobilization is $\mathrm{A}$. K. Herbst and R. J. Kirkham is the principal investigator for the silica gel tests.

In the evaporation or fractional crystallization options, much of the water and acid in the wastes are driven off. The acidic liquid becomes a secondary waste that must also be treated and disposed of. Research was completed to determine if this highly acidic waste could be grouted. The waste form would be disposed of at a low-level waste facility such as Envirocare of Utah. It is also noted that, in the case of heating the silica gel containing SBW to reduce the weight and increase waste loading, the water and acid condensates would also need such treatment.

In the case of steam reforming or calcination of the SBW, an off-gas treatment system would be required. It has been proposed to utilize an activated carbon bed to ensure that the off-gas meets air emission standards. For these thermal treatment options, it is expected that mercury would be volatilized; thus sulfur-impregnated activated carbon could capture the mercury and prevent its release. The mercury collection efficiency and the breakthrough capacity of the activated carbon for the New Waste Calciner Facility were also researched this fiscal year. J. A. DelDebbio is the principal investigator for mercury studies.

Also included in this report is a study completed by Idaho State University on the characterization of mercury in the off-gas scrub system of a pilot scale melter. Although vitrification is not currently being studied, this scrubber study is applicable to other SBW thermal treatment processes such as steam reforming or calcination. 


\section{GROUT FORMULATION TESTING}

\subsection{Background and Test Method}

The Idaho National Engineering and Environmental Laboratory (INEEL) is considering several process alternatives for disposal of sodium-bearing waste (SBW) at the Idaho Nuclear Technology and Engineering Center (INTEC). One process option is to remove the radioactive cesium from the SBW and grout the remaining liquid as transuranic (TRU) waste. By removing the cesium, the waste form would be contact handled TRU waste. The grouted waste could then be sent to the Waste Isolation Pilot Plant for disposal. It is proposed to remove the cesium via ion exchange; thus, the process is given the acronym of CsIX. Earlier research on CsIX grout was completed in fiscal year 2000 where it was reported that the SBW could be direct grouted with a waste loading as high as 70 weight percent. ${ }^{4}$ Since that time, the SBW was evaporated to reduce the waste volume and new SBW compositions and flowsheets have been prepared. Two SBW compositions have been reported: first is the composition for an individual storage tank designated as tank WM- $180^{5}$ and second is an average composition for all the SBW tanks and is called composite SBW. ${ }^{6}$ The molar compositions of these projected wastes are shown in Table 1.

Table 1. Projected Sodium-Bearing Waste Compositions

\begin{tabular}{|c|c|c|c|c|c|}
\hline Species & $\begin{array}{l}\text { WM-180 } \\
\text { SBW } \\
\text { Mole/Liter }\end{array}$ & $\begin{array}{l}\text { Composite } \\
\text { SBW } \\
\text { Mole/Liter }\end{array}$ & Species & $\begin{array}{c}\text { WM-180 } \\
\text { SBW } \\
\text { Mole/Liter }\end{array}$ & $\begin{array}{l}\text { Composite } \\
\text { SBW } \\
\text { Mole/Liter }\end{array}$ \\
\hline $\mathrm{Ag}^{+1}$ & $5.29 \mathrm{E}-06$ & $1.46 \mathrm{E}-05$ & $\mathrm{Mg}^{+2}$ & $1.20 \mathrm{E}-02$ & $9.26 \mathrm{E}-03$ \\
\hline $\mathrm{Al}^{+3}$ & $6.63 \mathrm{E}-01$ & $5.82 \mathrm{E}-01$ & $\mathrm{Mn}^{+4}$ & $1.41 \mathrm{E}-02$ & $1.56 \mathrm{E}-02$ \\
\hline $\mathrm{As}^{+5}$ & $4.99 \mathrm{E}-04$ & $2.14 \mathrm{E}-04$ & $\mathrm{Mo}^{+6}$ & $1.93 \mathrm{E}-04$ & $1.97 \mathrm{E}-04$ \\
\hline $\mathrm{B}^{+3}$ & $1.23 \mathrm{E}-02$ & $1.91 \mathrm{E}-02$ & $\mathrm{Na}^{+1}$ & $2.06 \mathrm{E}+00$ & $1.59 \mathrm{E}+00$ \\
\hline $\mathrm{Ba}^{+2}$ & $5.58 \mathrm{E}-05$ & $7.92 \mathrm{E}-05$ & $\mathrm{Ni}^{+2}$ & $1.47 \mathrm{E}-03$ & $3.46 \mathrm{E}-03$ \\
\hline $\mathrm{Ca}^{+2}$ & $4.72 \mathrm{E}-02$ & $5.37 \mathrm{E}-02$ & $\mathrm{NO}_{3}{ }^{-1}$ & $5.01 \mathrm{E}+00$ & $5.93 \mathrm{E}+00$ \\
\hline $\mathrm{Cd}^{+2}$ & $7.54 \mathrm{E}-04$ & $4.77 \mathrm{E}-03$ & $\mathrm{~Pb}^{+2}$ & $1.31 \mathrm{E}-03$ & $2.26 \mathrm{E}-03$ \\
\hline $\mathrm{Cl}^{-1}$ & $3.00 \mathrm{E}-02$ & $2.55 \mathrm{E}-02$ & $\mathrm{Pd}^{+3}$ & $2.35 \mathrm{E}-05$ & $9.87 \mathrm{E}-06$ \\
\hline $\mathrm{Cr}^{+3}$ & $3.35 \mathrm{E}-03$ & $4.93 \mathrm{E}-03$ & $\mathrm{PO}_{4}{ }^{-3}$ & $1.37 \mathrm{E}-02$ & $7.73 \mathrm{E}-03$ \\
\hline $\mathrm{Cs}^{+1}$ & $7.73 \mathrm{E}-06$ & $1.45 \mathrm{E}-05$ & $\mathrm{Ru}^{+4}$ & $1.25 \mathrm{E}-04$ & $5.51 \mathrm{E}-05$ \\
\hline $\mathrm{Cu}^{+2}$ & $6.97 \mathrm{E}-04$ & $8.47 \mathrm{E}-04$ & $\mathrm{Sb}^{+3}$ & $6.38 \mathrm{E}-05$ & $2.64 \mathrm{E}-05$ \\
\hline $\mathrm{F}^{-1}$ & $4.74 \mathrm{E}-02$ & $8.32 \mathrm{E}-02$ & $\mathrm{Se}^{+4}$ & $1.46 \mathrm{E}-04$ & $4.69 \mathrm{E}-05$ \\
\hline $\mathrm{Fe}^{+3}$ & $2.17 \mathrm{E}-02$ & $2.26 \mathrm{E}-02$ & $\mathrm{Si}^{+4}$ & $3.02 \mathrm{E}-07$ & $2.19 \mathrm{E}-03$ \\
\hline $\mathrm{Gd}^{+3}$ & $1.77 \mathrm{E}-04$ & $7.78 \mathrm{E}-05$ & $\mathrm{Sr}^{+2}$ & $1.19 \mathrm{E}-04$ & $5.10 \mathrm{E}-05$ \\
\hline $\mathrm{H}^{+1}$ & $1.01 \mathrm{E}+00$ & $2.24 \mathrm{E}+00$ & $\mathrm{SO}_{4}{ }^{-2}$ & $5.40 \mathrm{E}-02$ & $5.28 \mathrm{E}-02$ \\
\hline $\mathrm{Hg}^{+2}$ & $2.02 \mathrm{E}-03$ & $3.10 \mathrm{E}-03$ & $\mathrm{~V}^{+5}$ & $9.23 \mathrm{E}-04$ & $3.70 \mathrm{E}-04$ \\
\hline $\mathrm{K}^{+1}$ & $1.96 \mathrm{E}-01$ & $1.71 \mathrm{E}-01$ & $\mathrm{Zn}^{+2}$ & $1.05 \mathrm{E}-03$ & $1.46 \mathrm{E}-03$ \\
\hline $\mathrm{Li}^{+1}$ & $3.39 \mathrm{E}-04$ & $3.48 \mathrm{E}-04$ & $\mathrm{Zr}^{+4}$ & $6.33 \mathrm{E}-05$ & $1.16 \mathrm{E}-02$ \\
\hline
\end{tabular}

During fiscal year 2002, short scoping tests were conducted to verify the grout formulation for these latest sodium-bearing waste (SBW) composition and flowsheets. Additionally, 12 molar nitric acid, such as that projected from the Liquid Effluent Treatment and Disposal Facility (LET\&D) was test grouted. The simulated wastes were prepared and grouted in sets of three 2-inch cubes. For these small samples, manual stirring was used. Details of the sample sets are noted in Appendix A. Each waste was tested with two grout formulations. The CsIX formulation is designed to maximize waste loading while meeting the no free liquid and minimum physical strength requirements of the WIPP acceptance criteria. The second is 
the alkaline formulation which is designed as a "performance grout" that provides more physical strength and leach resistance. The alkaline formulation serves as a backup should the CsIX formulation prove unacceptable at a latter date. For the scoping tests, the waste loading for the CsIX formulation was tested at $70 \mathrm{wt} \%+/-5 \mathrm{wt} \%$ and the waste loading for the alkaline formulation was tested at $50 \mathrm{wt} \%+/-5 \mathrm{wt} \%$.

Since Portland cement chemistry is caustic and the projected wastes are acidic, the formulations utilize neutralization as part of the grouting process. The CsIX formulation uses powdered calcium hydroxide and the alkaline formulation uses liquid sodium hydroxide. Process designers want to know whether cooling is needed during the neutralization step. Thus, the neutralization temperatures were modeled using HSC Chemistry software and the experimental data recorded.

\subsection{Grouting Results and Discussion}

Table 2 lists the results of the neutralization portion of the grouting process. Chemical model and experimental neutralization temperatures are noted for each of the projected wastes using calcium hydroxide and sodium hydroxide. Table 3 lists the recommended grout formulation for the projected waste based on qualitative properties, such as no free liquid (bleed water), wet grout rheology, cure time, and grout stability. Further details and comments for each of the sample sets are noted in Appendix A. A discussion of the neutralization and grouting processes for each waste is noted in the subsections that follow.

Table 2. Acid Neutralization Temperature

\begin{tabular}{|c|c|c|c|c|}
\hline \multirow{2}{*}{ Simulant } & \multicolumn{2}{|c|}{$\mathrm{HSC}$ Chemistry Prediction } & \multicolumn{2}{c|}{ Experimental Results } \\
\cline { 2 - 5 } & $\mathrm{Ca}(\mathrm{OH})_{2}$ & $50 \% \mathrm{NaOH}$ & $\mathrm{Ca}(\mathrm{OH})_{2}$ & $50 \% \mathrm{NaOH}$ \\
\hline WM-180 SBW & $62^{\circ} \mathrm{C}$ & $50^{\circ} \mathrm{C}$ & $48^{\circ} \mathrm{C}$ & $56^{\circ} \mathrm{C}$ \\
\hline Composite SBW & $84^{\circ} \mathrm{C}$ & $66^{\circ} \mathrm{C}$ & $47^{\circ} \mathrm{C}$ & $67^{\circ} \mathrm{C}$ \\
\hline 12M Nitric Acid & $298^{\circ} \mathrm{C}$ & $200^{\circ} \mathrm{C}$ & $50^{\circ} \mathrm{C} *$ & $55^{\circ} \mathrm{C} *$ \\
\hline 3 M Nitric Acid & $87^{\circ} \mathrm{C}$ & $75^{\circ} \mathrm{C}$ & $63^{\circ} \mathrm{C}$ & $70^{\circ} \mathrm{C}$ \\
\hline
\end{tabular}

* Automated stirring - all others used manual stirring.

Table 3. Recommended Grout Formulation and Waste Form Density

\begin{tabular}{|c|c|c|c|c|c|}
\hline $\begin{array}{c}\text { Waste } \\
\text { Stream }\end{array}$ & $\begin{array}{c}\text { Waste } \\
(\mathrm{wt} \%)\end{array}$ & $\begin{array}{c}\mathrm{Ca}(\mathrm{OH})_{2} \\
(\mathrm{wt} \%)\end{array}$ & $\begin{array}{c}\text { Slag } \\
(\mathrm{wt} \%)\end{array}$ & $\begin{array}{c}\text { Cement } \\
(\mathrm{wt} \%)\end{array}$ & $\begin{array}{c}\text { Density } \\
\left(\mathrm{g} / \mathrm{cm}^{3}\right)\end{array}$ \\
\hline WM-180 SBW & 70 & 14 & 9 & 7 & 1.41 \\
\hline Composite SBW & 70 & 14 & 9 & 7 & 1.43 \\
\hline 12M Nitric Acid & 35 & 12.5 & 13.1 & 39.4 & 2.06 \\
\hline 3 M Nitric Acid & 47.5 & 9.7 & 21.4 & 21.4 & 1.61 \\
\hline
\end{tabular}

\subsubsection{WM-180 SBW Grouting}

Neutralization: The CsIX formulation utilizes calcium hydroxide to neutralize the SBW acidity. In this scoping test, the neutralization was done with manual stirring while adding small increments of calcium hydroxide to the acid. The WM-180 acidity is at 1.01 molar which is considerably less than other simulants tested to date. The HSC Chemistry software predicts the neutralization temperature to be $62.5^{\circ} \mathrm{C}$. With one-half the calcium hydroxide, the solution temperature reached $43^{\circ} \mathrm{C}$ and with all the calcium hydroxide, the maximum solution temperature was $48^{\circ} \mathrm{C}$. It is noted that with one-half the 
calcium hydroxide in the acid, the solution gelled; thus, this will need to be watched in the process neutralization vessel to avoid plugging problems. With the alkaline grout formulation, liquid sodium hydroxide at $50 \mathrm{wt} \%$ is used to neutralize the acidity. HSC Chemistry predicts the neutralization temperature to be $50^{\circ} \mathrm{C}$. In the test the temperature went to $56^{\circ} \mathrm{C}$ with manual stirring. The solution did not gel with the acid added slowly to the sodium hydroxide to keep the solution caustic.

Grouting: For the CsIX formulation, the $70 \mathrm{wt} \%$ was found to be satisfactory. The $75 \mathrm{wt} \%$ grout cubes shrunk in size and developed concave sides. For the $65 \mathrm{wt} \%$ batch, the wet grout mixture was too thick for good mixing. For the alkaline grout formulation, the $55 \mathrm{wt} \%$ batch produced stratified cubes where a layer of powdery grout was on the top of the cubes, indicating the mix was too thin and the cement particles settled in the wet mix prior to set up. The $50 \mathrm{wt} \%$ batch developed bleed water overnight. The $45 \mathrm{wt} \%$ batch was satisfactory as a thixotropic fluid mix. A $35 \mathrm{wt} \%$ batch was tried, but it was extremely thick. From these data points, the CsIX formulation at $70 \mathrm{wt} \%$ loading is recommended as noted in Table 3.

\subsubsection{Composite SBW Grouting}

Neutralization: Due to the higher acidity (2.24 molar), the HSC predicted temperatures are somewhat higher for composite SBW, but should be easily handled in a cooled neutralization vessel with stirring. It is noted that the experimental temperature results for sodium hydroxide are higher than for calcium hydroxide. It is postulated that this is a factor of the time of addition. As a liquid, the sodium hydroxide is easier and faster to add with a less vigorous reaction than is the solid calcium hydroxide. Automatic feed control and stirring will improve calcium hydroxide addition.

Grouting: From a qualitative perspective for the CsIX formulation, again the $75 \mathrm{wt} \%$ batch was very fluid, the $65 \mathrm{wt} \%$ batch was too thick, whereas the $70 \mathrm{wt} \%$ batch was acceptable at the mix stage. After 28 days of curing, it was noted that the $75 \mathrm{wt} \%$ batch was still soft, not fully set up. The $65 \mathrm{wt} \%$ and $70 \mathrm{wt} \%$ batch cubes were satisfactory after curing 28 days. Physical strength is not a required waste acceptance criterion, but is evidence of the grout consistency and lack of bleed water. The alkaline grout performed much the same. The $55 \mathrm{wt} \%$ batch did not set up. The $45 \mathrm{wt} \%$ and $50 \mathrm{wt} \%$ batches were thick and needed to be tamped and vibrated into the molds. Thus, the CsIX grout formulation maximizes the waste loading while meeting the acceptance criteria.

Based on the $70 \mathrm{wt} \%$ loading and the experimental densities, waste classification and radioactive dose calculations were completed for the composite SBW. The waste classification is made based on nine major radionuclides in the waste as noted by the data sheet in Appendix A. The waste would be classed as transuranic (TRU) as the sum of the long-lived alpha radionuclides is $429 \mathrm{nCi} / \mathrm{g}$, well over the required $100 \mathrm{nCi} / \mathrm{g}$. The radioactivity of the drum of grouted waste is estimated at $48 \mathrm{mR} / \mathrm{hr}$ on contact based on calculations using MicroShield (Appendix A). The values used in these calculations are found in Reference 6 where the values were decayed to 2016. Since the waste drum exposure rate is less than the maximum of $200 \mathrm{mR} / \mathrm{hr}$ for contact handling at WIPP, the grouted waste could be sent to WIPP for disposal as contact handled TRU waste.

\subsubsection{Nitric Acid Grouting}

Neutralization: Due to the very high neutralization temperatures for 12 molar nitric acid as noted by HSC in Table 2, the acid was initially diluted to 3 molar and then grouted as noted in Table 3 . This produced a good waste form but created a much larger volume for disposal than desired. The 12 molar neutralization was run through the Aspen chemical process model and found that the reaction could be sufficiently 
cooled to avoid boiling. Therefore, neutralization and grouting of 12 molar nitric acid was tested in the laboratory. As expected with both calcium hydroxide and sodium hydroxide, the reaction was rather violent producing vigorous bubbling and some off-gas. The reaction was controlled by placing the reaction beaker in a cold water bath, by adding automated stirring, and by adding very small incremental amounts of the caustic to the acid. These measures reduced the bubbling and off-gas considerably.

With calcium hydroxide the neutralization process is slower in that chemical solubility limits are being approached. The solution tends to stay acidic even after all the calcium hydroxide has been added to the acid but has not dissolved. Initially, the calcium hydroxide readily dissolves, but as the stoichiometric amount is approached, the dissolution slows down and considerable undissolved calcium hydroxide remains in the solution. Further mixing for up to an hour was needed to dissolve the calcium hydroxide and drive the solution basic. Excess calcium hydroxide is being added to help force the solution to go basic, but this leaves undissolved calcium hydroxide that must be slurried to the grout mixer. One other adverse reaction noted with calcium hydroxide was the generation of bubbles. As mentioned, as long as the calcium hydroxide is dissolving no foam is generated, but as the solution approaches neutrality, considerable bubbles are generated, as much as double the volume of the liquid. The foam eventually disappears as the calcium hydroxide dissolves with extended mixing. Further, it was noted that $2.5 \%$ of the mass of the combined waste and calcium hydroxide was lost during neutralization $(10 \mathrm{~g}$ lost out of $400 \mathrm{~g}$ batch). This is assumed to be water vapor given off due to the heat of reaction and bubbling.

The use of liquid sodium hydroxide is a much easier process to neutralize 12 molar nitric acid and does not have the adverse foaming noted above; however, the resulting solution was harder to grout as noted below. Thus, its use is not recommended in this application.

Grouting: The liquid from the sodium hydroxide neutralization was grouted with the standard alkaline formulation at $50 \mathrm{wt} \%$ produced bleed water, which is unacceptable. Modified batches at $30 \mathrm{wt} \%$ and 42 wt $\%$ with more Portland cement reduced the bleed water, but the cubes did not set up. Thus, the use of sodium hydroxide is not recommended until a better formulation can be developed to avoid bleed water and promote proper curing.

The $70 \mathrm{wt} \%$ batch made with the standard CsIX formulation and 3 molar nitric acid also did not work in that it was so fluid that it would never set up. Additional Portland cement was added to thicken the mix, which reduced to loading to about $50 \mathrm{wt} \%$. This is equivalent to $16 \mathrm{wt} \% 12$ molar nitric acid. Since both the CsIX and alkaline formulation were too fluid and more Portland cement had to be added, a modified grout formulation was developed that uses equal amounts of Portland cement and blast furnace slag as noted in Table 3 for 3 molar nitric acid. Using this formulation the waste loading for the 12 molar nitric acid was improved to $35 \mathrm{wt} \%$. This latter formulation does not produce bleed water, but took a week to set. It is preferred to have the grout solid after 24 hours. In this case, the grout is like hard clay after 24 hours and is free standing, but can be dented. Thus, one final formulation was tried with 3 parts Portland cement and 1 part slag as noted in Table 3 for 12 molar nitric acid. These latter samples set up as desired. The initial scoping tests will be verified with further laboratory testing next fiscal year. At the present, no radionuclide content has been projected for this nitric acid waste; however, it is expected to be low enough to allow disposal at Envirocare of Utah. 


\subsection{Grouting Conclusions and Recommendations}

The sodium-bearing and nitric acid wastes can be neutralized and solidified as noted in Tables 2 and 3 . The following bullets highlight the findings from these scoping tests.

- Composite and WM-180 SBW can be neutralized and grouted at $70 \mathrm{wt} \%$ :

○ Utilize the standard CsIX grout formulation.

- Partial neutralization is needed to avoid precipitate gelling prior to grout mixing.

○ Grouted waste volume increases by a factor of 1.23

- 12 molar nitric acid can be neutralized and grouted at $35 \mathrm{wt} \%$ with the following notes:

$\circ$ The mass loss during neutralization must be noted in the flowsheets.

$\circ$ The extensive foaming must be controlled.

$\circ$ Good cooling and mixing is essential during neutralization.

- Extended stirring is needed to dissolve the calcium hydroxide.

- Grout with 3 parts Portland cement to 1 part blast furnace slag. 


\title{
3. SBW ABSORPTION ON SILICA GEL
}

\author{
Supplemental Investigation of the Silica Gel Process \\ Alternative Waste Form for Sodium Bearing Waste
}

\subsection{Background}

Previous work using silica gel ( $\mathrm{Si} \mathrm{Gel}$ ) to process sodium bearing waste was reported in October $2000{ }^{4}$ The process appeared to be feasible and possessed some desirable advantages but some information was lacking to completely evaluate the process. This investigation was conducted to obtain that information:

1. The kinetics of absorption and drying were needed to design the mixer and drier.

2. Could the gel be used to absorb and dry the waste in-situ (within the disposal container)?

3. Are there better gel materials than those used during the prior work?

\subsection{Summary}

At the onset of this investigation it was assumed that only the information regarding items 2 and 3 above could be adequately obtained during the allotted time frame so an experimental plan was devised to seek them. It was believed that a drier mixer could not be designed and procured in time. Much information, however, was obtained about all three.

A rotary drier was assembled from available laboratory equipment. Dried Si Gel product was obtained at waste loadings of up to $89 \%$ and volume reductions of around $50 \%$.

Attempts to dry within the disposal container were frustrated by the inability to properly mix the simulant with the gel. One part of the gel was loaded heavier and would produce blockages that inhibited drying. Drying time was too long to be practical and a reasonable approach to the distribution of the liquid and drying airflow within drums seemed insurmountable. Higher temperatures could have improved the drying time and airflow but the other problem resulted in the decision to stop all work on this method. We just simply failed to find a way we could make it work. Higher simulant waste loadings require good simulantgel mixing. If lower waste loadings are practical, then this method can be re-examined. A simple test using waste simulant and Grade $646 \mathrm{Gel}$ produced a waste loading of $74 \mathrm{wt} \%$ and volume loading of 0.84 liters of simulant per liter of product without mixing or drying.

Another gel with a larger pore size than Grade 12 was found to perform better under maximum loading conditions and using the rotary drier. Gel Grade 646 with a 150 micron pore size can be loaded to over 90 $\mathrm{wt} \%$. The volumetric loading at $89 \mathrm{wt} \%$ was similar to that obtained using Grade 12 gel at an $80 \mathrm{wt} \%$ loading but it can be loaded and dried at about twice the rate. The total mass of gel needed using Grade 646 for a given mass of waste is about half that for Grade 12.

Several volatile constituents of the waste and were collected in the condensate. Hg showed the greatest variability with temperature. At $84^{\circ} \mathrm{C}$ only $0.3 \%$ of the $\mathrm{Hg}$ from the simulant was found in the condensate but at $132{ }^{\circ} \mathrm{C}$ about $36 \%$ was collected. Chloride and of course nitrate were found to be present at over $20 \%$ of that in the simulant. Fluoride and sulfate showed only a very minor amount transferred to the condensate. No cations were detected in past work where the simulant contained no Hg; so most of the transport is assumed to be as volatile acids. 


\subsection{Rotary Drier Process Tests}

A rotary drier was constructed from a ball mill drive, a clear gallon reagent bottle, and three hot air guns. A controlled purge air supply, monitoring thermocouples and simulant feed supply entered though the filtered open end. The rotation of the drive was set at the lowest setting, 54-rpm. A metering pump was used for the simulant feed and a mass flow controller set at $18 \mathrm{slm}$ metered the purge air. The apparatus was tested using water soaked Grade $12 \mathrm{Si}$ gel. Minor modifications were made to correct the problems found. After Run 1 a filter was designed from the bottle lid using glass wool within holes drilled into the lid. Stationary glass wool was installed on the bundle of purge line feed line and thermocouples where the bundle entered the bottle. Two hot air guns did not provide enough heat for higher feed rates and another was added. The total was about 5000 watts. Much of the energy was not used for evaporation but was lost outside the jar.

A picture of the jar is shown as Figure 1. The air purge line and two thermocouples are visible inside the rotating jar. The Si gel is being continuously fed SBW simulant while mixing and drying are taking place during Run 6. The loaded damp gel on the air purge line falls off during the non-feed final drying phase.

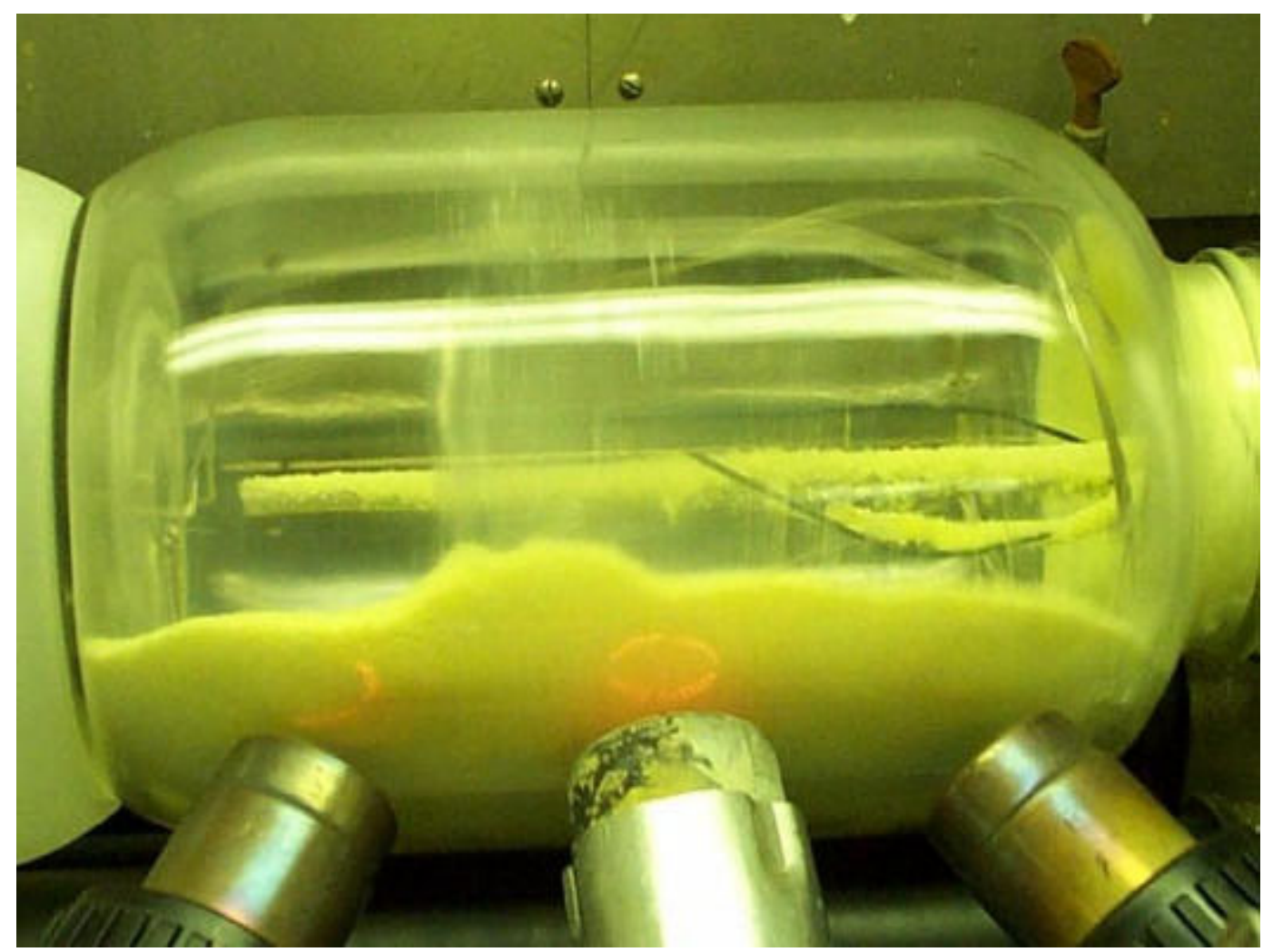

Figure 1. Rotary Drier with Hot Air Guns

Mixing of the SBW with the gel is extremely important to loadings over 50-60 weight \%. (Note: For all the presently reported tests the new composite SBW simulant was used, Tables 1 and 5.) If good mixing does not occur then crusting and caking inhibit further loading and non-sorbed drying SBW adheres to the walls of the containers and sticks with overloaded crusty material that builds up in layers. This type of product is 
shown as Figure 5. With continuous mixing and feeding with drying, the problems are avoided and very high loadings can be achieved. Over feeding results in uneven mixing.

Table 4 is a summary of the rotary drier Runs. Settled volumetric bulk densities of products from both gel types used meet the $40 \%$ volume reduction. Grade 12 gel was used for runs 1 through 4 and the last two were Grade 646. Grade 646 produced a maximum $89 \mathrm{wt} \%$ waste loading while the Grade 12 gel is at 81 $\mathrm{wt} \%$. Less gel mass is used for the same volume of SBW. Because of the larger pore size and free volume of the Grade 646 gel, loading and drying are much faster. An overall SBW evaporation rate of $12.1 \mathrm{~kg} / \mathrm{m}^{2}$ h. was obtained for Type 646 compared to $4.94 \mathrm{~kg} / \mathrm{m}^{2} \mathrm{~h}$. for the Grade 12 at equivalent temperatures.

Table 4. Silica Gel Process Rotary Drier Results

\begin{tabular}{|c|c|c|c|c|c|c|}
\hline Run \# & $\begin{array}{c}\text { Average } \\
\text { Internal Gas } \\
\text { Temperature } \\
\text { While } \\
\text { Feeding } \\
{ }^{\circ} \mathrm{C}\end{array}$ & $\begin{array}{c}\text { Average } \\
\text { Internal Gas } \\
\text { Temperature } \\
\text { While } \\
\text { Finishing } \\
{ }^{\circ} \mathrm{C} \text { Note } 2\end{array}$ & $\begin{array}{c}\text { Mass } \\
\text { Loading } \\
\mathrm{wt} \%\end{array}$ & $\begin{array}{c}\text { \% Simulant } \\
\text { Mass } \\
\text { Remaining } \\
\text { In Product }\end{array}$ & $\begin{array}{c}\text { Volumetric } \\
\text { Loading } \\
\mathrm{m}^{3} \text { Simulant } \\
\text { per } \\
\mathrm{m}^{3} \text { Product } \\
\text { Note 3 }\end{array}$ & $\begin{array}{c}\text { Overall } \\
\text { Simulant } \\
\text { Evap. Rate } \\
\mathrm{kg} / \mathrm{m}^{2} / \mathrm{h}\end{array}$ \\
\hline 1 & 100 & 116 & 81.3 & 14.1 & $2.02 / 2.1 / 2.17$ & 4.59 \\
\hline 2 & 85 & 117 & 80.3 & 19.9 & & 4.84 \\
\hline 3 & 116 & 128 & 80 & 15.3 & $1.35 / 1.6 / 1.95$ & 4.94 \\
\hline 4 & 112 & 122 & 80.2 & 20.6 & $1.6 / 1.6 / 1.66$ & 6.21 \\
\hline 5 & 92 & 105 & 81.9 & 32.9 & $0.93 / 1.04 / 1.14$ & 7.71 \\
\hline 6 & 114 & 134 & 89.2 & 21 & $1.56 / 1.67 / 2.0$ & 12.07 \\
\hline
\end{tabular}

Note 1: Area is based on gel contact area to the heat transfer surface.

Note 2: Finishing is the heated time at the end of feed addition.

Note 3: Volumetric loading values are derived from product bulk densities taken: loose / tapped for settling / and tamped with a rod.

\subsection{Drum Drying Process Tests}

Work in this area was terminated because desired loadings were not obtained. Two runs were completed in a glass tube sized to meet the drum height (1.5 in. ID. by 34 in. long). It was believed that the height was the crucial dimension for the drying process. The material can be dried and reloaded but the gel at the top half of the tube does not get loaded well and the bottom is overloaded causing the gas flow to be inhibited after just a second loading iteration. A minimum of three would be required for the gel used. Grade 12 gel could not be used because the smaller particle size would plug off the simulant access to most of the gel. Grade 646 gel was not available at the time. Another problem related to the gel used is the fact that the air must be allowed to escape as the liquid is absorbed. Indications are that lighter loadings, up to $60 \mathrm{wt} \%$, can be drum dried with heat input and purge air. The goal input of 1.67 liters SBW per liter of product appears not to be practical. Absorption properties of Grade 646 gel allow up to $74 \%$ waste loading by slowly adding the gel to the simulant. The resultant product is a non-fluid, (will not fall out of an inverted beaker), that could be subsequently partially dried at low temperature for weight reduction to reduce shipping costs. At temperatures less than $70^{\circ} \mathrm{C}$ very little $\mathrm{Hg}$ would be emitted. 
Table 5. New Sodium-Bearing Waste Simulant Composition and Analyses

\begin{tabular}{|c|c|c|c|}
\hline \multirow{2}{*}{ Specie } & \multicolumn{3}{|c|}{ All Values in gmol/L } \\
\cline { 2 - 4 } & Goal & $\begin{array}{c}\text { Analyses } \\
\text { (Hazardous) }\end{array}$ & $\begin{array}{c}\text { Analyses } \\
\text { (Non-Haz. }\end{array}$ \\
\hline $\mathrm{Al}$ & 0.582 & 0.57 & 0.616 \\
\hline $\mathrm{B}$ & 0.0191 & 0.017 & 0.0099 \\
\hline $\mathrm{Ca}$ & 0.0537 & 0.044 & 0.041 \\
\hline $\mathrm{Cd}$ & 0.0048 & 0.0049 & $\mathrm{NA}$ \\
\hline $\mathrm{Cl}$ & 0.0255 & $\mathrm{NA}$ & $\mathrm{NA}$ \\
\hline $\mathrm{Cr}$ & 0.0049 & 0.0048 & $\mathrm{NA}$ \\
\hline $\mathrm{Cu}$ & 0.00085 & 0.0008 & 0.00092 \\
\hline $\mathrm{F}$ & 0.0832 & $\mathrm{NA}$ & $\mathrm{NA}$ \\
\hline $\mathrm{Fe}$ & 0.0226 & 0.026 & 0.0256 \\
\hline $\mathrm{H}$ & 2.24 & 2.16 & 1.99 \\
\hline $\mathrm{Hg}$ & 0.0031 & 0.0039 & $\mathrm{NA}$ \\
\hline $\mathrm{Mg}$ & 0.0093 & 0.0092 & 0.009 \\
\hline $\mathrm{Mn}$ & 0.0156 & 0.0157 & 0.015 \\
\hline $\mathrm{Na}$ & 1.59 & 1.57 & 1.55 \\
\hline $\mathrm{Ni}$ & 0.0035 & 0.0033 & 0.0034 \\
\hline $\mathrm{NO}$ & 5.93 & $\mathrm{NA}$ & $\mathrm{NA}$ \\
\hline $\mathrm{Pb}$ & 0.00226 & 0.0024 & $\mathrm{NA}$ \\
\hline $\mathrm{Si}$ & 0.0022 & 0.0007 & 0.001 \\
\hline $\mathrm{SO}{ }_{4}$ & 0.0528 & 0.052 & 0.0453 \\
\hline $\mathrm{Zn}$ & 0.0015 & 0.0015 & 0.0015 \\
\hline $\mathrm{Zr}$ & 0.0116 & 0.009 & 0.0005 \\
\hline $\mathrm{NA}-\mathrm{Not}^{\mathrm{Analyzed}}$ & & & \\
\hline
\end{tabular}

\subsection{Gel Loading Capacity Tests}

Some new gels were ordered for maximum loading tests using the new SBW simulant (Table 5). Simulant was added in nearly the same saturation increments for each test. Light loadings were initially allowed to dry in the hood exhaust air. Loading of about $60 \mathrm{wt} \%$ easily dried overnight when the relative humidity was below $20 \%$. Drying was very slow at relative humidities above $50 \%$. Mass loadings over $80 \%$ gain weight over night in open air.

Three gels were fully tested for loading capacity: Grade 12, Grade 636 and Grade 646. The desiccating indicator gel, Grade 42, was not fully tested because a non-indicating replacement was expected and on order. Limited testing showed it to be similar to Grade 12. A summary of the loading capacity is shown as Table 6. Both Grade 12 and the chromatographic Grade 646 can be loaded to volume reduction values of over $59 \%$. Grades 636 and 646 could possibly go higher but the radiation levels of products will exceed the contact handling radiation limit. Other values in the Table indicate the volume loadings at lower mass waste loadings. As was mentioned in the section on the rotary drier, the higher mass loading of the lighter gels allow for less inert mass to be in the product and for greater flexibility for any subsequent handling or processing. The shipping costs may also be incrementally reduced. 
Table 6. Gel Capacity Checks

\begin{tabular}{|l|c|c|c|c|}
\hline Gelxx-ex\# & $\begin{array}{c}\text { Loading } \\
\text { wt } \%\end{array}$ & $\begin{array}{c}\text { Number of } \\
\text { Loading } \\
\text { Iterations }\end{array}$ & $\begin{array}{c}\text { Volume } \\
\text { SBW/m } \\
\text { Settled }\end{array}$ & $\begin{array}{c}\text { Loading } \mathrm{m}^{3} \\
\text { Product } \\
\text { Tamped }\end{array}$ \\
\hline Grd 12-1 & 83.79 & 5 & 2.19 & 2.44 \\
\hline Grd 12-2 & 80.98 & 4 & 1.97 & 2.17 \\
\hline Grd 12-3 & 84.96 & 5 & 1.93 & 2.22 \\
\hline Grd 12-4 & 84.80 & 5 & 2.18 & 2.39 \\
\hline Grd-636-1 & 68.34 & 1 & 0.82 & 1.00 \\
\hline Grd-636-2 & 80.62 & 2 & 1.37 & 1.56 \\
\hline Grd-636-3 & 85.16 & 3 & 1.86 & 2.19 \\
\hline Grd-646-1 & 76.18 & 1 & 0.87 & 1.05 \\
\hline Grd-646-2 & 83.96 & 2 & 1.39 & 1.56 \\
\hline Grd-646-3 & 90.11 & 3 & 2.12 & 2.45 \\
\hline
\end{tabular}

The characteristics of the raw gels are shown in Table 7. The bulk density of Grade 646 is half that of Grades 12 and 42.

Table 7. Raw Gel Characteristics

\begin{tabular}{|c|c|c|c|c|c|}
\hline Gel & $\begin{array}{c}\text { Particle } \\
\text { Mesh Size }\end{array}$ & Pore Size & $\begin{array}{c}\text { Loose Bulk } \\
\text { Density }\end{array}$ & $\begin{array}{c}\text { Settled Bulk } \\
\text { Density }\end{array}$ & $\begin{array}{c}\text { Tamped Bulk } \\
\text { Density }\end{array}$ \\
\hline Grade 12 & $28-200$ & & 0.73 & 0.78 & 0.81 \\
\hline Grade 42 & $6-16$ & & 0.74 & 0.74 & 0.82 \\
\hline Grade 636 & $35-60$ & 60A & 0.44 & 0.48 & 0.50 \\
\hline Grade 646 & $35-60$ & 150A & 0.32 & 0.36 & 0.41 \\
\hline
\end{tabular}

Table 8, "Comparison of SBW Loaded Gel Products," shows the fraction of the products which are silica and the $\mathrm{Na} / \mathrm{Si}$ ratio. Volume increase of the product over that of the starting gel is more dramatic for the Grade 12 than for the Grade 646 gel. This could be another indication that there is still loading capacity left in the Grade 646 gel.

Table 8. Comparison of SBW Loaded Gel Products

\begin{tabular}{|c|c|c|c|c|c|}
\hline Gel Grade & $\begin{array}{c}\text { Silica in } \\
\text { Product } \\
\mathrm{wt} \%\end{array}$ & $\begin{array}{c}\mathrm{Na} / \mathrm{Si} \\
\text { Ratio }\end{array}$ & $\begin{array}{c}\text { Maximum } \\
\text { Volume Reduction } \\
\text { Ratio for Product }\end{array}$ & $\begin{array}{c}\text { Maximum } \\
\text { Demonstrated } \\
\text { Loading wt\% }\end{array}$ & $\begin{array}{c}\text { Product Volume } \\
\text { Increase Over } \\
\text { Original Gel \% }\end{array}$ \\
\hline 12 & 53.7 & 0.15 & 2.44 & 84 & 53.5 \\
\hline 626 & 33.7 & 0.26 & 2.45 & 90 & 30.6 \\
\hline
\end{tabular}

\subsection{Evaporation Volatiles}

During the runs for in-drum drying the off-gas was passed through a condenser and the condensate collected. This was sampled and sent for analysis. A separate experiment was conducted on loaded Grade 12 gel. 
The gel was loaded incrementally with separate condensate samples taken with each iteration. The first three load iterations were conducted at a temperature of $110^{\circ} \mathrm{C}$. A temperature of $132^{\circ} \mathrm{C}$ was used for the last two. The last iteration at a temperature was ran overnight. An air purge was ran through evaporating vapor space at the rate of about $250 \mathrm{cc} / \mathrm{min}$. the condensate collection vent was passed through a drier tube loaded with Grade 42 indicating gel to collect the moisture that was carried downstream. The loading was calculated to be $77.4 \mathrm{wt} \%$. A total mass balance was $+4.3 \%$. (For some reason nearly all of the mass balances from earlier work also showed a minor increase. This may be due to absorption of water from the air while the evaporating flask is open for weighing and recharging).

Volatile fractions collected in the condensate are shown in Figure 2. The mercury fraction changes from 0.003 to 0.36 as the temperature is increased form $84^{\circ} \mathrm{C}$ to $132^{\circ} \mathrm{C}$. None of the other potential volatile species increases nearly as much. The nitrate fraction in the condensate increases from about 0.13 to 0.45 . The fraction of chloride is also high but does not show the large proportional increase indicated by $\mathrm{Hg}$ and $\mathrm{NO}_{3}{ }^{-}$. Indications are that fluoride and sulfate are not very volatile at these temperatures and compositions. The volatiles other than $\mathrm{Hg}$ are assumed to have been transported to the condensate as acids, $\mathrm{NO}_{\mathrm{x}}$, or $\mathrm{SO}_{\mathrm{x}}$. Earlier work without $\mathrm{Hg}$ in the simulant, noted in Section 3.1, showed no cations except for acid and $40 \mathrm{ppm} \mathrm{Si}$.

\section{Mass Fraction of Volatiles Found in the Condensate vs Temperature}

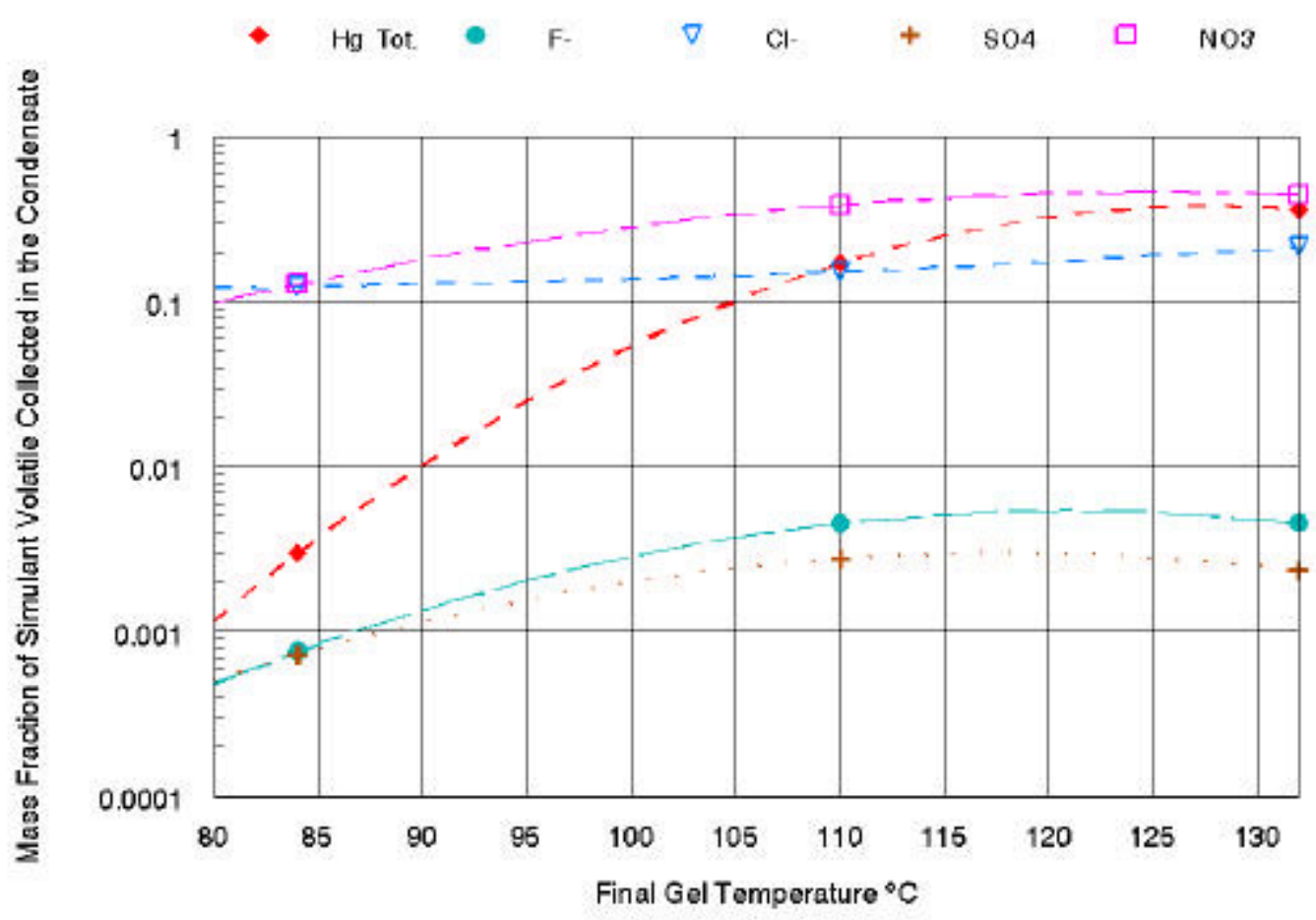

Figure 2. Mass Fraction of Volatiles Found in the Condensate vs. Temperature. 


\subsection{Product Visual Observations}

Under the microscope the raw gel particles are very clear and as the loading is increased they become opaque. A greater fraction of them are broken into smaller particle and clumped together in the rotary dryer product. Figure 3 is a picture of the raw Grade $646 \mathrm{Gel}$. The particles look like transparent broken glass with a smooth surface and are of similar size. Loaded Grade 646 gel from rotary run 6 is shown as Figure 4. The loaded gel particles are opaque and have more variability in size and shape. A fraction of the original particles have been broken as a result of the mixing action. Some of the smaller particles have become agglomerated. The surface of the particles appears to be rough but under higher magnification is smooth indicating that almost all of the dried simulant is inside the particles. Figure 5 is a picture of unevenly loaded gel taken to $132{ }^{\circ} \mathrm{C}$. It is noted that there are several shades of brown coloring and gross differences in opacity. Some of the particles are not loaded at all and are clear. The brown color is due to the formation of hydrated ferric oxide by the prolonged exposure of air after the evaporation of the acid.

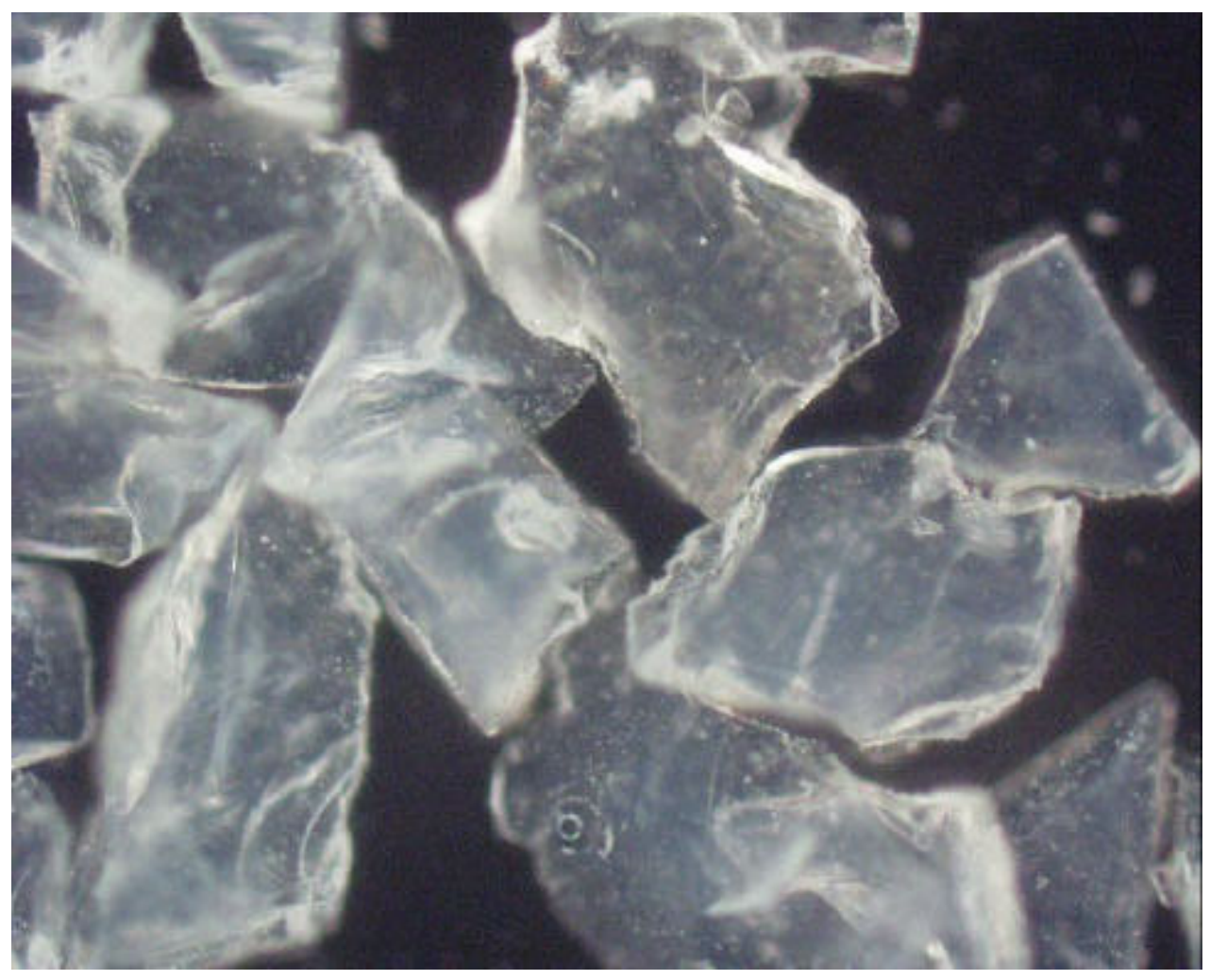

Figure 3. Raw Grade 646 Gel @ 100 X. 


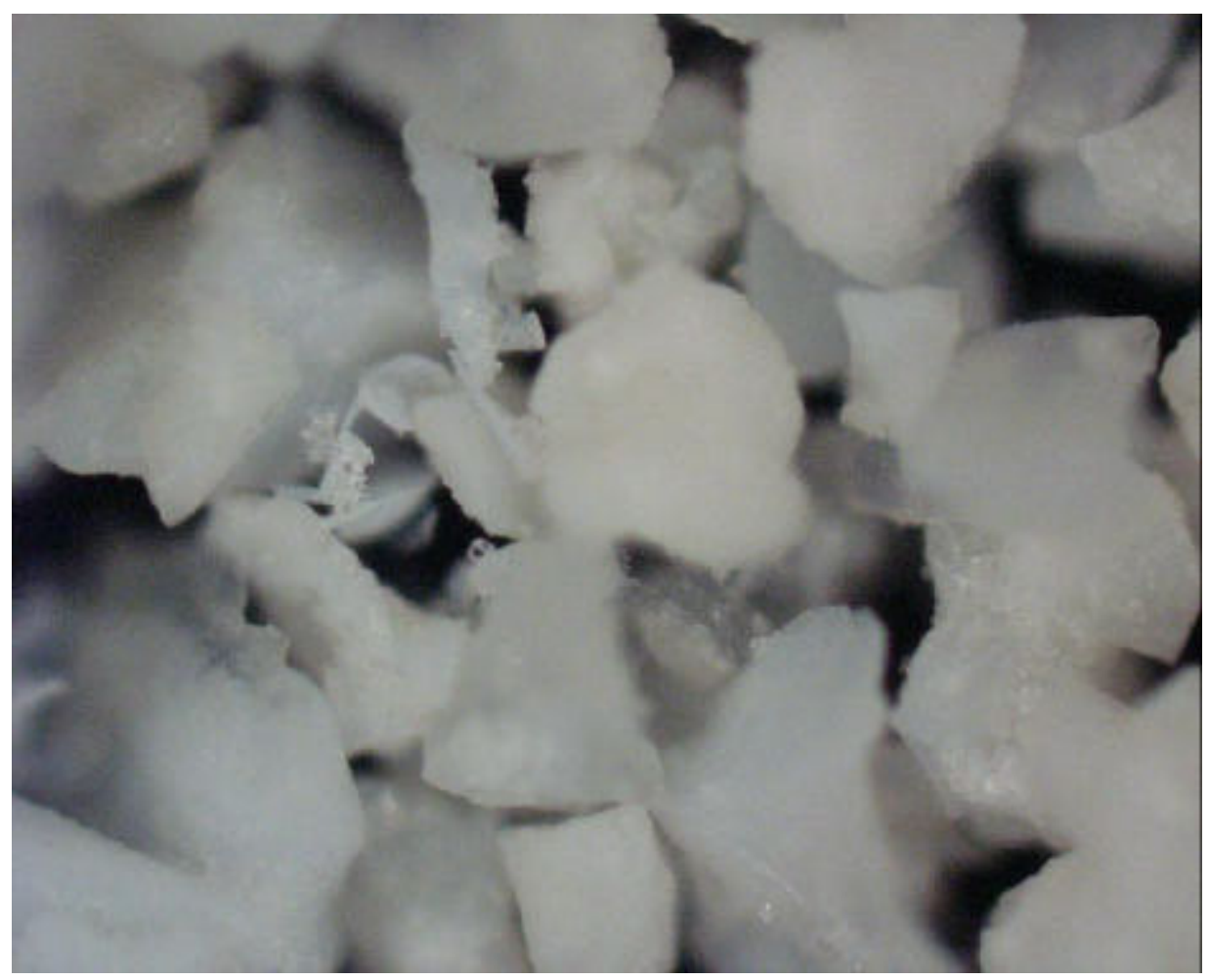

Figure 4. Loaded Grade 646 Gel (89wt\%) @ 100 X.

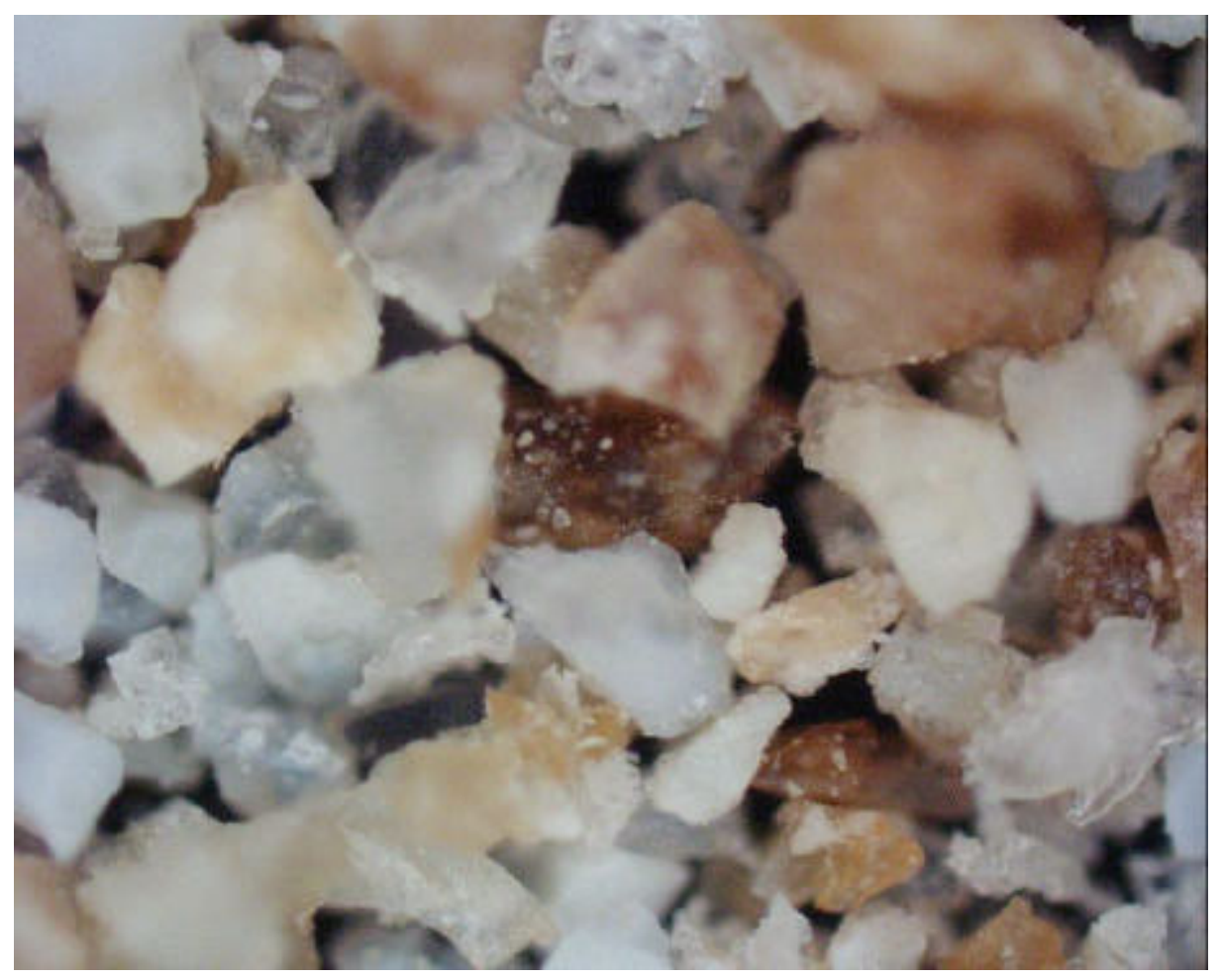

Figure 5. Unevenly Loaded Gel @ 50 X. 


\subsection{Recommendations}

To more fully evaluate the high loaded dry gel and the lower loaded single addition iteration options, further work is necessary. Also needed are values of loading for different SBW tank compositions. Most important are values at different aluminum, iron and sodium concentrations.

If the drying option is to be pursued several pieces of information are required for adequate design evaluation:

- A bench scale continuous drier system should be designed and tested.

- Off-gas composition of the drier at various temperatures should be obtained.

- The option of treating the off-gas and disposing of the cleaned and reduced gas to the atmosphere should be explored. 


\title{
4. MERCURY REMOVAL BY ACTIVATED CARBON
}

\author{
Removal of Mercury From NWCF Off-Gas By Activated Carbon: Removal Efficiencies, \\ Breakthrough Loadings and TCLP Results
}

\subsection{Introduction}

Off-gas emissions from possible future New Waste Calciner Facility (NWCF) operations may be required to comply with the revised maximum achievable control technology (MACT) standards for new facilities. ${ }^{7}$ The mercury emission limit for new facilities is $45 \mu \mathrm{g} / \mathrm{dscm} @ 7 \% \mathrm{O}_{2}$. Current material balances list the mercury mole fraction in the off-gas from the Noxidizer as 1.0E-7 prior to entering the Granulated Activated Carbon (GAC) beds. ${ }^{8,9}$ This value is equivalent to $2400 \mu \mathrm{g} / \mathrm{dscm} @ 7 \% \mathrm{O}_{2}$ based on use of the following equation prescribed by the Environmental Protection Agency (EPA) ${ }^{10}$ :

$\mathrm{C}_{\mathrm{c}}=\mathrm{C}_{\mathrm{m}}[14 / \mathrm{E}-\mathrm{Y}]$

where,

$\mathrm{C}_{\mathrm{c}}=$ Corrected Mercury Concentration, $\mu \mathrm{g} / \mathrm{dscm} @ 7 \% \mathrm{O}_{2}$

$\mathrm{C}_{\mathrm{m}}=$ Measured Mercury Concentration, $\mu \mathrm{g} / \mathrm{dscm}$

$\mathrm{E}=\mathrm{O}_{2}$ Concentration in Oxidizing Gas, estimated to be $22 \%{ }^{11}$

$\mathrm{Y}=\mathrm{O}_{2}$ Concentration in the Dry Process Gas, estimated to be $4.64 \%$

By comparison, the average mercury concentration measured during the $\mathrm{H} 4$ campaign was $3200 \mu \mathrm{g} / \mathrm{dscm}$ (a) $7 \% \mathrm{O}_{2}{ }^{12}$

As a conservative estimate, reduction of $2400 \mu \mathrm{g} / \mathrm{dscm} @ 7 \% \mathrm{O}_{2}$ to $30 \mu \mathrm{g} / \mathrm{dscm} @ 7 \% \mathrm{O}_{2}$ will require a removal efficiency of $98.8 \%$ or a decontamination factor (DF) of 86 . Past studies in support of calcination and vitrification flow sheets have demonstrated $>99 \%$ removal efficiencies for elemental mercury $\left(\mathrm{Hg}^{\mathrm{o}}\right)$ and mercuric chloride $\left(\mathrm{HgCl}_{2}\right) .{ }^{13,14}$

The purpose of this study was to provide an estimate of expected breakthrough mercury loadings and to determine the suitability of the mercury-laden carbon for disposal by means of TCLP tests. An additional objective was to determine the effect of the increased water content $(72 \%)$ in the off-gas due to the Noxidizer, and whether the anticipated decrease in removal efficiency due to water could be offset by increasing the operating temperature of the carbon bed. Pilot tests at Mountain States Energy (MSE) with simulated off-gas indicated that the mercury downstream of the Noxidizer was $99.8 \%$ elemental mercury. ${ }^{15}$ Therefore, only $\mathrm{Hg}^{\mathrm{o}}$ was used in the tests.

Breakthrough capacity is a function of many factors. It is influenced by temperature, linear velocity, mercury concentration, water content and possibly other factors. To reach breakthrough in a reasonable time, shallow beds (short residence times) and high mercury concentrations were used. In the ideal experiment, lower mercury concentrations (to simulate actual off-gas concentrations) and long beds would be used to maximize the removal efficiency. In this case however, breakthrough times would have been impractically long. Thus, the values reported here are considered estimates for comparison with vendor data. 


\subsection{Test Methods}

The test apparatus for the breakthrough runs is illustrated in Figure 6. Mercury vapor was generated by passing nitrogen over a pool of mercury contained in a constant temperature bath. The mercury-laden gas was diluted by either dry or humidified nitrogen. The nitrogen was humidified by passing it through a temperature-controlled impinger. The temperature of the carbon was maintained by the use of temperature-controlled heat tapes. Due to the high mercury concentrations, the inlet gas was doublediluted and the carbon bed effluent was single-diluted before being measured. Mercury concentrations were measured in the bypass loop before and after a breakthrough run. Mercury concentrations after the run were used to calculate removal efficiencies. Breakthrough times were defined as the time when the removal efficiency decreased by about $2 \%$ (e.g. when the removal efficiency decreased from $96 \%$ to $94 \%$ ). This was usually the point at which a sustained increase in the mercury effluent concentration was verified. Fractional breakthrough loadings were defined as grams of mercury per gram of carbon.

The test gas consisted of either $100 \% \mathrm{~N}_{2}$, or $50 \% \mathrm{H}_{2} \mathrm{O} / 50 \% \mathrm{~N}_{2}$. The reason for using only nitrogen in the dry tests was to assure that the carbon bed would be loaded with mercury only, so that the mercury loading could be determined by weight difference. The mercury loading determined in this manner could then be compared with the microwave digestion/cold vapor atomic absorption method used by the analytical laboratory. Microwave digestion as a sample preparation technique is still in the development stage. In previous tests, Mersorb ${ }^{\circledR}$ has been shown to adsorb about $8 \mathrm{wt} \%$ of what was presumed to be oxygen from the air. The inclusion of $\mathrm{O}_{2}$ or other adsorbable gases in the dry tests would have precluded a comparison with the microwave digestion method. Since the $\mathrm{NO}_{2}$ in the Noxidizer effluent is expected to be less than $50 \mathrm{ppmv}$, the only gas that is expected to seriously effect removal efficiencies and breakthrough loadings is $\mathrm{H}_{2} \mathrm{O}$, which was included in these tests.

For the breakthrough tests, flow rates were $218 \mathrm{cc} / \mathrm{min}$ at a carbon bed temperature of $90^{\circ} \mathrm{C}$ or $120^{\circ} \mathrm{C}$. The superficial linear velocity was $0.05 \mathrm{~m} / \mathrm{s}$ and the residence time was $0.25 \mathrm{~s}$. The bed size was $1 \mathrm{~cm} \times 1 \mathrm{~cm}$.

In order to demonstrate higher removal efficiencies and determine the effect of water content and temperature, a single run was conducted in which the bed length was increased to $4.0 \mathrm{~cm}$, and the residence time to $0.5 \mathrm{~s}$. For this run, the water content was increased to $72 \%$ to simulate the Noxidizer effluent gas. The flow rate increased to $400 \mathrm{cc} / \mathrm{min}$ due to the additional water present. During this run, the water content was either 0 or $72 \%$, and the temperature was either $90^{\circ} \mathrm{C}$ or $120^{\circ} \mathrm{C}$.

The mercury-loaded carbon from the breakthrough runs was submitted for standard TCLP tests. The carbon was then analyzed for mercury by microwave digestion in aqua regia $\left(3 \mathrm{HCl}: 1 \mathrm{HNO}_{3}\right)$, followed by cold vapor atomic absorption.

\subsection{Results and Discussion}

Table 9 lists mercury removal efficiencies, breakthrough loadings and TCLP results. Run 1 consisted of partially loading the carbon in order to compare the mercury leaching results with higher loaded carbon from runs 2, 3 and 4 . There was no effect of mercury loading on the amount of mercury released during leaching. All TCLP results were below the maximum of $0.025 \mathrm{mg} / \mathrm{L}$ required by Land Disposal Restrictions.

Fractional breakthrough loadings, determined by weighing the carbon before and after a run, were in very good agreement with those determined by mercury analysis of the carbon for run 2 and in fair agreement 
for run 4. Loadings for runs 2 and 4 were in reasonably good agreement. The Mersorb ${ }^{\circledR}$ vendor indicated that breakthrough loadings for a well designed packed bed should be about $0.15 \mathrm{~g}$ of mercury per gram of carbon. Thus, the values obtained may be conservative estimates. The breakthrough loading for run 3 was less than that obtained for runs 2 and 4 . This was not a normal run in that it was started with $0.2031 \mathrm{~g}$ of carbon and later another $0.2010 \mathrm{~g}$ was added when large mercury concentration spikes occurred early in the run. Its lower breakthrough loading could not be adequately explained.

The low removal efficiency (0.644) of run 5 demonstrated the effect of $50 \%$ water on mercury removal. This effect was observed only at very high mercury concentrations. Past tests at this water level with mercury concentrations in the range of $500-1500 \mu \mathrm{g} / \mathrm{m}^{3}$ showed no effect on removal efficiencies. The blockage of reactive sites by water becomes significant at the higher mercury concentrations because more sites are needed to achieve high removal efficiencies. Run 5 was terminated due to the low removal efficiency. Run 6 , in which the water content was also $50 \%$, showed a more normal removal efficiency of 0.975 , and an increase in the DF by a factor of 13 due to the increase in carbon bed temperature to $120^{\circ} \mathrm{C}$. The weight of the carbon after the run indicated that no sorption of water had occurred. This indicated that operation of the carbon beds at $120^{\circ} \mathrm{C}$ should prevent sorption of water. This run was proceeding smoothly until a switch to bypass to measure the inlet mercury concentration, followed by a switch back through the carbon bed produced large mercury concentration spikes. Apparently some upset condition occurred because of the switches. The run was terminated. Because of the high removal efficiency obtained, it is felt that this run would have resulted in a breakthrough loading similar to runs 2 and 4 , if left to continue without switching to bypass until the end of the run. Therefore, an estimate of the expected breakthrough loading is listed in Table 9.

Run 7 was a short run designed to demonstrate that higher removal efficiencies could be obtained, even at a water content of $72 \%$, by increasing the residence time from $0.25 \mathrm{~s}$ to $0.5 \mathrm{~s}$, which is still a short residence time compared to that recommended by the vendor $(10 \mathrm{~s})$. The results indicate that at both $90{ }^{\circ} \mathrm{C}$ and $120^{\circ} \mathrm{C}$, removal efficiencies $(0.997$ and 0.998 , respectively) were in excess of that required $(0.988)$ to meet the MACT rules. The results also indicate the effect of increasing the temperature on mercury removal. Under dry conditions, increasing the temperature from $90^{\circ} \mathrm{C}$ to $120^{\circ} \mathrm{C}$ had very little effect on the DF. At $72 \%$ water, increasing the temperature from $90^{\circ} \mathrm{C}$ to $120^{\circ} \mathrm{C}$ increased the $\mathrm{DF}$ from 391 to 462 , an $18 \%$ increase. Since no water would be expected to sorb onto the carbon at $120^{\circ} \mathrm{C}$, a larger increase in DF was expected. This indicates that water interfered with the reaction between mercury and sulfur, and that increasing the temperature did not mitigate the effect to a large degree. The effect of water on mercury removal by carbon should be further investigated.

\subsection{Conclusions and Recommendations}

Mercury breakthrough loadings, defined as weight of mercury per unit weight of carbon, for Mersorb ${ }^{\circledR}$ should be at least 0.11 . Since conditions for these tests were not optimized for maximum loadings, the actual loadings will probably be closer to the 0.15 claimed by the vendor. Since high fractional removal efficiencies (0.998) were obtained at a water content of $72 \%$, and a carbon bed temperature of $120^{\circ} \mathrm{C}$, at a short residence time of $0.5 \mathrm{~s}$, it is probable that the claimed breakthrough loading is achievable. However, as a conservative measure, a long-term breakthrough test should be conducted at $72 \%$ water and $120^{\circ} \mathrm{C}$ in order to verify the claimed breakthrough loading. The duration of this test would be about 80 hours and would require unattended operation.

The carbon beds should be operated at a temperature of at least $120^{\circ} \mathrm{C}$ in order to prevent sorption of water. Further tests should be conducted to determine the effect of higher temperatures on removal 
efficiencies in order to define an operational temperature range.

Based on the positive TCLP results, the carbon should be suitable for final disposal if the case for amalgamation can be made. That is, that the mercury is amalgamated as $\mathrm{HgS}$, which is the requirement for carbon having a mercury content of greater than $260 \mathrm{mg} / \mathrm{Kg}$.

All tests to date have indicated that Mersorb ${ }^{\circledR}$ is a suitable sorbent for the removal of mercury from the off-gas from all thermal treatment processes that have been considered, and are being considered for the processing of SBW. The removal efficiencies obtained exceed those required to meet the MACT rules. 


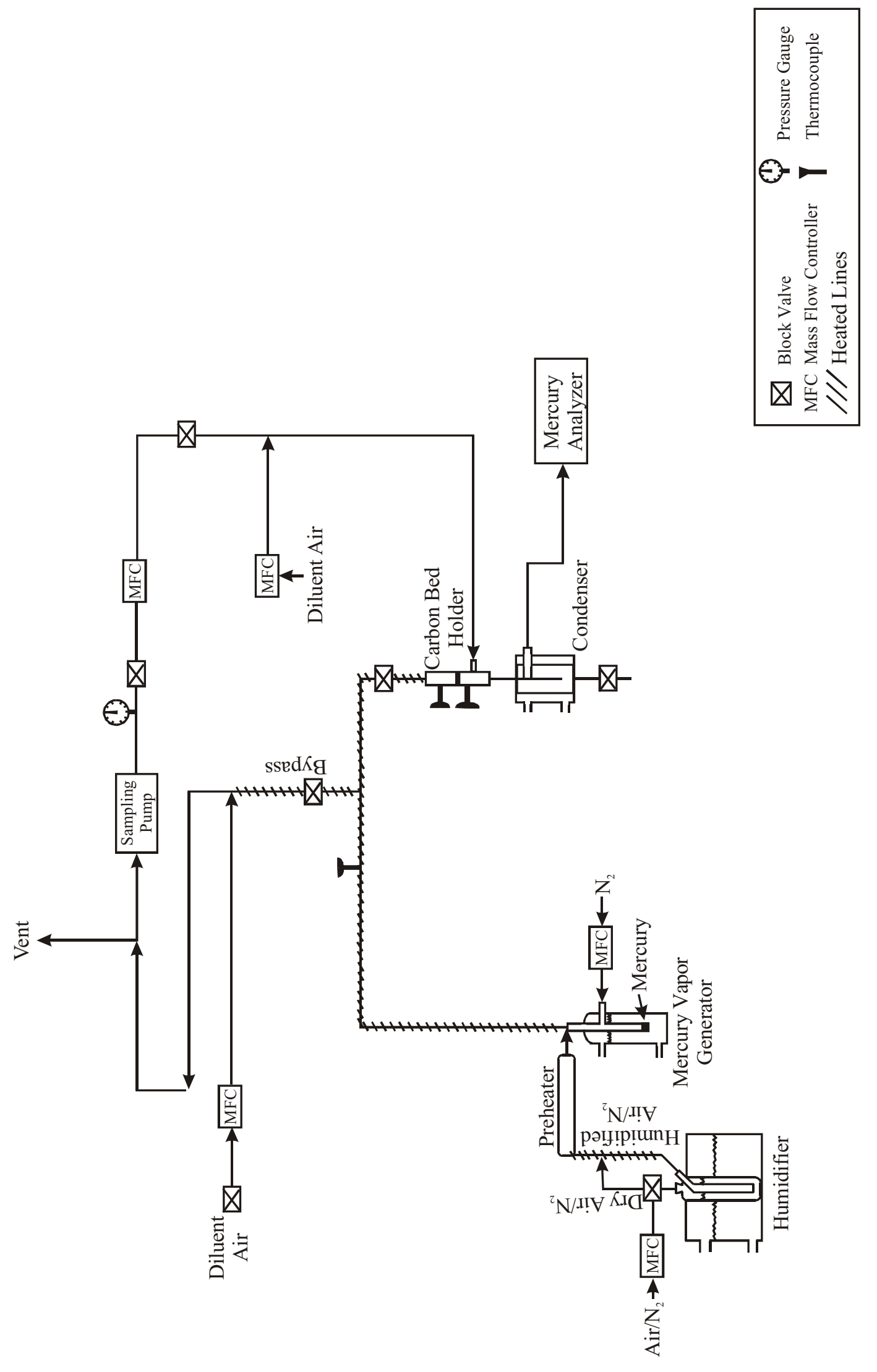




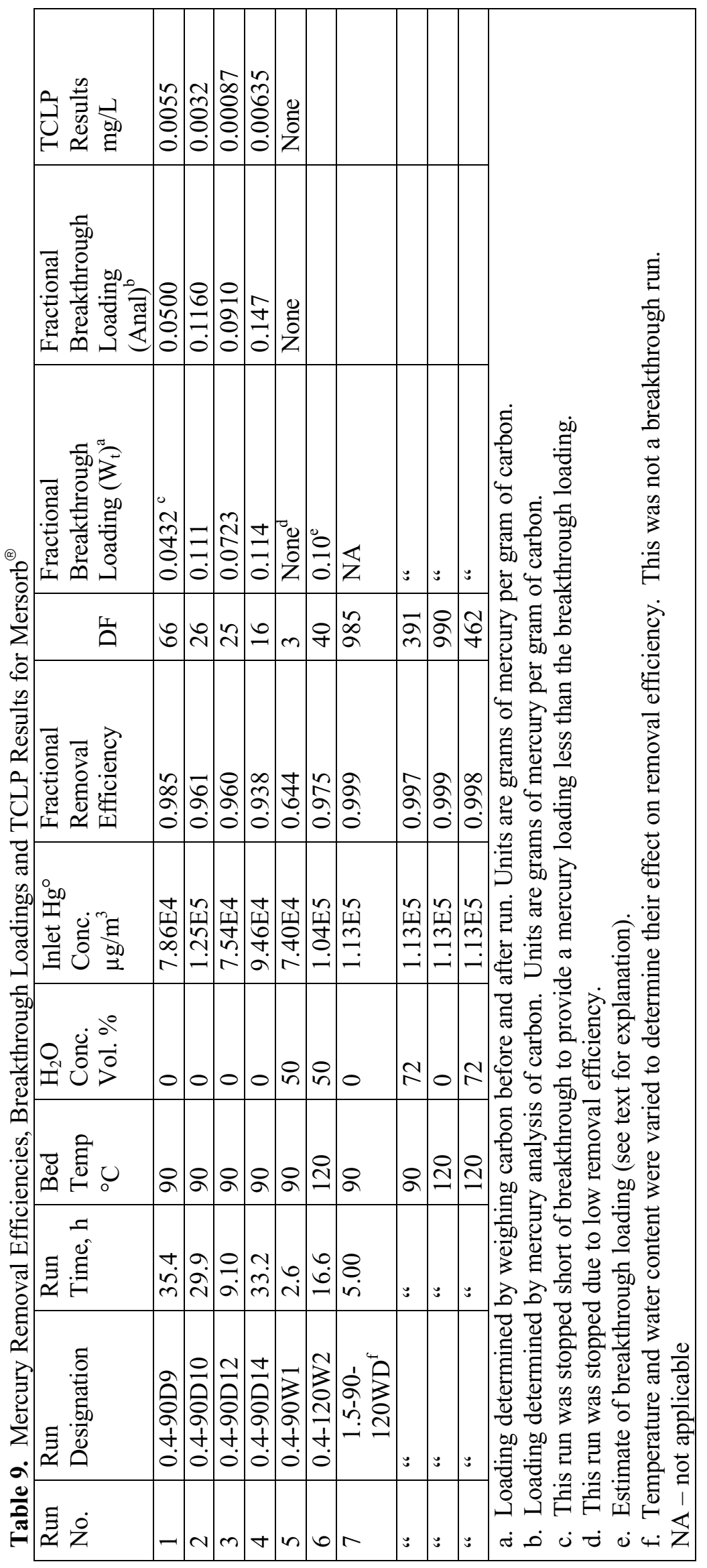




\section{MERCURY IN OFF-GAS SCRUB SOLUTIONS}

In August , 2001, a pilot-scale test of the sodium-bearing waste (SBW) vitrification flow sheet was conducted at Pacific Northwest National Laboratory (PNNL) by personnel from PNNL and INTEC. ${ }^{16}$ Mercury in the melter feed was volatilized and became trapped in the ejector venturi scrubber (EVS) and the high efficiency mist eliminator (HEME). Since sugar was added as a denitrating agent, there was a concern that organic by-products from sugar pyrolization may have reacted with the mercury to form organo-mercury compounds which became trapped in the EVS and HEME solutions. The presence of organo-mercury compounds may impact mercury removal methods and grouting of scrubber solutions for disposal. Thus, a subcontract to characterize mercury compounds in off-gas scrub solution samples was issued to Idaho State University (ISU) of Pocatello, Idaho.

A cold vapor atomic absorption (CVAA) method was used to distinguish between inorganic and organic mercury compounds. This was accomplished by a permanganate/persulfate digestion of the samples to decompose organic mercury compounds to obtain total mercury in the sample, and analysis of the samples without the digestion to obtain inorganic (non-bound) mercury. The difference between the two values was the organic mercury present. Analysis of a HEME sample having the highest mercury concentration $(1000 \mathrm{ppm})$ resulted in $961 \pm 80 \mathrm{ppm}$ inorganic mercury and $855 \pm 70 \mathrm{ppm}$ total mercury. These results indicate that, within experimental error, the organic mercury, if present, is present in very small concentrations.

Since some organic mercury may have been present, a variety of spectroscopic techniques were applied in order to identify the compound. These included, infra-red, Raman, Fourier Transform Infra-Red ( FTIR), gas chromatography/mass spectroscopy (GC/MS) and liquid chromatography/mass spectroscopy (LC/MS). These techniques were applied both directly to the samples and to carbon tetrachloride extractions. Only the results obtained with FTIR and GC/MS indicated the possible presence of an organic mercury compound. The GC/MS spectra showed peaks consistent with the presence of methyl mercuric chloride when compared with a standard, although the peaks could also be attributed to chloroethyl or chlorophenyl mercury. Comparison with the mass spectra of the methyl mercuric chloride standard indicated a rough concentration estimate of less than $70 \mathrm{ppm}$ organic mercury.

From this investigation, it can be concluded that mercury in the scrub solution was present predominately in the inorganic form, probably as unassociated mercuric chloride $\left(\mathrm{HgCl}_{2}\right)$. A detailed report of the ISU studies appears in Appendix B. 


\section{REFERENCES}

1. N.O. Valles, et al., "Sodium-Bearing Waste to WIPP Waste $\left(\mathrm{SBW}^{3}\right)$ Optimization Study," INEEL/EXT-99-00975, November 1999.

2. J. A. McCray, et al., "Verification of Direct Evaporation and Fractional Crystallization Technologies for Sodium-Bearing Waste Treatment," INEEL/EXT-02-01043, September 2002.

3. S. J. Losinski and D. W. Marshall, "Steam Reforming 6-Inch Bench Scale Design and Testing Project Technical and Functional Requirements Description," INEEL/EXT-02-01018, August 2002.

4. A. K. Herbst, et al., "Idaho Nuclear Technology and Engineering Center Low-Activity Waste Process Technology Program FY-2000 Status Report," INEEL/EXT-2000-01167, October 2000.

5. J. D. Christian, "Composition and Simulation of Tank WM-180 Sodium-Bearing Waste at the Idaho Nuclear Technology and Engineering Center," INEEL/EXT-2001-00600, May 2001.

6. C. M. Barnes, INEEL Interoffice Memorandum to L. Lauerhass, "Interim SBW Vitrification Mass Balance Update," CMB-13-01, November 14, 2001.

7. Revised Hazardous Waste Combustor MACT Emission Standards, 40CFR 63 Subpart EEE. February, 2002.

8. R. A. Wood, C. M. Barnes, and B. H. O’Brien, "Process Design of Sodium-Bearing Waste Treatment Alternatives," Engineering Design File, EDF-2373, August, 2002.

9. S. C. Ashworth, et al., "NWCF Mercury Feasibility Study," INEEL/INT-2000-00539, September, 2000.

10. J. K. Rawlins, "Feasibility Study Report for NWCF MACT Compliance Facility," INEEL/INT-9700992, page D-4, November, 1997.

11. D. D. Taylor, Personal Communication, July 30, 2002.

12. R. D. Boardman, L. J. Young, N. R. Soelberg and L. A. Matejka, "NWCF Calciner Emissions Inventory-Final Report for Phase IV Testing," INEEL/EXT-01-00260, February, 2001.

13. J. A. Del Debbio, L. G. Olson, T. L. Watson and L. G. Blackwood, "Removal of Mercury from the Off-Gas from Thermal Treatment of Radioactive Liquid Wastes," Proceedings of the International Conference on Incineration and Thermal Treatment Technologies, May 14-19, Philadelphia, PA, available from the University of Maryland, Conference and Visitors Service, 0101 Annapolis Hall, College Park, MD 20742-9811, 301-314-7884.

14. J. A. Del Debbio, T. L. Watson and R. J. Kirkham, "Removal of Mercury from SBW Vitrification Off-Gas by Activated Carbon," INEEL/EXT-01-01227, September, 2001.

15. MSE Technology Applications, Inc. John Zink Noxidizer ${ }^{T M}$ Propane-Fired Performance Assessment and Mercury Emission Speciation, 01-MSE-153, PTP-81, February 2001.

16. R. W. Goles*, J. A. Del Debbio**, R. J. Kirkham**, B. D. MacIsaac*, J. A. McCray**, D. D. Siemer**, N. R. Soelberg**, "Test Summary Report INEEL Sodium-Bearing Waste Vitrification Demonstration RSM-01-2," PNNL-13869, May, 2002. * Pacific Northwest National Laboratory $(\mathrm{PNNL}), * *$ Idaho National Engineering and Environmental Laboratory (INEEL) 
APPENDIX A

GROUTED WASTE FORMULATION DATA 



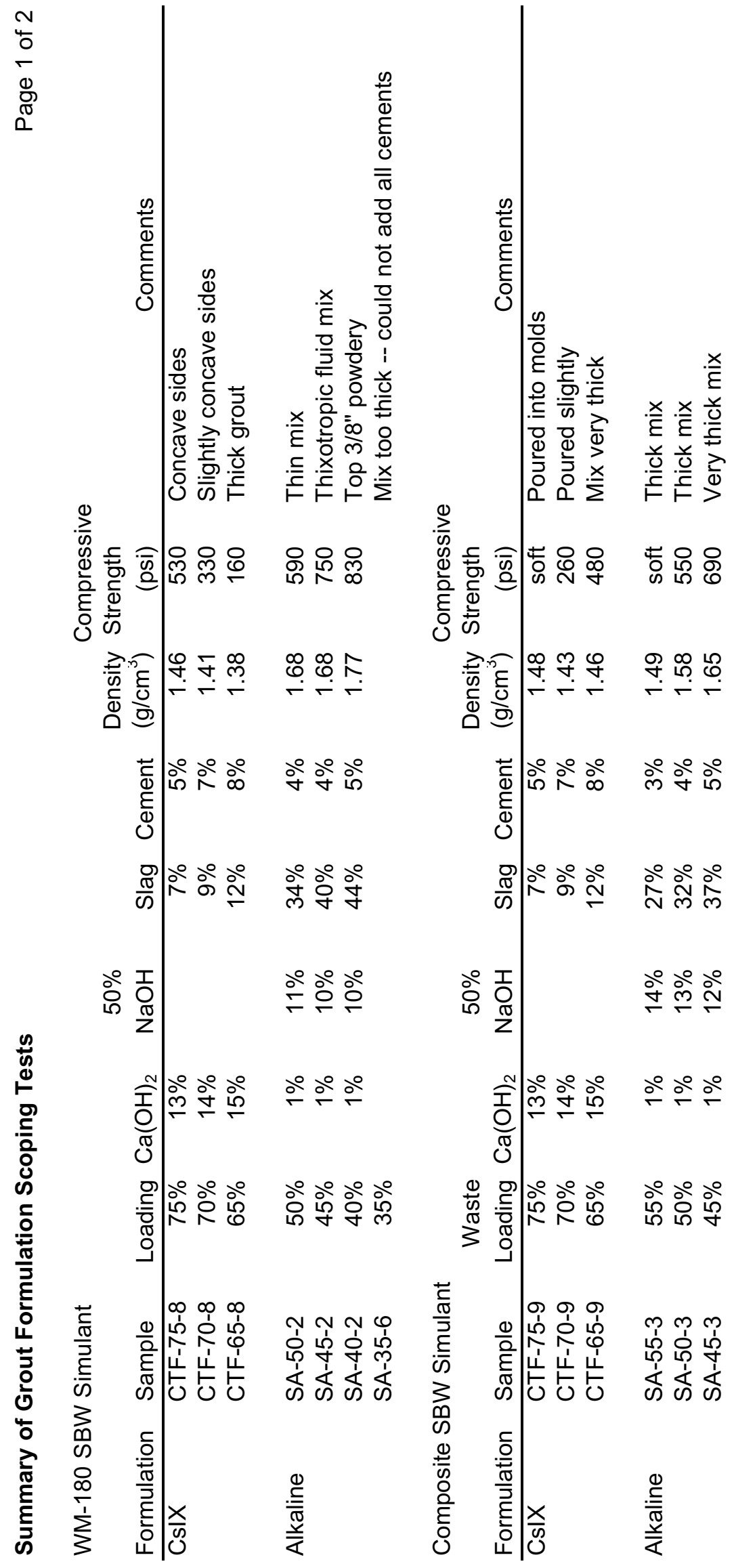




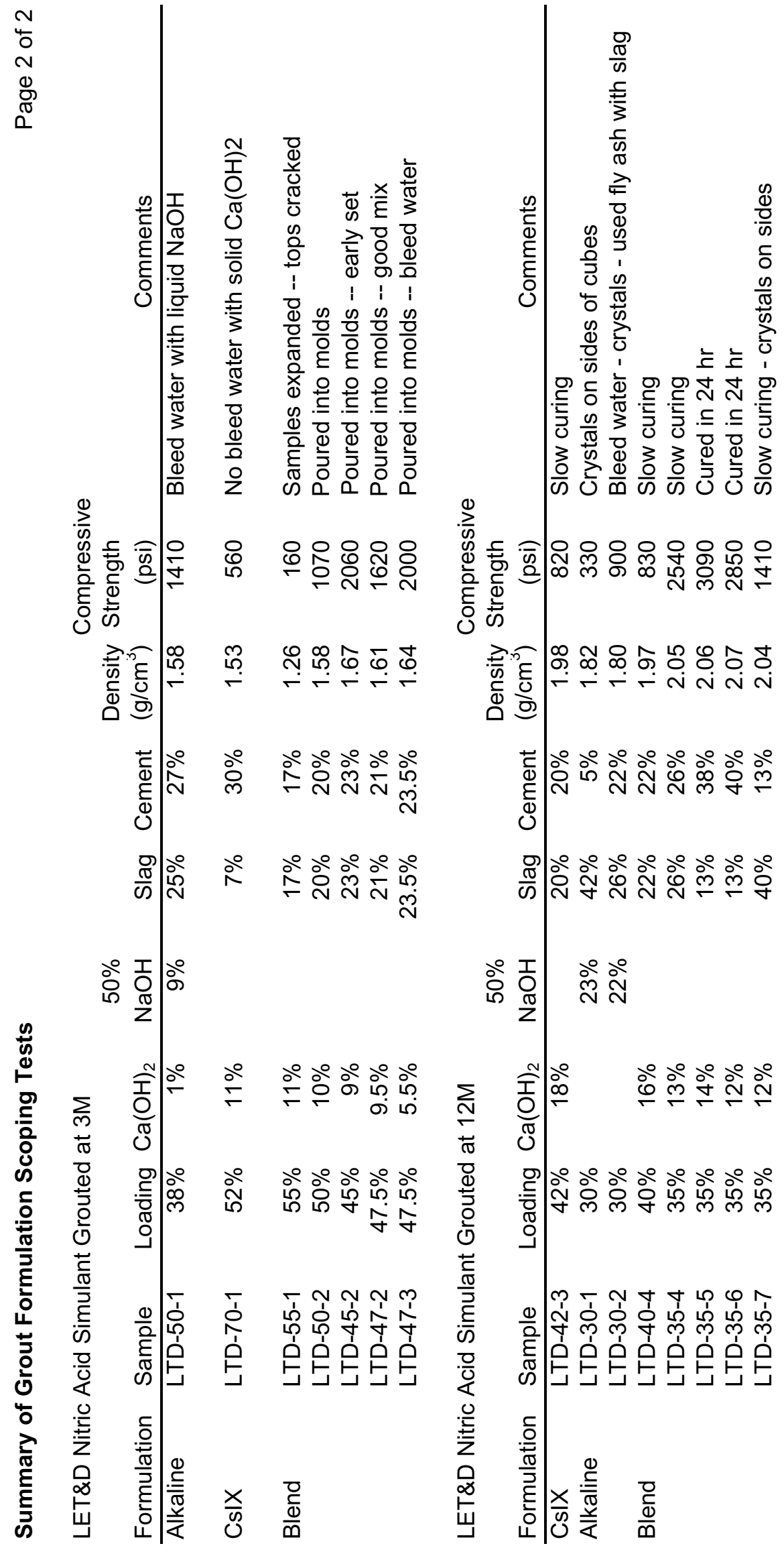



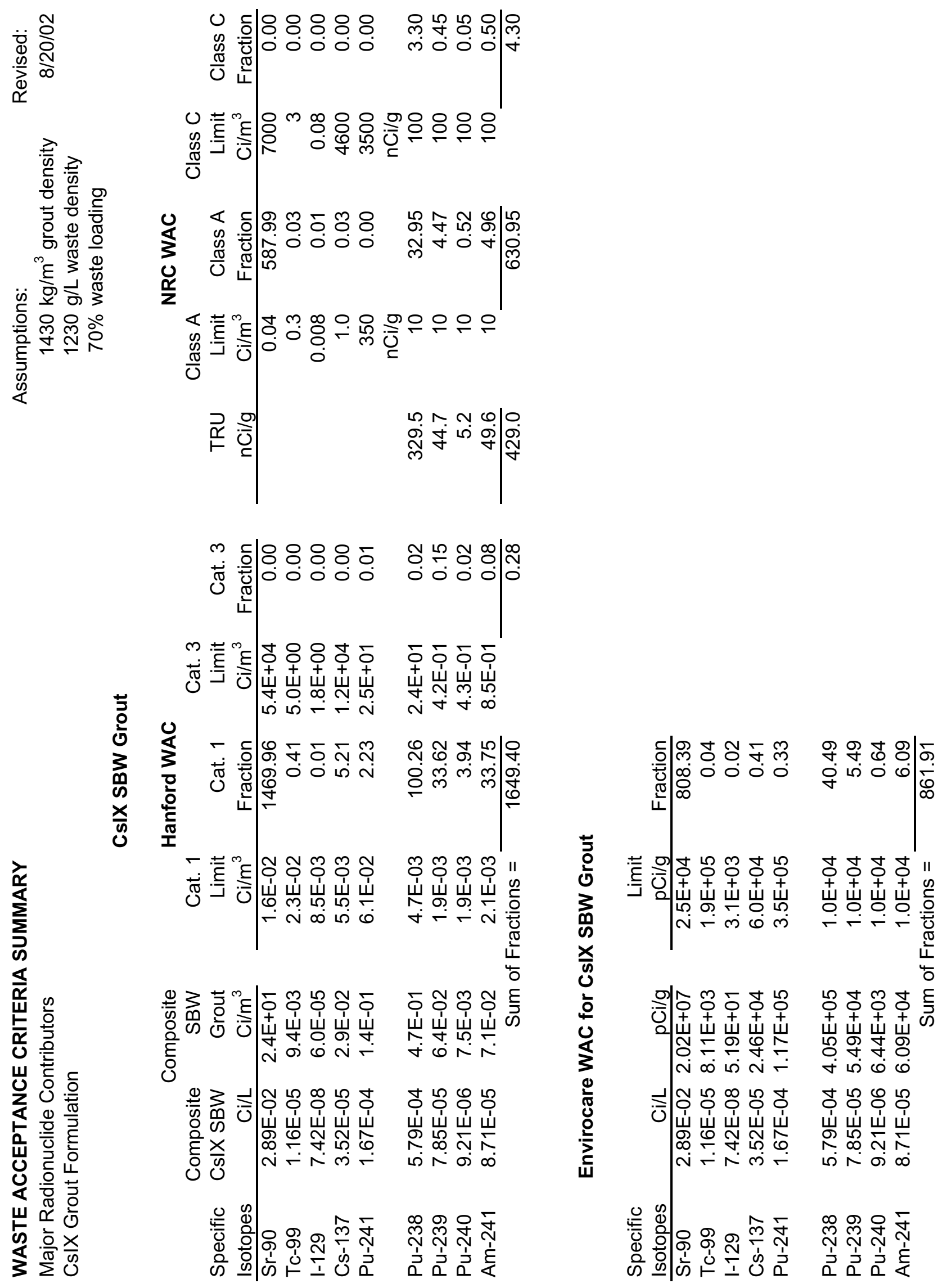
Page : 1

DOS File : CSIX-02.MS5

Run Date: August 21, 2002

Run Time: 13:13:04

Duration : 00:01:02
File Ref:

Date:

By:

Checked:

Case Title: TRU Waste Drum

Description: Grouted Composite SBW following CsIX

Geometry: 7 - Cylinder Volume - Side Shields

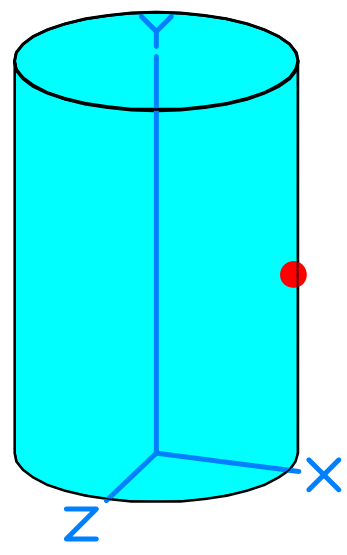

Source Dimensions

$\begin{array}{lrr}\text { Height } & 86.36 \mathrm{~cm} & 2 \mathrm{ft} 10.0 \text { in } \\ \text { Radius } & 29.21 \mathrm{~cm} & 11.5 \mathrm{in}\end{array}$

\begin{tabular}{cccc}
\multicolumn{4}{c}{ Dose Points } \\
$\# 1$ & $\underline{\mathrm{X}}$ & $\underline{\mathrm{Y}}$ & $\underline{\mathrm{Z}}$ \\
& $30.37 \mathrm{~cm}$ & $43.18 \mathrm{~cm}$ & $0 \mathrm{~cm}$ \\
$12.0 \mathrm{in}$ & $1 \mathrm{ft} 5.0 \mathrm{in}$ & $0.0 \mathrm{in}$
\end{tabular}

\begin{tabular}{|c|c|c|c|}
\hline \multicolumn{4}{|c|}{ Shields } \\
\hline Shield Name & Dimension & Material & Density \\
\hline Source & $2 . \overline{31 \mathrm{e}+05 \mathrm{~cm}^{3}}$ & $\overline{\text { Concrete }}$ & 1.43 \\
\hline Transition & $1.0 \mathrm{~cm}$ & Air & 0.00122 \\
\hline Air Gap & & Air & 0.00122 \\
\hline Wall Clad & $.16 \mathrm{~cm}$ & Iron & 7.86 \\
\hline Top Clad & $.16 \mathrm{~cm}$ & Iron & 7.86 \\
\hline
\end{tabular}

\section{Source Input \\ Grouping Method : Standard Indices \\ Number of Groups : 25 \\ Lower Energy Cutoff : $\mathbf{0 . 0 1 5}$ \\ Photons $<0.015$ : Excluded}

\begin{tabular}{|c|c|}
\hline Nuclide & curies \\
\hline Am-241 & $1.6412 \mathrm{e}-002$ \\
\hline Am-242 & $2.5001 \mathrm{e}-006$ \\
\hline Am-242m & $2.5001 \mathrm{e}-006$ \\
\hline Am-243 & $3.6112 \mathrm{e}-006$ \\
\hline $\mathrm{Ba}-137 \mathrm{~m}$ & $6.0418 \mathrm{e}-003$ \\
\hline C-14 & $2.2385 \mathrm{e}-004$ \\
\hline Cd-113m & $3.0788 \mathrm{e}-004$ \\
\hline $\mathrm{Cm}-242$ & $2.0903 \mathrm{e}-006$ \\
\hline $\mathrm{Cm}-243$ & $3.6112 \mathrm{e}-006$ \\
\hline $\mathrm{Cm}-244$ & $3.0788 \mathrm{e}-004$ \\
\hline Co-60 & $1.3033 \mathrm{e}-003$ \\
\hline Cs-134 & $7.4307 \mathrm{e}-008$ \\
\hline Cs-135 & $1.5324 \mathrm{e}-007$ \\
\hline Cs-137 & $6.6205 \mathrm{e}-003$ \\
\hline Eu-152 & $2.2408 \mathrm{e}-004$ \\
\hline Eu-154 & $1.0996 \mathrm{e}-002$ \\
\hline Eu-155 & $2.9862 \mathrm{e}-003$ \\
\hline $\mathrm{H}-3$ & $1.8843 \mathrm{e}-003$ \\
\hline I-129 & $1.3982 \mathrm{e}-005$ \\
\hline $\mathrm{Nb}-93 \mathrm{~m}$ & $3.1945 \mathrm{e}-004$ \\
\hline
\end{tabular}

Library : ICRP-38

$\begin{array}{ccc}\underline{\text { becquerels }} & \begin{array}{c}\mu \mathrm{Ci} / \mathrm{cm}^{3} \\ \text { Bq/cm }\end{array} \\ 6.0726 \mathrm{e}+008 & 7.0900 \mathrm{e}-002 & 2.6233 \mathrm{e}+003 \\ 9.2502 \mathrm{e}+004 & 1.0800 \mathrm{e}-005 & 3.9960 \mathrm{e}-001 \\ 9.2502 \mathrm{e}+004 & 1.0800 \mathrm{e}-005 & 3.9960 \mathrm{e}-001 \\ 1.3361 \mathrm{e}+005 & 1.5600 \mathrm{e}-005 & 5.7720 \mathrm{e}-001 \\ 2.2355 \mathrm{e}+008 & 2.6100 \mathrm{e}-002 & 9.6570 \mathrm{e}+002 \\ 8.2824 \mathrm{e}+006 & 9.6700 \mathrm{e}-004 & 3.5779 \mathrm{e}+001 \\ 1.1391 \mathrm{e}+007 & 1.3300 \mathrm{e}-003 & 4.9210 \mathrm{e}+001 \\ 7.7342 \mathrm{e}+004 & 9.0300 \mathrm{e}-006 & 3.3411 \mathrm{e}-001 \\ 1.3361 \mathrm{e}+005 & 1.5600 \mathrm{e}-005 & 5.7720 \mathrm{e}-001 \\ 1.1391 \mathrm{e}+007 & 1.3300 \mathrm{e}-003 & 4.9210 \mathrm{e}+001 \\ 4.8221 \mathrm{e}+007 & 5.6300 \mathrm{e}-003 & 2.0831 \mathrm{e}+002 \\ 2.7494 \mathrm{e}+003 & 3.2100 \mathrm{e}-007 & 1.1877 \mathrm{e}-002 \\ 5.6700 \mathrm{e}+003 & 6.6200 \mathrm{e}-007 & 2.4494 \mathrm{e}-002 \\ 2.4496 \mathrm{e}+008 & 2.8600 \mathrm{e}-002 & 1.0582 \mathrm{e}+003 \\ 8.2909 \mathrm{e}+006 & 9.6800 \mathrm{e}-004 & 3.5816 \mathrm{e}+001 \\ 4.0684 \mathrm{e}+008 & 4.7500 \mathrm{e}-002 & 1.7575 \mathrm{e}+003 \\ 1.1049 \mathrm{e}+008 & 1.2900 \mathrm{e}-002 & 4.7730 \mathrm{e}+002 \\ 6.9719 \mathrm{e}+007 & 8.1400 \mathrm{e}-003 & 3.0118 \mathrm{e}+002 \\ 5.1733 \mathrm{e}+005 & 6.0400 \mathrm{e}-005 & 2.2348 \mathrm{e}+000 \\ 1.1820 \mathrm{e}+007 & 1.3800 \mathrm{e}-003 & 5.1060 \mathrm{e}+001\end{array}$


Page $: 2$

DOS File : CSIX-02.MS5

Run Date: August 21, 2002

Run Time: 13:13:04

Duration : 00:01:02

\begin{tabular}{|c|c|c|c|c|}
\hline$\underline{\text { Nuclide }}$ & curies & becquerels & $\mu \mathrm{Ci} / \mathrm{cm}^{3}$ & $\underline{\mathrm{Bq} / \mathrm{cm}^{3}}$ \\
\hline $\mathrm{Nb}-94$ & $1.9584 \mathrm{e}-004$ & $7.2460 \mathrm{e}+006$ & $8.4600 \mathrm{e}-004$ & $3.1302 \mathrm{e}+001$ \\
\hline Ni-63 & $7.2918 \mathrm{e}-003$ & $2.6980 \mathrm{e}+008$ & $3.1500 \mathrm{e}-002$ & $1.1655 \mathrm{e}+003$ \\
\hline $\mathrm{Np}-237$ & $3.6112 \mathrm{e}-004$ & $1.3361 \mathrm{e}+007$ & $1.5600 \mathrm{e}-003$ & $5.7720 \mathrm{e}+001$ \\
\hline Np-239 & $3.6112 \mathrm{e}-006$ & $1.3361 \mathrm{e}+005$ & $1.5600 \mathrm{e}-005$ & $5.7720 \mathrm{e}-001$ \\
\hline $\mathrm{Pa}-233$ & $5.0001 \mathrm{e}-004$ & $1.8500 \mathrm{e}+007$ & $2.1600 \mathrm{e}-003$ & $7.9920 \mathrm{e}+001$ \\
\hline $\mathrm{Pa}-234 \mathrm{~m}$ & $3.6112 \mathrm{e}-006$ & $1.3361 \mathrm{e}+005$ & $1.5600 \mathrm{e}-005$ & $5.7720 \mathrm{e}-001$ \\
\hline Pd-107 & $2.7778 \mathrm{e}-006$ & $1.0278 \mathrm{e}+005$ & $1.2000 \mathrm{e}-005$ & $4.4400 \mathrm{e}-001$ \\
\hline Pm-146 & $1.6736 \mathrm{e}-006$ & $6.1925 \mathrm{e}+004$ & $7.2300 \mathrm{e}-006$ & $2.6751 \mathrm{e}-001$ \\
\hline Pm-147 & $9.4678 \mathrm{e}-004$ & $3.5031 \mathrm{e}+007$ & $4.0900 \mathrm{e}-003$ & $1.5133 \mathrm{e}+002$ \\
\hline $\mathrm{Pu}-236$ & $1.9584 \mathrm{e}-008$ & $7.2460 \mathrm{e}+002$ & $8.4600 \mathrm{e}-008$ & $3.1302 \mathrm{e}-003$ \\
\hline $\mathrm{Pu}-238$ & $1.0903 \mathrm{e}-001$ & $4.0341 \mathrm{e}+009$ & $4.7100 \mathrm{e}-001$ & $1.7427 \mathrm{e}+004$ \\
\hline $\mathrm{Pu}-239$ & $1.4792 \mathrm{e}-002$ & $5.4730 \mathrm{e}+008$ & $6.3900 \mathrm{e}-002$ & $2.3643 \mathrm{e}+003$ \\
\hline $\mathrm{Pu}-240$ & $1.7361 \mathrm{e}-003$ & $6.4237 \mathrm{e}+007$ & $7.5000 \mathrm{e}-003$ & $2.7750 \mathrm{e}+002$ \\
\hline $\mathrm{Pu}-241$ & $3.1482 \mathrm{e}-002$ & $1.1648 \mathrm{e}+009$ & $1.3600 \mathrm{e}-001$ & $5.0320 \mathrm{e}+003$ \\
\hline $\mathrm{Pu}-242$ & $3.1714 \mathrm{e}-006$ & $1.1734 \mathrm{e}+005$ & $1.3700 \mathrm{e}-005$ & $5.0690 \mathrm{e}-001$ \\
\hline Rh-102 & $6.6900 \mathrm{e}-009$ & $2.4753 \mathrm{e}+002$ & $2.8900 \mathrm{e}-008$ & $1.0693 \mathrm{e}-003$ \\
\hline Rh-106 & $1.8357 \mathrm{e}-008$ & $6.7920 \mathrm{e}+002$ & $7.9300 \mathrm{e}-008$ & $2.9341 \mathrm{e}-003$ \\
\hline Ru-106 & $1.8357 \mathrm{e}-008$ & $6.7920 \mathrm{e}+002$ & $7.9300 \mathrm{e}-008$ & $2.9341 \mathrm{e}-003$ \\
\hline $\mathrm{Sb}-125$ & $1.2894 \mathrm{e}-004$ & $4.7707 e+006$ & $5.5700 \mathrm{e}-004$ & $2.0609 \mathrm{e}+001$ \\
\hline Sb-126 & $9.8845 \mathrm{e}-006$ & $3.6573 \mathrm{e}+005$ & $4.2700 \mathrm{e}-005$ & $1.5799 \mathrm{e}+000$ \\
\hline $\mathrm{Sb}-126 \mathrm{~m}$ & $7.1066 \mathrm{e}-005$ & $2.6295 \mathrm{e}+006$ & $3.0700 \mathrm{e}-004$ & $1.1359 \mathrm{e}+001$ \\
\hline Se-79 & $7.5465 \mathrm{e}-005$ & $2.7922 \mathrm{e}+006$ & $3.2600 \mathrm{e}-004$ & $1.2062 \mathrm{e}+001$ \\
\hline Sm-151 & $5.3010 \mathrm{e}-002$ & $1.9614 \mathrm{e}+009$ & $2.2900 \mathrm{e}-001$ & $8.4730 \mathrm{e}+003$ \\
\hline Sn-121m & $9.6298 \mathrm{e}-006$ & $3.5630 \mathrm{e}+005$ & $4.1600 \mathrm{e}-005$ & $1.5392 \mathrm{e}+000$ \\
\hline Sn-126 & $7.1066 \mathrm{e}-005$ & $2.6295 \mathrm{e}+006$ & $3.0700 \mathrm{e}-004$ & $1.1359 \mathrm{e}+001$ \\
\hline Sr-90 & $5.4399 \mathrm{e}+000$ & $2.0128 \mathrm{e}+011$ & $2.3500 \mathrm{e}+001$ & $8.6950 \mathrm{e}+005$ \\
\hline Tc-99 & $2.1852 \mathrm{e}-003$ & $8.0854 \mathrm{e}+007$ & $9.4400 \mathrm{e}-003$ & $3.4928 \mathrm{e}+002$ \\
\hline Te-125m & $2.0903 \mathrm{e}-005$ & $7.7342 \mathrm{e}+005$ & $9.0300 \mathrm{e}-005$ & $3.3411 \mathrm{e}+000$ \\
\hline Th-231 & $3.6112 \mathrm{e}-006$ & $1.3361 \mathrm{e}+005$ & $1.5600 \mathrm{e}-005$ & $5.7720 \mathrm{e}-001$ \\
\hline Th-234 & $3.6112 \mathrm{e}-006$ & $1.3361 \mathrm{e}+005$ & $1.5600 \mathrm{e}-005$ & $5.7720 \mathrm{e}-001$ \\
\hline $\mathrm{U}-232$ & $1.1482 \mathrm{e}-006$ & $4.2482 \mathrm{e}+004$ & $4.9600 \mathrm{e}-006$ & $1.8352 \mathrm{e}-001$ \\
\hline U-233 & $1.4908 \mathrm{e}-007$ & $5.5159 \mathrm{e}+003$ & $6.4400 \mathrm{e}-007$ & $2.3828 \mathrm{e}-002$ \\
\hline U-234 & $2.0162 \mathrm{e}-004$ & $7.4601 \mathrm{e}+006$ & $8.7100 \mathrm{e}-004$ & $3.2227 \mathrm{e}+001$ \\
\hline U-235 & $5.3010 \mathrm{e}-006$ & $1.9614 \mathrm{e}+005$ & $2.2900 \mathrm{e}-005$ & $8.4730 \mathrm{e}-001$ \\
\hline U-236 & $8.4493 \mathrm{e}-006$ & $3.1262 \mathrm{e}+005$ & $3.6500 \mathrm{e}-005$ & $1.3505 \mathrm{e}+000$ \\
\hline U-237 & $2.1297 \mathrm{e}-006$ & $7.8798 \mathrm{e}+004$ & $9.2000 \mathrm{e}-006$ & $3.4040 \mathrm{e}-001$ \\
\hline U-238 & $5.8798 \mathrm{e}-006$ & $2.1755 \mathrm{e}+005$ & $2.5400 \mathrm{e}-005$ & $9.3980 \mathrm{e}-001$ \\
\hline Y-90 & $5.4399 \mathrm{e}+000$ & $2.0128 \mathrm{e}+011$ & $2.3500 \mathrm{e}+001$ & $8.6950 \mathrm{e}+005$ \\
\hline Zr-93 & $3.7732 \mathrm{e}-004$ & $1.3961 \mathrm{e}+007$ & $1.6300 \mathrm{e}-003$ & $6.0310 \mathrm{e}+001$ \\
\hline
\end{tabular}

Buildup

The material reference is : Source

Radial

Integration Parameters

Circumferential

Y Direction (axial)

Results 
Page : 3

DOS File: CSIX-02.MS5

Run Date: August 21, 2002

Run Time: 13:13:04

Duration : 00:01:02

\begin{tabular}{|c|c|c|c|c|c|}
\hline$\frac{\text { Energy }}{\underline{\mathrm{MeV}}}$ & $\begin{array}{c}\text { Activity } \\
\text { photons/sec }\end{array}$ & $\frac{\frac{\text { Fluence Rate }}{\mathrm{MeV} / \mathrm{cm}^{2} / \mathrm{sec}}}{\underline{\text { No Buildup }}}$ & $\frac{\frac{\text { Fluence Rate }}{\mathrm{MeV} / \mathrm{cm}^{2} / \mathrm{sec}}}{\underline{\text { With Buildup }}}$ & $\frac{\frac{\text { Exposure Rate }}{\mathrm{mR} / \mathrm{hr}}}{\text { No Buildup }}$ & $\frac{\frac{\text { Exposure Rate }}{\mathrm{mR} / \mathrm{hr}}}{\underline{\text { With Buildup }}}$ \\
\hline 0.015 & $3.261 \mathrm{e}+08$ & $1.207 \mathrm{e}-34$ & $3.778 \mathrm{e}-24$ & $1.036 \mathrm{e}-35$ & $3.240 \mathrm{e}-25$ \\
\hline 0.02 & $2.405 \mathrm{e}+08$ & $6.963 \mathrm{e}-16$ & $8.774 \mathrm{e}-16$ & $2.412 \mathrm{e}-17$ & $3.039 \mathrm{e}-17$ \\
\hline 0.03 & $3.557 \mathrm{e}+07$ & $6.162 \mathrm{e}-06$ & $1.031 \mathrm{e}-05$ & $6.107 \mathrm{e}-08$ & $1.022 \mathrm{e}-07$ \\
\hline 0.04 & $1.207 \mathrm{e}+08$ & $2.653 \mathrm{e}-02$ & $5.954 \mathrm{e}-02$ & $1.174 \mathrm{e}-04$ & $2.633 \mathrm{e}-04$ \\
\hline 0.05 & $2.995 \mathrm{e}+07$ & $1.458 \mathrm{e}-01$ & $4.245 \mathrm{e}-01$ & $3.885 \mathrm{e}-04$ & $1.131 \mathrm{e}-03$ \\
\hline 0.06 & $2.188 \mathrm{e}+08$ & $5.569 \mathrm{e}+00$ & $1.944 \mathrm{e}+01$ & $1.106 \mathrm{e}-02$ & $3.861 \mathrm{e}-02$ \\
\hline 0.08 & $3.805 \mathrm{e}+07$ & $5.110 \mathrm{e}+00$ & $2.084 \mathrm{e}+01$ & $8.087 \mathrm{e}-03$ & $3.298 \mathrm{e}-02$ \\
\hline 0.1 & $1.981 \mathrm{e}+08$ & $5.997 \mathrm{e}+01$ & $2.528 \mathrm{e}+02$ & $9.175 \mathrm{e}-02$ & $3.868 \mathrm{e}-01$ \\
\hline 0.15 & $8.309 \mathrm{e}+05$ & $6.601 \mathrm{e}-01$ & $2.644 \mathrm{e}+00$ & $1.087 \mathrm{e}-03$ & $4.355 \mathrm{e}-03$ \\
\hline 0.2 & $2.924 \mathrm{e}+07$ & $3.863 \mathrm{e}+01$ & $1.443 \mathrm{e}+02$ & $6.818 \mathrm{e}-02$ & $2.547 \mathrm{e}-01$ \\
\hline 0.3 & $1.190 \mathrm{e}+07$ & $2.974 \mathrm{e}+01$ & $9.800 \mathrm{e}+01$ & $5.640 \mathrm{e}-02$ & $1.859 \mathrm{e}-01$ \\
\hline 0.4 & $8.520 \mathrm{e}+06$ & $3.292 \mathrm{e}+01$ & $9.818 \mathrm{e}+01$ & $6.414 \mathrm{e}-02$ & $1.913 \mathrm{e}-01$ \\
\hline 0.5 & $2.419 \mathrm{e}+06$ & $1.308 \mathrm{e}+01$ & $3.606 \mathrm{e}+01$ & $2.568 \mathrm{e}-02$ & 7.077e-02 \\
\hline 0.6 & $2.344 \mathrm{e}+08$ & $1.669 \mathrm{e}+03$ & $4.295 \mathrm{e}+03$ & $3.258 \mathrm{e}+00$ & $8.384 \mathrm{e}+00$ \\
\hline 0.8 & $1.695 \mathrm{e}+08$ & $1.867 \mathrm{e}+03$ & $4.334 \mathrm{e}+03$ & $3.551 \mathrm{e}+00$ & $8.244 \mathrm{e}+00$ \\
\hline 1.0 & $1.784 \mathrm{e}+08$ & $2.761 \mathrm{e}+03$ & $5.941 \mathrm{e}+03$ & $5.090 \mathrm{e}+00$ & $1.095 \mathrm{e}+01$ \\
\hline 1.5 & $2.095 \mathrm{e}+08$ & $6.012 \mathrm{e}+03$ & $1.133 \mathrm{e}+04$ & $1.011 \mathrm{e}+01$ & $1.907 \mathrm{e}+01$ \\
\hline 2.0 & $8.246 \mathrm{e}+03$ & $3.636 \mathrm{e}-01$ & $6.334 \mathrm{e}-01$ & $5.622 \mathrm{e}-04$ & $9.794 \mathrm{e}-04$ \\
\hline 3.0 & $1.850 \mathrm{e}+00$ & $1.463 \mathrm{e}-04$ & $2.301 \mathrm{e}-04$ & $1.984 \mathrm{e}-07$ & $3.122 \mathrm{e}-07$ \\
\hline OTALS: & $2.052 \mathrm{e}+09$ & $1.250 \mathrm{e}+04$ & $2.658 \mathrm{e}+04$ & $2.234 \mathrm{e}+01$ & $4.782 \mathrm{e}+01$ \\
\hline
\end{tabular}


APPENDIX B

\section{MERCURY CHARACTERIZATION} IN OFF-GAS SCRUB SOLUTIONS 



\title{
Final Report
}

\author{
for
}

Analysis of Mercury-Containing Processing Byproducts

Prepared by:

Prof. Rene Rodriguez

Dept. of Chemistry

Idaho State University

Pocatello, ID 83209

\author{
for \\ John Del Debbio \\ Idaho National Environmental and Engineering Laboratory \\ Idaho Falls, ID 83415
}

August 1, 2002 


\section{Introduction}

The purpose of this study was to determine the relative amounts of organically and inorganically bound mercury contained in scrub solutions from the treatment of off-gas from pilotscale waste vitrification tests. The mercury may have reacted with organic material in the glass or with sugar decomposition products. Sugar is added to the waste feed as a de-nitration agent and is pyrolized at melt temperatures of $1000-1200^{\circ} \mathrm{C}$. Attempts were also made to quantify and identify the amount of organically bound mercury.

Several scrub solutions were provided from INEEL and the analyses of these solutions for atomic composition had been previously done at the INEEL. We chose to focus on two solutions, one with the highest concentration of mercury and the other with the lowest: Sample \#103 with INEEL total reported concentration of mercury of $1060 \mathrm{ppm}$ Sample \#061 with INEEL total reported concentration of mercury of $42.10 \mathrm{ppm}$ Most of the analyses were done on the scrub solution \#103, as the spectroscopic techniques require relatively high concentrations of analyte. Depending on the cross section of the Raman scattering, detection with Raman spectroscopy is limited to $1000 \mathrm{ppm}$ or higher. Infrared spectroscopy is nominally good to several ppm, again in this case depending on the strength of the absorption.

The techniques used with the highest sensitivity were gas chromatography/mass spectrometry, GC/MS and liquid chromatography/mass spectrometry, LC/MS. With the GC/MS, both a direct injection and an SPME (solid phase micro-extraction) technique were employed. In the solid phase micro-extraction technique, a coated solid thin fiber made of polydimethylsiloxane is inserted into the head space volume through a septum covering the solution to be analyzed. The fibre selectively absorbs the volatile components of the mixture with polarity similar to the coating on the fiber. The fiber is then inserted through the inlet septum of the GC/MS and at the high temperature of the inlet, the volatile components are desorbed from the fiber material and enter the helium stream into the GC column and eventually into the mass spectrometer for detection. Both total ion count was used to give the GC trace as a function of the retention time

In general this technique has been found to be viable for determination of concentrations of mercury containing species including alkyl mercury compounds such as dimethyl mercury, methyl mercury chloride, ethyl mercury chloride, diethyl mercury. ${ }^{1,2}$ Metallic mercury and mercuric chloride also have sufficient volatility for detection by this method as do some of the aromatic mercury compounds. Previous researchers have found that a calibration curve can be made by varying the concentration of the mercury species in the solution. The calibration curve may however be dependent on the constitution of the solution.

Since one of the main interest in the study revolved around the organically bound mercury in the solution, a separation by extracting the samples with an organic solvent was employed. Identification by spectroscopic methods was expected to minimize the amount of chemicals needed to prepare the samples for analysis. Other wet chemical methods exist to help identify the organic mercury present in the samples, but they are chemically intensive and generate a lot of waste. ${ }^{3}$ And as expected, the spectroscopic methods required some trial-and-error to determine the correct parameters for analysis. In fact there was not sufficient time to maximize the analytical capability of the instruments used for the analysis. 


\section{Experimental}

The following investigations were carried out for these studies:

1. Determination of the relative concentrations of inorganic mercury and organically bound mercury using a Buck Scientific Model 400A Mercury Analyzer. This analysis is based on detection by cold vapor atomic absorption and Method 245.1, the "Manual Cold Vapor Technique. ${ }^{4}$ According to Method 245.1 cold vapor atomic absorption is not sensitive to organic mercury unless they are first broken down and converted into mercuric ions. "Potassium permanganate oxidizes many of these compounds, but recent studies have shown that a number of organic mercurials, including phenyl mecuric acetate and methyl mercuric chloride are only partially oxidized.." However a potassium persulfate oxidation, at near the boiling point of water, following the permanganate oxidation was found to give $100 \%$ oxidation. Thus to distiguish between the inorganic mercury and the organic mercury present in the sample, the cold vapor technique was employed on aliquots of Samples \#103 and \#61 without the permanganate and persulfate oxidation (yielding only the concentration of inorganic mercury present) and then other aliquots were treated with the permanganate and $90^{\circ} \mathrm{C}$ persulfate solution before the cold vapor analysis (yielding the total mercury concentration, both the inorganic and organic mercury. There was no $\mathrm{pH}$ adjustment for these determinations.

2. Infrared Spectra of $\mathrm{pH}$-adjusted Sample \#103. The $\mathrm{pH}$ was adjusted to $\mathrm{pH} 7$ and $\mathrm{pH}$ 3. Two $\mathrm{pH}$ adjustments were used because at approximately $\mathrm{pH} 4$, a precipitate formed in the mixture. The precipitate could have contained some mercury. Infrared Spectra of the Aqueous Solution and a $2 \mathrm{~mL}$ aliquot extracted with carbon tetrachloride were performed using a Perkin Elmer FTIR and/or a Nicolet FTIR. A few drops of the sample to be analyzed were placed between two silver chloride windows after taking a background of the windows or the windows with water. An infrared spectrum of an extracted $\sim 700 \mathrm{ppm}$ methyl mercuric chloride solution was also obtained for comparison purposes.

3. Raman Spectra of $\mathrm{pH}$ adjusted Sample \#103 were attempted. The samples were injected into a capillary tube which was sealed on one end. After the sample was injected and placed in the tube, the open end of capillary was sealed with a Bunsen burner. Raman Spectra were acquired with a Spex system consisting of a Spex half-meter monochromator with associated collection and detection optics and equipment. In one layout a CCD was used to detect the Raman scattered light, and this resulted in spectral sections of roughly $1000 \mathrm{~cm}^{-1}$. Two incident laser wavelengths were attempted in the case of the sample, as it was colored and fluoresced. Incident laser powers were typically 75 milliwatts. Another Raman system with much higher laser power was used in an attempt to bleach out the fluorescence and to increase the signal. This system used an a photomultiplier tube as a detector. Laser intensities for this system were roughly 750 milliwatts.

4. GC/MS was performed on the sample using a Perkin Elmer QMASS, Quadrupole Mass Spectrometer coupled to a Perkin Elmer Model 1500 GC. A Supelco Equity 5 capillary column, $30 \mathrm{~m}$ in length was used to perform the separations. Initially, several conditions were attempted for operation of the GC/MS, many based on conditions reported in the literature. We settled on conditions of injector temperatures of 150 or $230^{\circ} \mathrm{C}$, and column temperatures of 40 or $100^{\circ} \mathrm{C}$. 
The repeatability of this instrument was found to be 1-3 amu depending on the mass range and the automatic calibration performed before data was taken. Limited amounts of LC/MS were also performed on methyl mercuric chloride and Sample 103. The LC/MS used was a Finnegan ion trap LC/MS with proton activation thermospray. The system was capable of performing MS/MS and occassionally even MS/MS/MS.

A solution of methyl mercuric chloride was prepared from a $0.100 \mathrm{~g}$ sample of $99.9 \%$ methyl mercuric chloride obtained from Aldrich. This solution was used as an example of an organically bound mercury material. Approximately $0.07 \mathrm{~g}$ of the sample was transferred to a 100 $\mathrm{mL}$ volumetric flask and deionized water was added to fill it to the mark. The solution was stirred overnight and there still appeared to be a very slight amount of crystals floating in the solution. The solubility of the material is on the order of $700 \mathrm{ppm}$ in deionized water. Thus, the concentration of mercury is about $550 \mathrm{ppm}$. The solution was acidified to $\mathrm{pH} 3$ upon completion by addition of a very small amount of nitic acid.

A solution of mercuric chloride was also prepared as a standard material for analysis. Roughly, a 200 ppm solution was prepared by weighing out the mercuric chloride and diluting it with deionized water in a $100 \mathrm{~mL}$ volumetric flask. The solubility of the mercuric chloride was a) similar to the methy mercuric chloride.

\section{Results and Discussion}

The results will be given presented according to the type of determination performed as outlined previously in the experimental section. Subsequently, they will be combined in the conclusions section where inferences about the presence of organic mercury will be drawn.

\section{Mercury Analyzer}

As described in the experimental section, two different determinations were performed on the mercury samples after calibration of the instrument. In one case, an aliquot of the sample was taken and subjected to the standard cold vapor method which involves the addition of stannous chloride to the sample to reduce the mercuric ions present in solution to metallic mercury. The metallic mercury has a relatively high vapor pressure. The mercury is then detected by the vapor absorbing light at $253.7 \mathrm{~nm}$. This measurement only gives the mercury present as inorganic mercury. Another aliquot was then first treated with potassium permanganate and potassium persulfate and then heated to about $90^{\circ} \mathrm{C}$. After cooling the mixture was subjected to the stannous chloride. The absorbance at 253.7 now included both the inorganic and organic mercury. The results of these analyses are given below. The error reported is based upon the repeatability determined by multiple measurements of a standard solution of mercuric nitrate at the $95 \%$ confidence based on student $t$ test.

\begin{tabular}{ccc}
$\begin{array}{c}\text { INEEL } \\
\text { Sample \# }\end{array}$ & $\begin{array}{l}\text { (Inorganic Mercury) } \\
\text { Mercury Determined } \\
\text { without using Persulfate }\end{array}$ & $\begin{array}{l}\text { (Total Mercury) } \\
\text { Mercury Determined } \\
\text { with Persulfate Oxidation }\end{array}$ \\
\hline 103 & $961 \mathrm{ppm}^{+} / 80$ & $855 \mathrm{ppm}+.70$ \\
61 & $13.2 \mathrm{ppm}+1.3$ & $11.1 \mathrm{ppm}+1.1$ \\
Note that in both cases the concentration determined for the total mercury was below the value
\end{tabular}


determined for just the inorganic mercury. This suggests that during the persulfate heating step, as described above, some mercury vapor could have been lost in the form of volatile mercury compounds or that there was some oxidizable substance other than mercury which absorbed at $254 \mathrm{~nm}$. This oxidizable substance would have had to be subsequently oxidized to another species that did not absorb at $254 \mathrm{~nm}$ upon the addition of permanganate and hot persulfate. We attempted to minimize any loss of volatile mercury-containing substances by covering the persulfate solution during heating.

Note also that in both cases the concentration numbers are around 30-100 ppm lower than the values determined at INEEL, and that the percentage difference is much higher for the lower concentration sample. This is somewhat expected since the materials were received in plastic containers which will leach out the mercury materials more readily than glass. Although it is disconcerting that the concentration based on the total mercury in the solution is lower than the concentration based on the inorganic mercury, the values are within the $95 \%$ confidence interval of one another, and the results suggest that most if not all of the mercury is present in the form of inorganic mercury.

Infrared Studies

Based on the information obtained from the Mercury Analyzer study, the concentration of organic mercury was expected to be small. Infrared Spectroscopy is a somewhat sensitive technique. For a substance with a very strong absorption band, concentrations of that material may be detectable at near ppm levels. To facilitate a search of the infrared spectrum for organic mercury, the infrared and Raman bands of methyl mercuric chloride were obtained from the literature. ${ }^{5}$ The infrared and Raman active vibrational peaks of solid methyl mercuric chloride are:

\begin{tabular}{cccl} 
Infrared & $\begin{array}{c}\text { Solid State Vibrational Peaks of } \mathbf{C H}_{3} \mathbf{H g C l} \text { in } \mathbf{~ c m}^{-1} \\
\text { Raman }\end{array}$ & \multicolumn{2}{c}{ Assignment } \\
\hline 3008 & 3012 & $v_{5}$ & C-H stretch (asym) \\
2950 & 2950 & & \\
2922 & 2927 & $v_{1}$ & C-H stretch (sym) \\
2796 & & $2 v_{6}$ & \\
1403 & & $v_{6}$ & $\mathrm{CH}_{3}$ deform (asym) \\
1191 & 1186 & $v_{2}$ & $\mathrm{CH}_{3}$ deform (sym) \\
788 & 774 & $v_{7}$ & $\mathrm{CH}_{3}$ rock \\
539 & 558 & $v_{3}$ & $\mathrm{C}-\mathrm{Hg}$ stretch \\
304 & 299 & $v_{4}$ & $\mathrm{Hg}-\mathrm{Cl}$ stretch \\
112 & & $v_{8}$ & $\mathrm{C}-\mathrm{Hg}-\mathrm{Cl}$ bend
\end{tabular}

Fourier Transform Infrared Spectroscopy was attempted for sample \#103. The $\mathrm{pH}$ was adjusted to $\mathrm{pH} 3$ to minimize damage to the window material, yet at that $\mathrm{pH}$ there was no significant amount of precipitation. Further adjustment to $\mathrm{pH} 7$ resulted in significant amounts of precipitation. The following spectum was obtained: 


\section{FTIR Spectrum of Sample \#103 at pH 3}

4

.3

.2

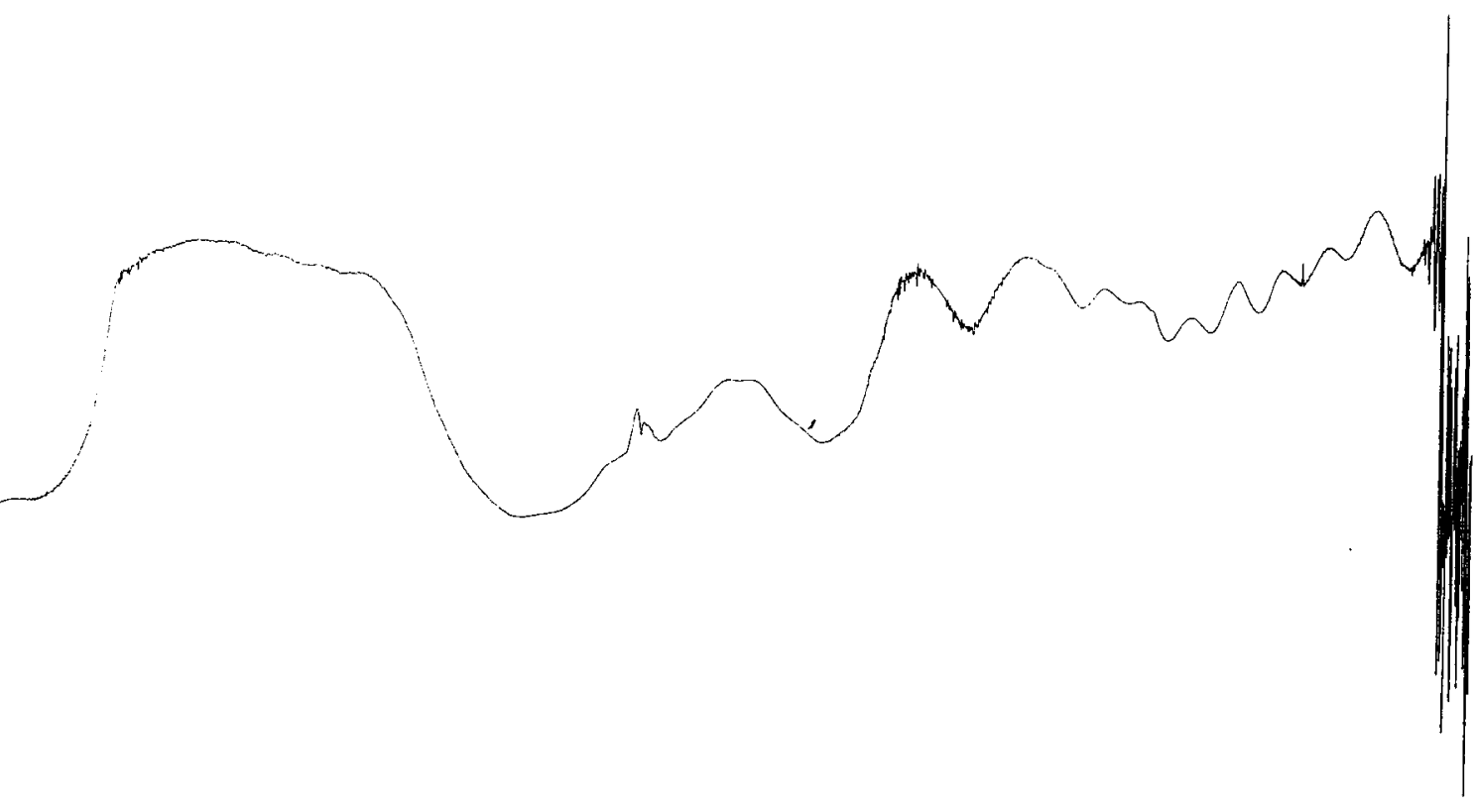

Absorbance / Wavenumber (cm-1) 3500

3000

2500

2000

1500

1000

500

The FTIR absorption curve is rather broad. It is dominated by the absorption features due to water which mask the smaller absorptions due to the organic material in the sample. Also note that there appears to be some fringing due to the window material. A spectrum of just water was also obtained to subtract from the above spectrum.

\section{FTIR Spectrum of Pure Water}

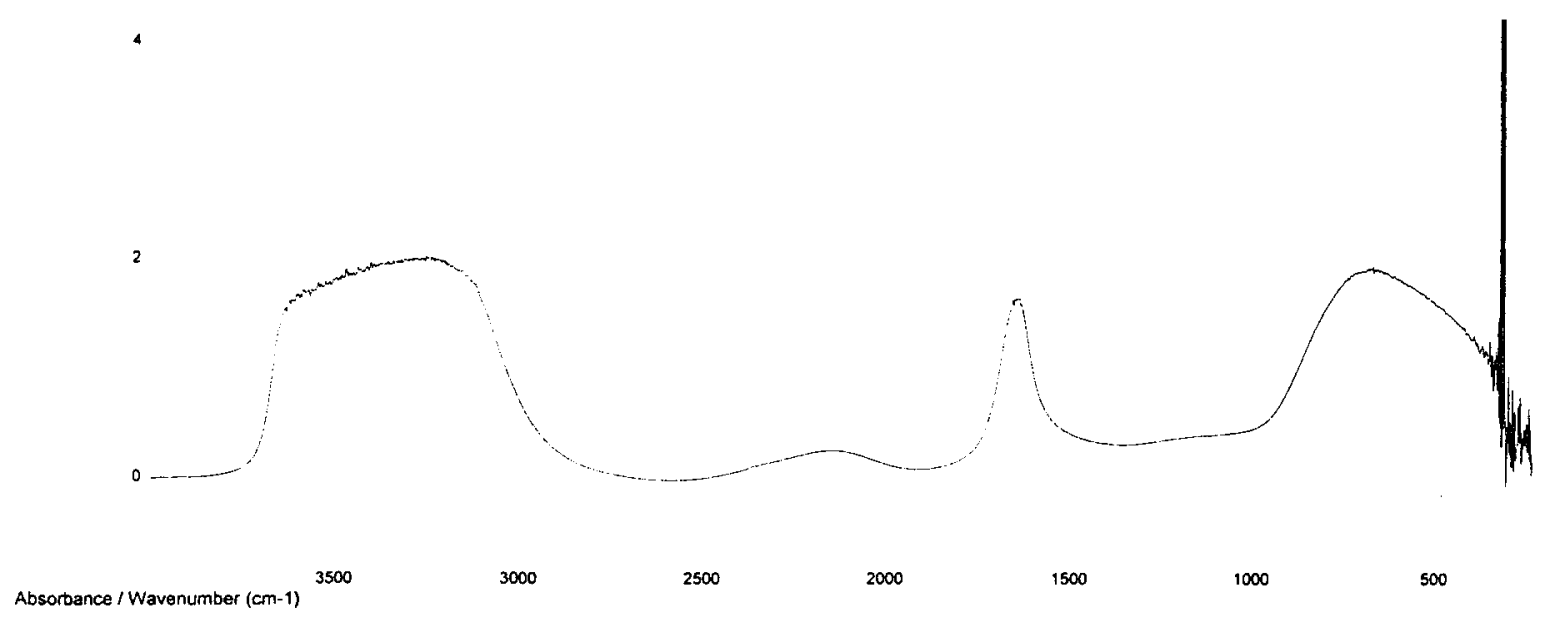

The water spectrum was subtracted from the Sample \#103 spectrum in an attempt to bring out 
absorption features that were due to the organic or organo-mercury material in the sample. This was done in a spectral analysis program from Galactic ${ }^{\mathrm{TM}}$ called GRAMS 5. A multiplication factor was in an attempt to get the best subtraction possible. This was judged by minimizing the absorption from $3500 \mathrm{~cm}^{-1}$ to $3100 \mathrm{~cm}^{-1}$ to be as close to baseline as possible. The result of the subtraction is given below:

\section{FTIR of Sample 103 after subtracting out the FTIR of water}

.2

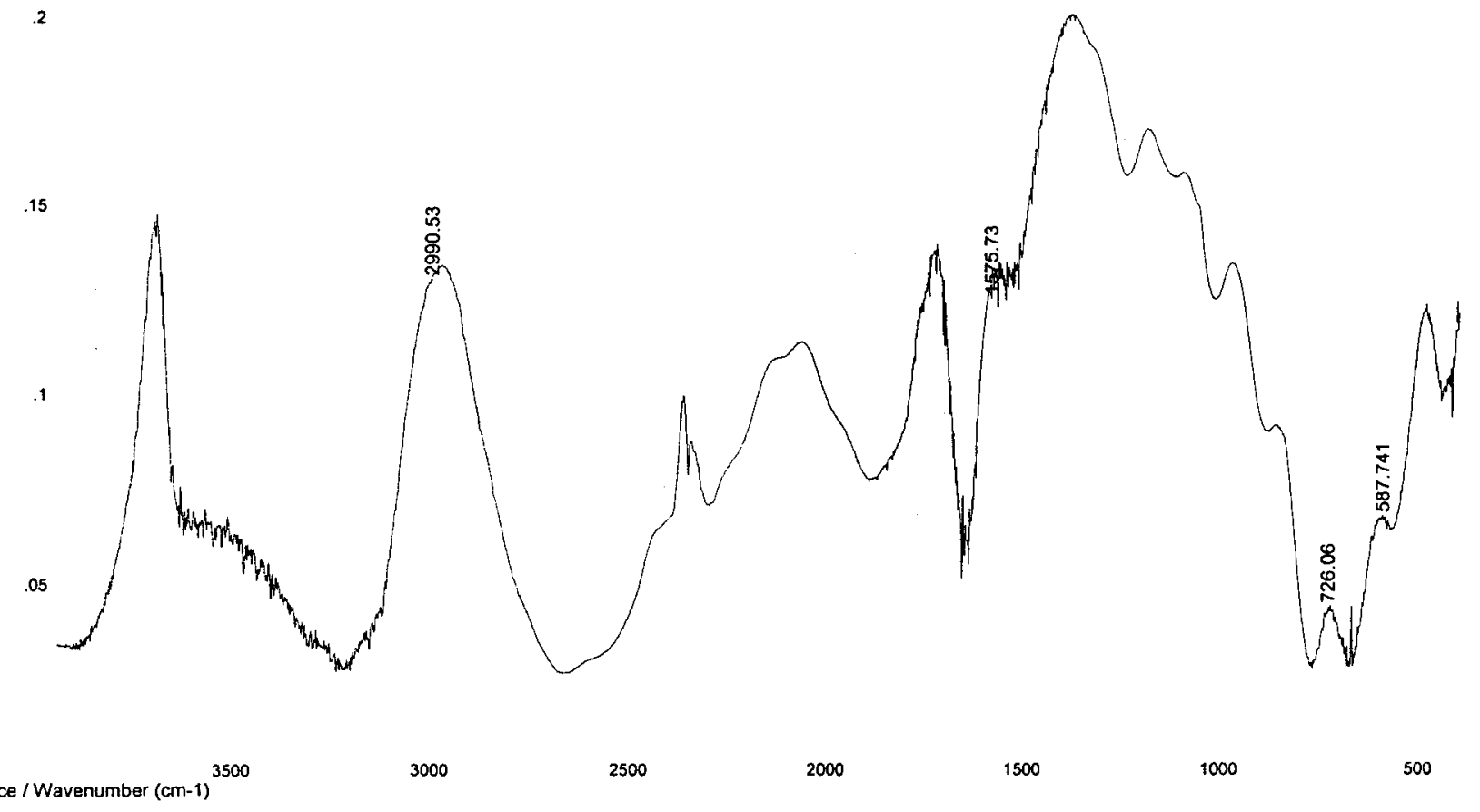

The subtraction is somewhat incomplete in that there is still a small absorption in the $3500 \mathrm{~cm}^{-1}$ to $3100 \mathrm{~cm}^{-1}$ range, and in the $1550 \mathrm{~cm}^{-1}$ range, but some of the features left after the subtraction are worthy of note. The large broad peak at $2900 \mathrm{~cm}^{-1}$ and the smaller features near 1400,726 , and 520 are consistent with the presence of a species like methyl mercuric chloride. The peaks at 726 and 520 are rather small, but they could be related to $\mathrm{CH}_{3}$ rock and a $\mathrm{C}-\mathrm{Hg}$ stretch respectively.

Since interest in the sample was related to the organic component, Sample 103 was extracted using $\mathrm{CCl}_{4}$. The expanded spectrum is given below: 


\section{Expanded FTIR Spectrum of Sample 103 extract with $\mathrm{CCI}_{4}$}

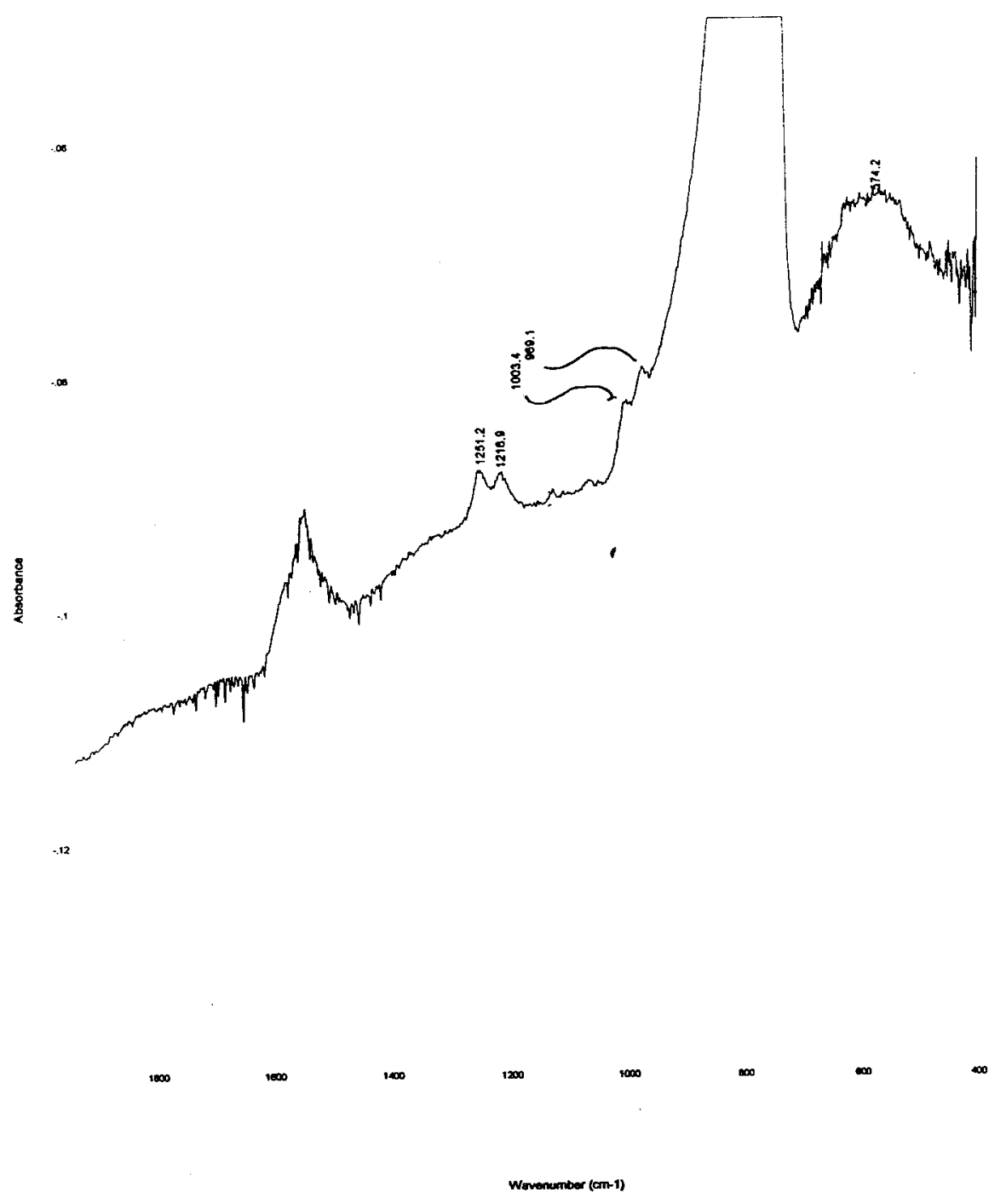

The large feature from 786 to $763 \mathrm{~cm}^{-1}$ is largely due to the $\mathrm{CCl}_{4}$. The peaks centered at 1500 $\mathrm{cm}^{-1}$ and $574 \mathrm{~cm}^{-1}$ are likely at least due in part to the organic component of Sample 103. The feature at 574 is in the range where a Hg-C stretch typically absorbs.

Overall it appears that the observed FTIR spectra are not inconsistent with the presence of a material containing an $\mathrm{Hg}-\mathrm{C}$ stretch. However, in the case of the aqueous solutions, the subtraction of water is rather difficult and the peak in this range could be an artifact. In the case of the $\mathrm{CCl}_{4}$ extract, the peak at 574 is not a reported peak for $\mathrm{CCl}_{4}$, but again the absorbance is very low and the peak could be due to a combination band of low intensity. In an attempt to quantify the amount of organic mercury, assuming that the peak around $570 \mathrm{~cm}^{-1}$ was due to an $\mathrm{Hg}-\mathrm{C}$ stretch, the $\mathrm{CCl}_{4}$ extract of a $\sim 600 \mathrm{ppm} \mathrm{Hg}$ solution of methyl mercuric chloride was prepared as described in the experimental section. The expanded FTIR spectrum is given below. 


\section{FTIR Spectrum of $700 \mathrm{ppm}$ methyl mecuric chloride extract in $\mathrm{CCl}_{4}$}

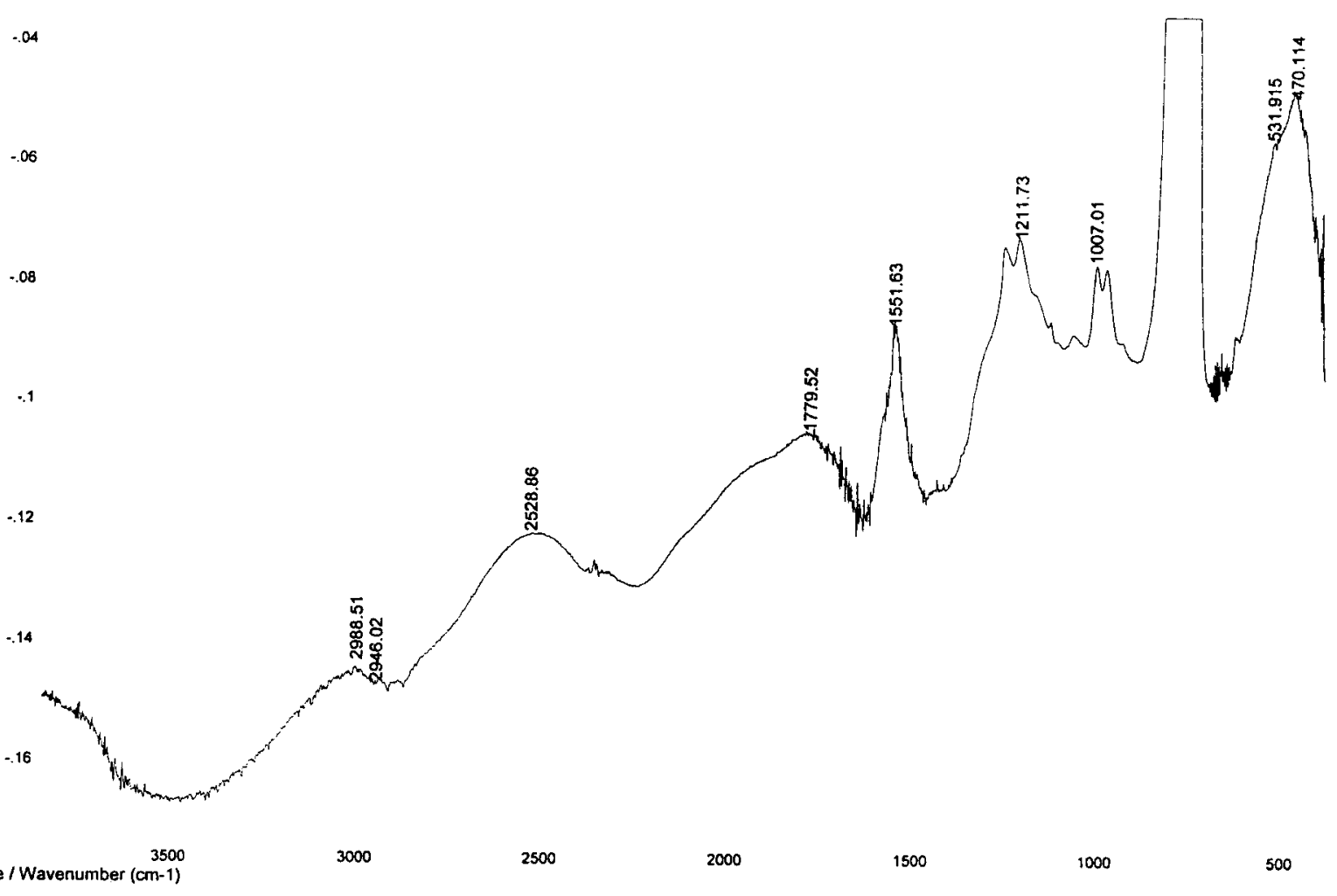

The feature that was assigned as the $\mathrm{Hg}-\mathrm{C}$ stretch has now shifted and is centered about $520 \mathrm{~cm}^{-1}$. The fact that this has shifted suggests the following. First, since it is shifting by more than 3 or 4 $\mathrm{cm}^{-1}$, then it is not likely completely due to the $\mathrm{CCl}_{4}$ while the peak at 1550 did not shift significantly and may be due to $\mathrm{CCl}_{4}$. Secondly, this would suggest that the Sample 103 extract is not simply methyl mercuric chloride but must contain other compounds. Assuming that the absorbance coefficients of these $\mathrm{Hg}-\mathrm{C}$ containing species are the same, one can estimate a concentration for $\mathrm{Hg}-\mathrm{C}$ compounds. The peak areas differ by about an order of magnitude, so the concentration of $\mathrm{Hg}-\mathrm{C}$ compounds could be on the order of $60 \mathrm{ppm} \mathrm{Hg}$ for this sample. Again there are many assumptions that went into this estimate. Also it is known that other metals in the sample that could be combined with carbon, and would have a similar absorption feature.

\section{Raman Spectroscopy}

As mentioned in the experimental section, Raman spectroscopy is not as sensitive a technique as FTIR. In fact, concentrations of a part per thousand are difficult to measure even for molecules with a high Raman scattering cross section. But, water is not as much a problem in the Raman spectrum. Initial attempts to obtain a Raman spectrum of Sample 103, were thwared by a large fluorescence signal. It was very intense and would certainly have swamped the Raman signal from components in Sample 103. We switched to a different Raman system with higher laser power to try to bleach out the fluorescent material, but it did not easily bleach out. We even 
switched laser lines from $514.5 \mathrm{~nm}$ to $488 \mathrm{~nm}$ in an attempt to lower the fluorescence. This helped just a very small amount.

It was surmised that perhaps the fluorescence might be due to a non-organic component of the solution, and extractions of Sample \#103 in cyclohexane and in $\mathrm{CCl}_{4}$ were performed and the extracted material was placed in a capillary tube. The Raman spectra of the extracted materials are shown below along with a Raman spectrum of the pure solvent.

\section{Raman Spectrum of Sample 103 extracted in Cyclohexane}
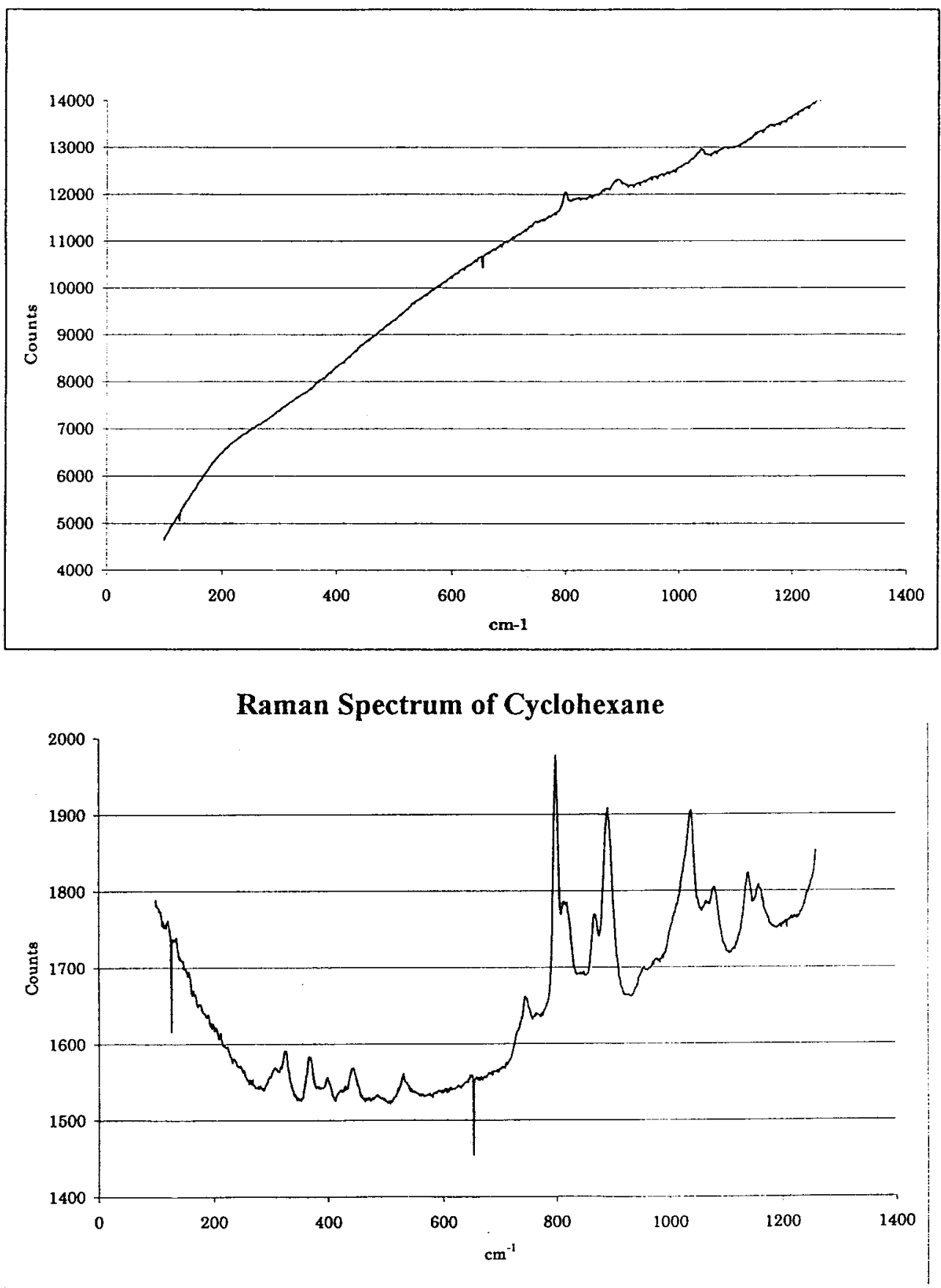


\section{Raman Spectrum of Sample 103 in Carbon Tetrachloride}

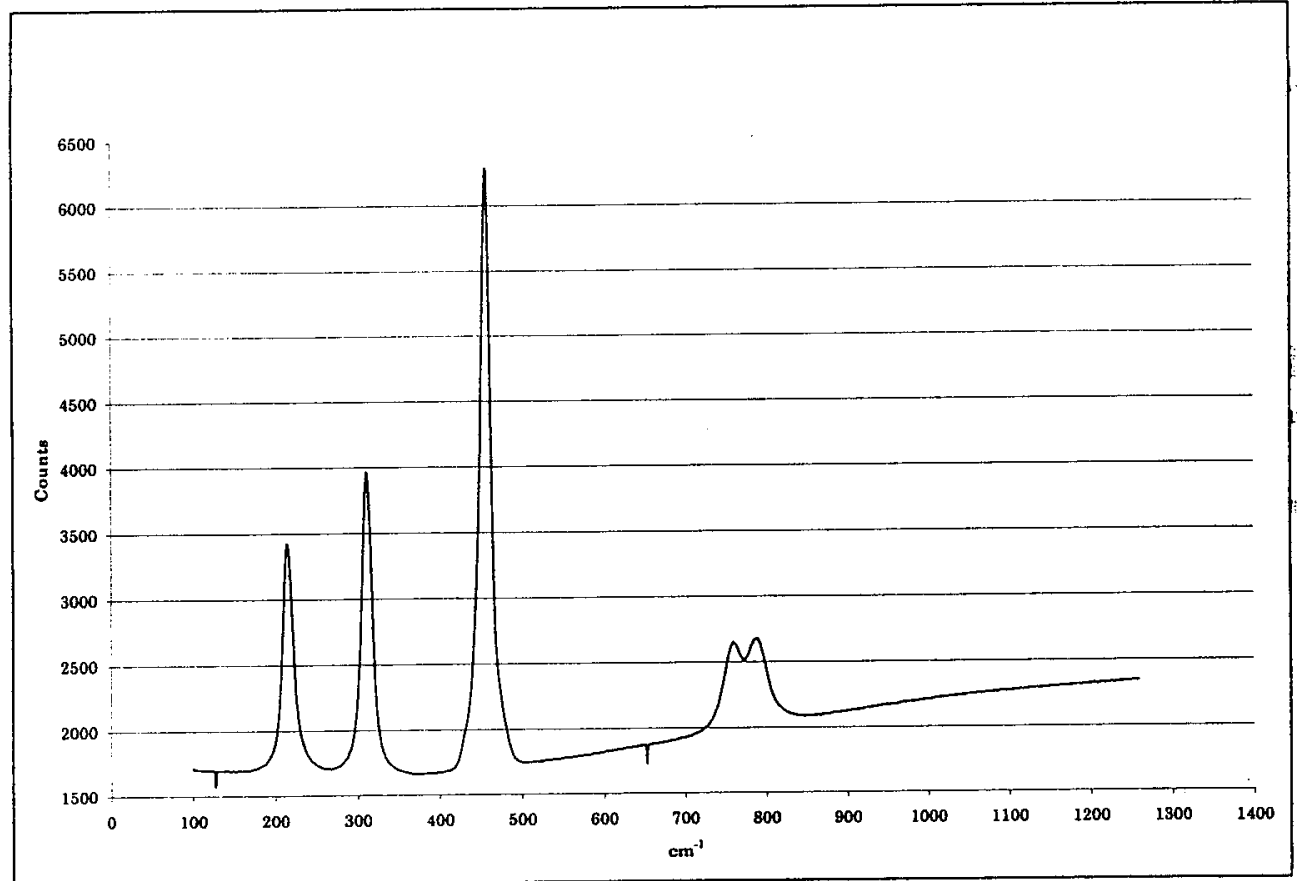

\section{Raman Spectrum of Carbon Tetrachloride}

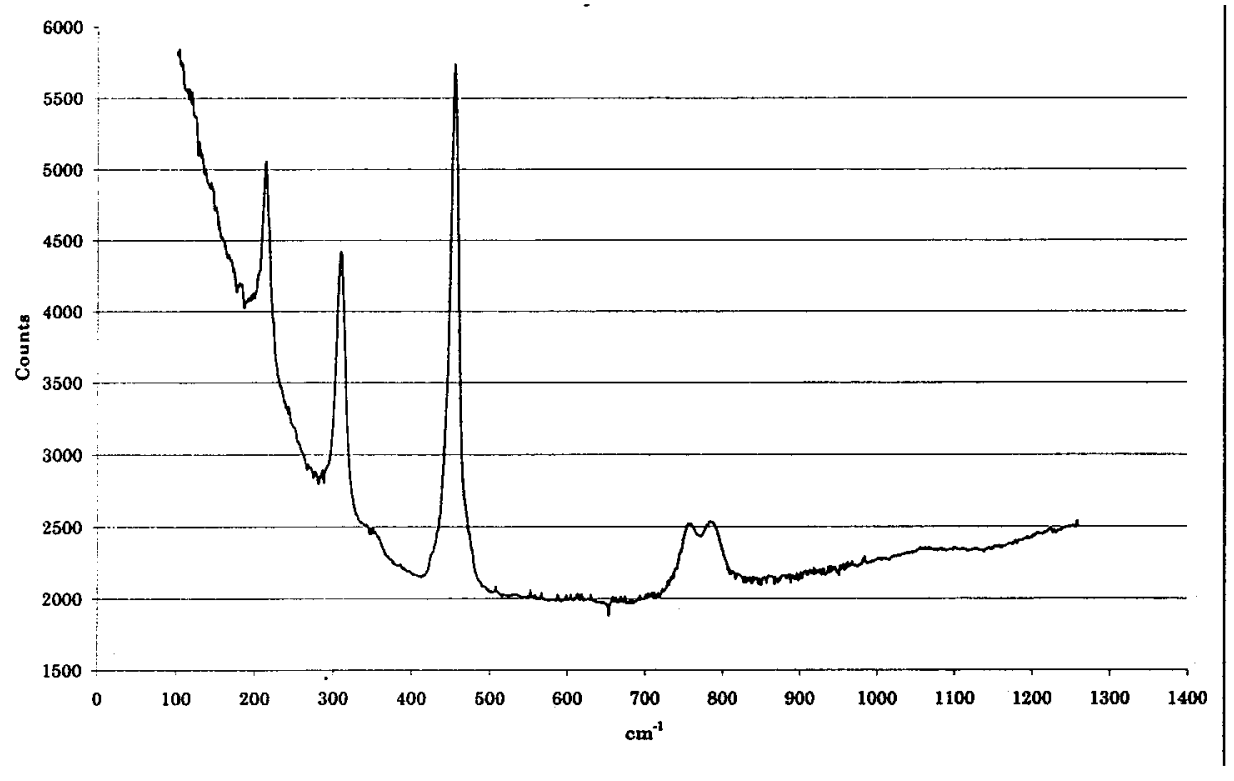

The fluorescence in the cyclohexane extract was still rather high as can be seen in the figure above. Note how the fluorescence background makes it very difficult to observe even the relatively intense solvent peaks of the cyclohexane let alone any organo-mercury material that may have been extracted into the cyclohexane. The fluorescence background in the carbon tetrachloride is not as intense, and the main peak features due to carbon tetrachloride are present. 
However, no smaller features due to the organic extract from Sample 103 could be observed in the Raman spectrum.

The Raman technique did not yield any useful information about the presence or amount of organic mercury present in the samples. The two reasons for this were the large fluorescent background due to some material in the Sample, and the inherent high detection limits of the Raman Spectroscopy.

\section{$\underline{\text { GC/MS }}$}

Since the IR was inconclusive and the Raman spectra were too weak, the lion's share of the time for these studies were spent on developing techniques for characterization by mass spectrometry. A literature search revealed several methodologies to pursue. In the end the limitations of the instrumentation limited the approaches.

GC/MS was attempted in two ways. First attempts were direct injections into the column of the organic extract from a mixture of approximately $2 \mathrm{ml}$ of Sample 103 and $2 \mathrm{~mL}$ of carbon tetrachloride. Several oven and injector temperatures were attempted as well as several splits. A new Equity 5 capillary column was purchased. Conditions taken from similar studies given in the literature were used for guidance. In most all cases, the solvent peak appeared to bleed over a retention time from 1.5 to 5 minutes resulting in difficulty resolving peaks other than the solvent. Thus mass spectra were analyzed at several retention times to determine times when mass peaks corresponding to masses other than solvent mass peaks were present. In most cases this occurred at a retention time of about 2.7-3.5 min. Below is shown the background from an injection of just carbon tetrachloride.

\section{GC/MS at a retention time of $2.42 \mathrm{~min}$ for pure $\mathrm{CCl}_{4}$ direct injection}

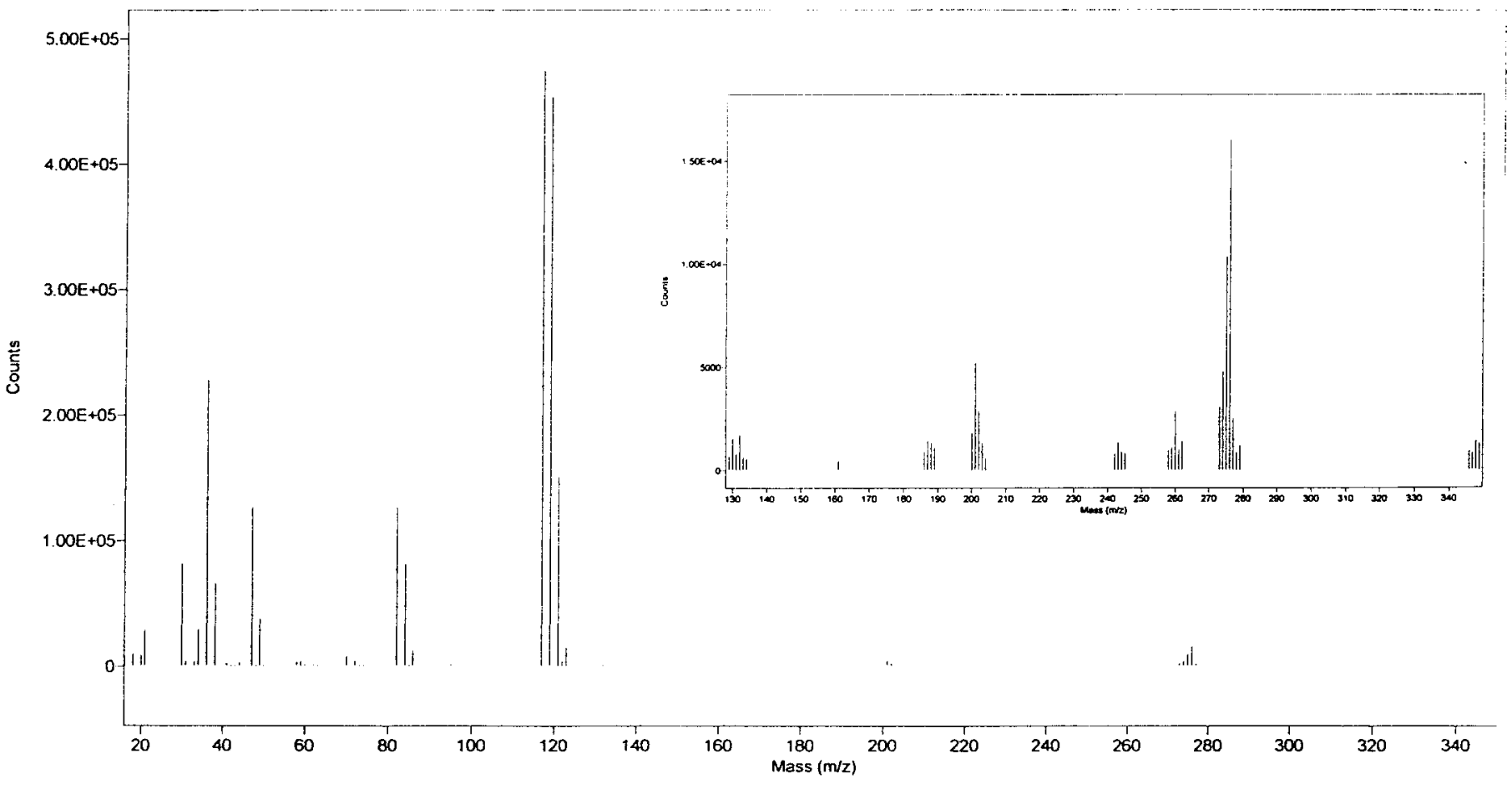


Note that there are several peaks. For comparison, in Appendix 1 the NIST mass spectrum of carbon tetrachloride is given. Note the major peak features near 120,84, 47 amu are in fair agreement. However, there also appear to be some very minor features near 187, 200, 243, 260, 277 , and $350 \mathrm{amu}$. The peaks above $200 \mathrm{amu}$ were cause for concern. Any organic material containing mercury would have a mass larger than $200 \mathrm{amu}$, and one of the fragments that should appear in an organo-mercury compound should be $\mathrm{Hg}$. Mercury should have a peak cluster at around $200 \mathrm{amu}$. The high mass peaks with showed up in the $\mathrm{CCl}_{4}$ could be due to an impurity in the solvent or perhaps some degredation of the column. A background in the column was obtained to determine the baseline.

\section{GC/MS background}

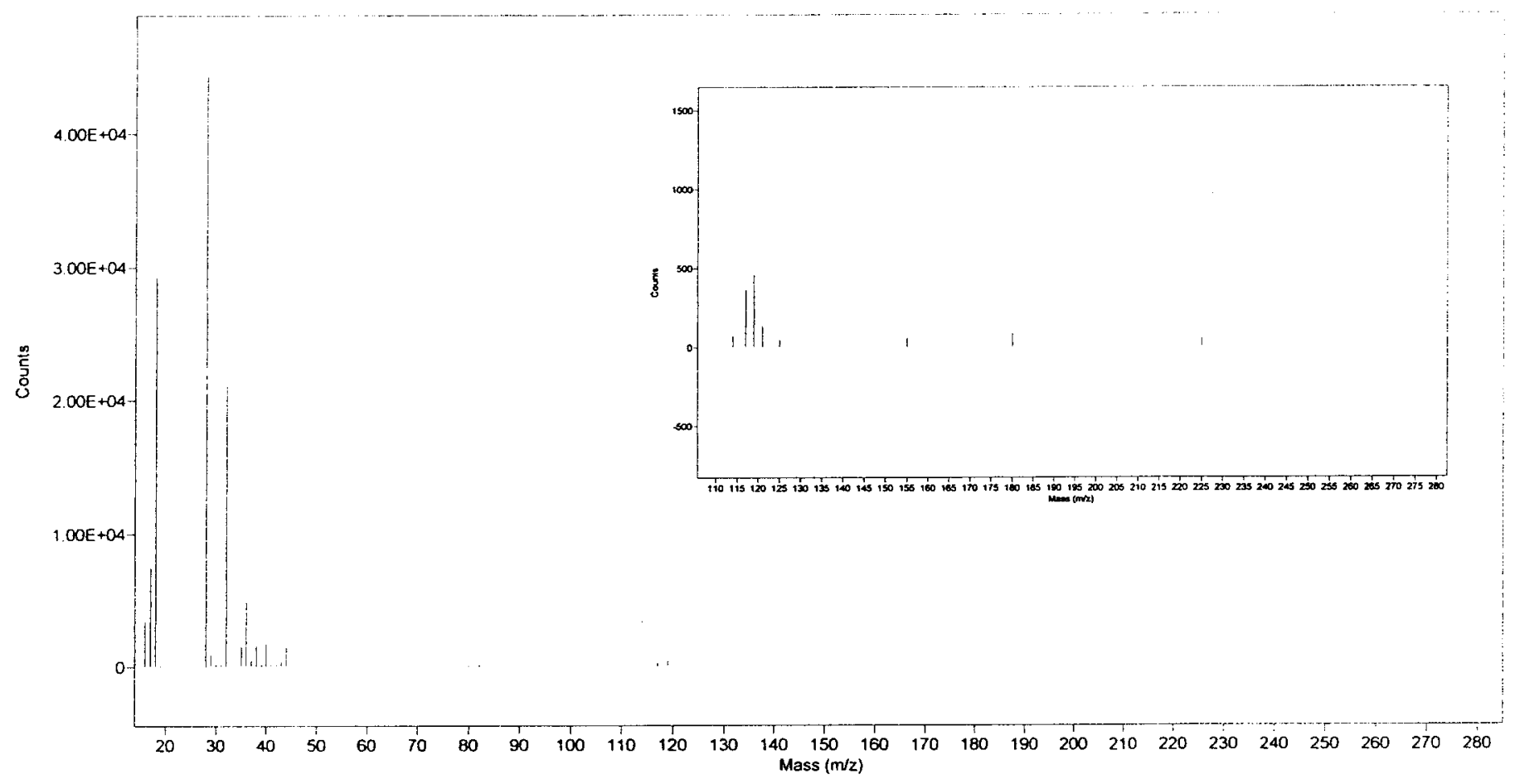

There are several peaks in the low mass region corresponding to water, nitrogen, and oxygen, and argon, with some impurity peaks, just barely above the baseline. These are apparently related to some retention of the $\mathrm{CCl}_{4}$, since the largest is a peak cluster near $120 \mathrm{amu}$.

Contrast the above traces with a direct injection of the $\mathrm{CCl}_{4}$ extracted Sample 103 


\section{GC/MS at a retention time of 3.5 min for direct injection of $\mathrm{CCl}_{4}$ extracted Sample 103}

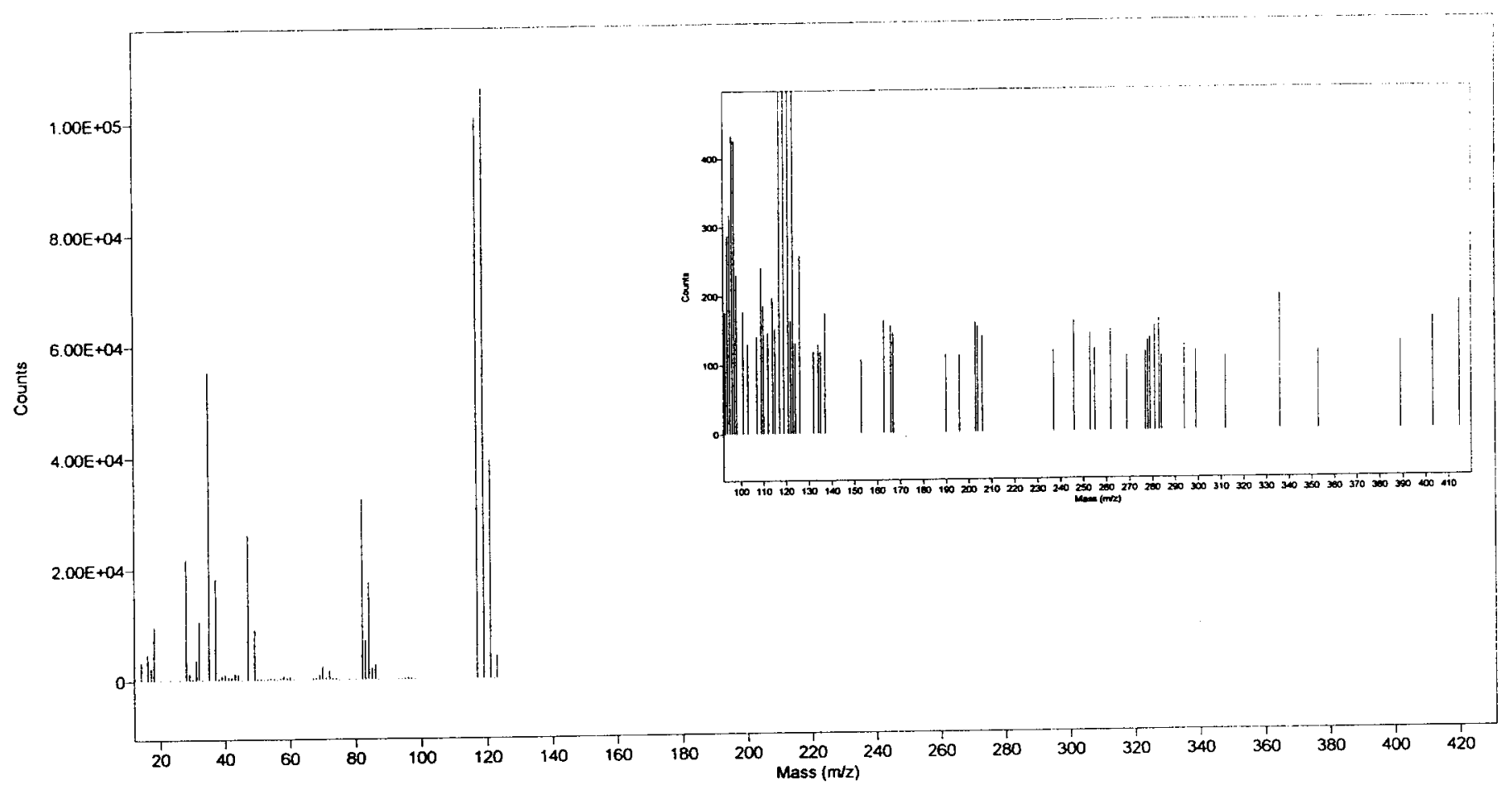

Note that there are additional peaks at masses both higher and lower than 120 mass units. Their signal is not very significant in most cases. The peaks that are most important in this analysis are those at masses at and above $196 \mathrm{amu}$ since $\mathrm{Hg}$ has several isotopes in masses ranging from 196 to $202 \mathrm{amu}$. The GC/MS trace reveals the presence of peaks at near 200,235, 240, 250, 280, $310,334,390,400$, and $410 \mathrm{amu}$. In addition there are peaks at lower mass units which could be due to the large organic component in the Sample mixture. Since the signals were so small in comparison with the $\mathrm{CCl}_{4}$ signal (300 cts compared to $10^{5} \mathrm{cts}$ ) an alternative method was investigated that would concentrate the mercury containing organic species.

A search of the literature on GC/MS of organo-mercury compounds lead us to an alternative method that was viable with our system. It involves the use of a SPME (solid phase micro-extraction) fiber. A Carboxen ${ }^{\mathrm{TM}}$ (CAR) coated polydimethylsiloxane (PDMS) fiber made by Supelco has been found by other researchers to produce quantifiable results for peaks of elemental mercury and organic mercury. Essentially, about an inch of the $2 \mathrm{~mm}$ dia fiber is inserted into the head space above the solution containing the mercurial compounds for a 10 minute exposure time. The volatile compounds of a polarity similar to the fiber material adsorb on the fiber. They then desorb from the fiber at the high temperature of the injector inlet, in this case about $230^{\circ} \mathrm{C}$.

The fiber can be used to concentrate volatile species both above the aqueous solution, as well as above the solvent extracted species. A background spectrum of the SPME fiber reveals a low background. 
SPME injection with no previous adsorntion of material at $2 \mathrm{~min}$

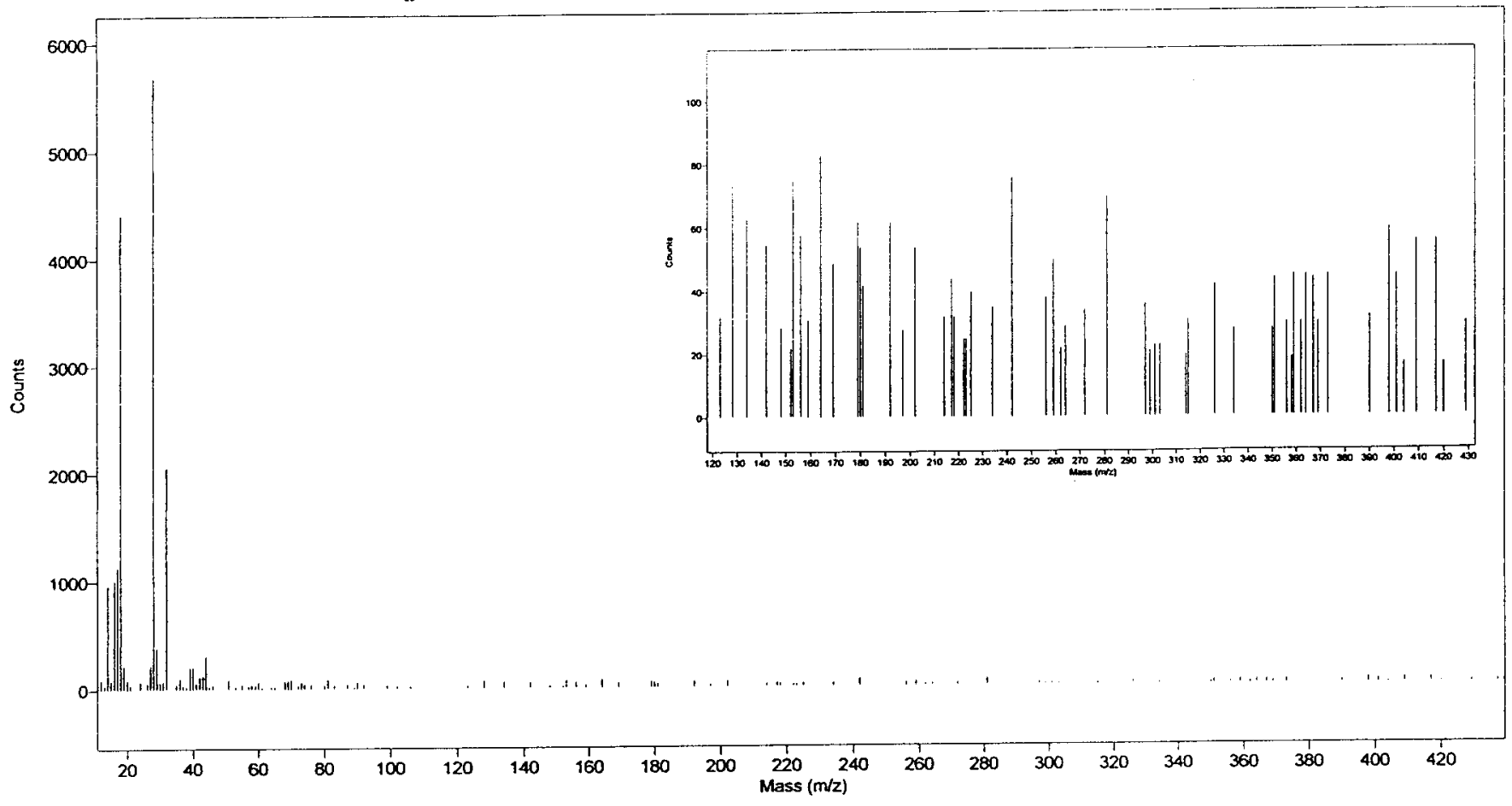

The background at masses other than those such as $\mathrm{N}_{2}, \mathrm{H}_{2} \mathrm{O}$, and $\mathrm{O}_{2}$ are below 100 counts.

The SPME fiber was exposed to Sample 103 which had been adjusted to $\mathrm{pH} 7$ by adding sodium hydroxide to the solution. The trace is given below.

GC/MS of desorption from SPME fiber inserted in Sample 103

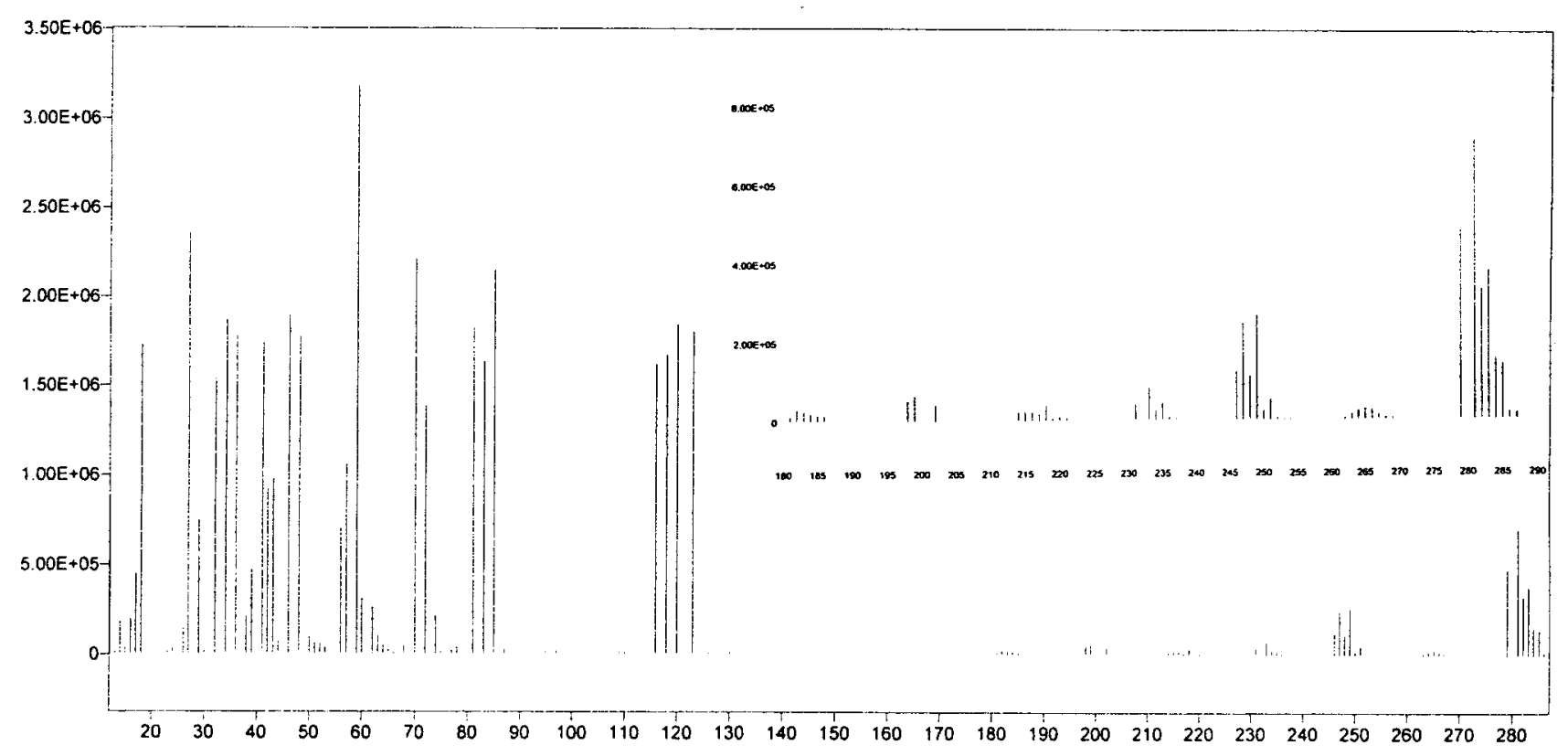


There is a very large signal at many masses below 200 mass units. These are likely the volatile organic components of Sample 103 other than the mercury. Above 200 mass units the signal is more than an order of magnitude lower. A blow up of that region shows peak clusters near 200, $215,233,249,265$, and $282 \mathrm{amu}$. These could be part of the decomposition of the column mentioned previously, but there are new features particularly at 233 and $215 \mathrm{amu}$. Also the peak cluster near 249 is large than those at 233,215, and $200 \mathrm{amu}$. The separation of the former peaks from mercury isotopic cluster at $200 \mathrm{amu}$ is roughly $35 \mathrm{amu}$ and $15 \mathrm{amu}$ respectively. These could correspond to the attachment of a chlorine and a methyl group to mercury respectively, and the compound methyl mercuric chloride would have a total mass cluster near $250 \mathrm{amu}$. As mentioned before, there is a cluster with higher intensity near $250 \mathrm{amu}$. This leads to the question as to the possibility that there is some methyl mercuric chloride present in the sample. A NIST Spectrum is given in Appendix 1 for comparison. Note that absolute masses and the number of peaks in all ranges is not consistent with all of the feature being due to methyl mercuric chloride, but the mass ranges can vary by up to 2 amu depending on the calibration consistency.

The peak features near 282 and 265 could also be organic mercury containing species such as chloroethyl or chlorophenyl mercury. Their NIST Spectra are also given in Appendix 1 for comparison. These would also contribute to the peaks clusters at 233 and $215 \mathrm{amu}$. Thus a mixture containing several of these species would lead to a complicated spectrum. NIST spectra of other organic mercury species are also given in Appendix 1.

To try to concentrate the species even more, we decided to try to extract the organic portion again from the $\mathrm{pH}$ adjusted aqueous portion. Both hexane and carbon tetrachloride solvent were tried at the conditions of $230^{\circ} \mathrm{C}$ injection port with a 100 degree oven temperature.

\section{SPME GC/MS of Sample \#103 extracted in hexane at 2.7 min retention time, pH 7}

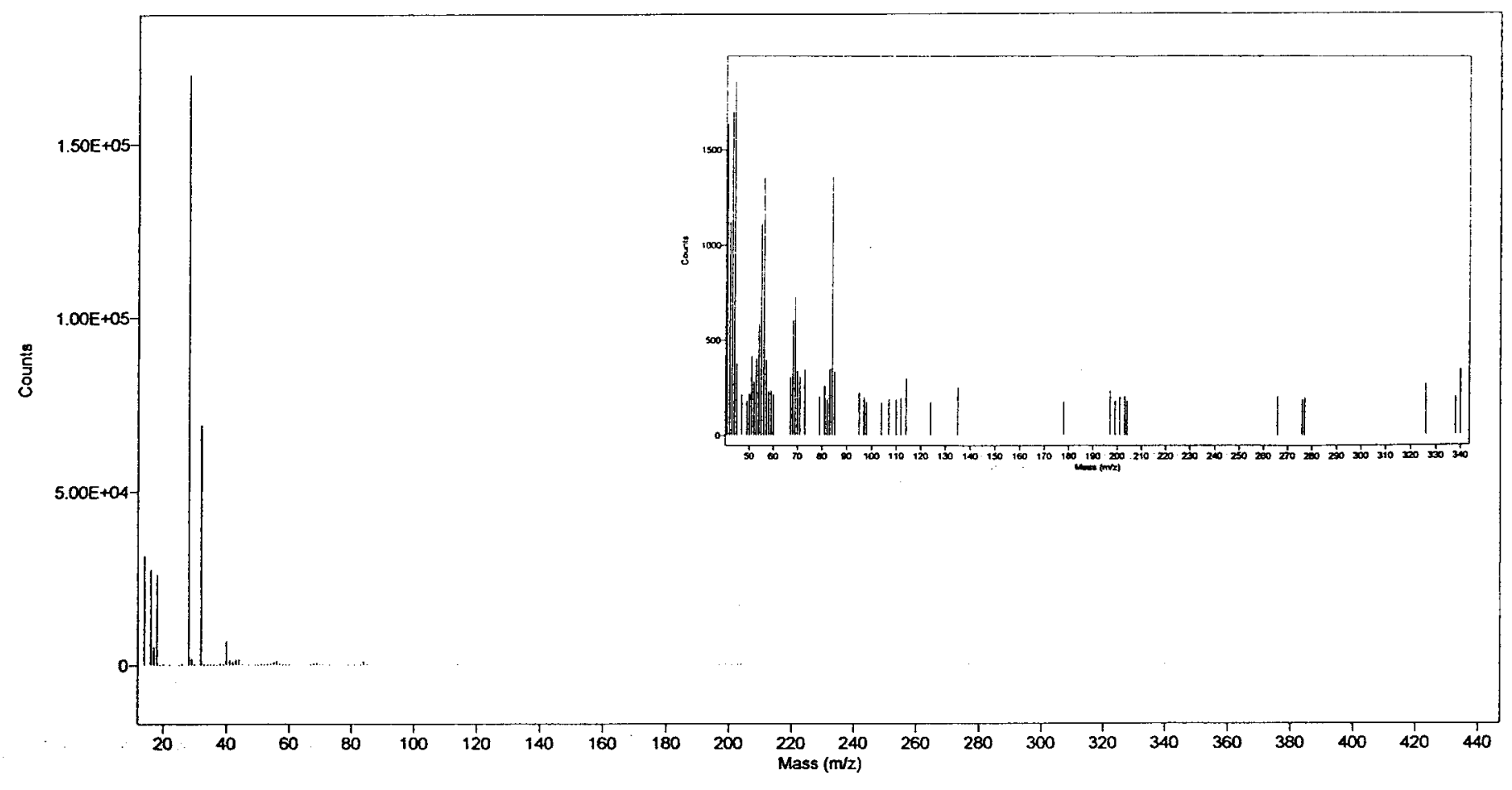


SPME GC/MS of Sample \#103 extracted in $\mathrm{CCl}_{4}$ at 2.9 min retention time, $\mathrm{pH} 7$

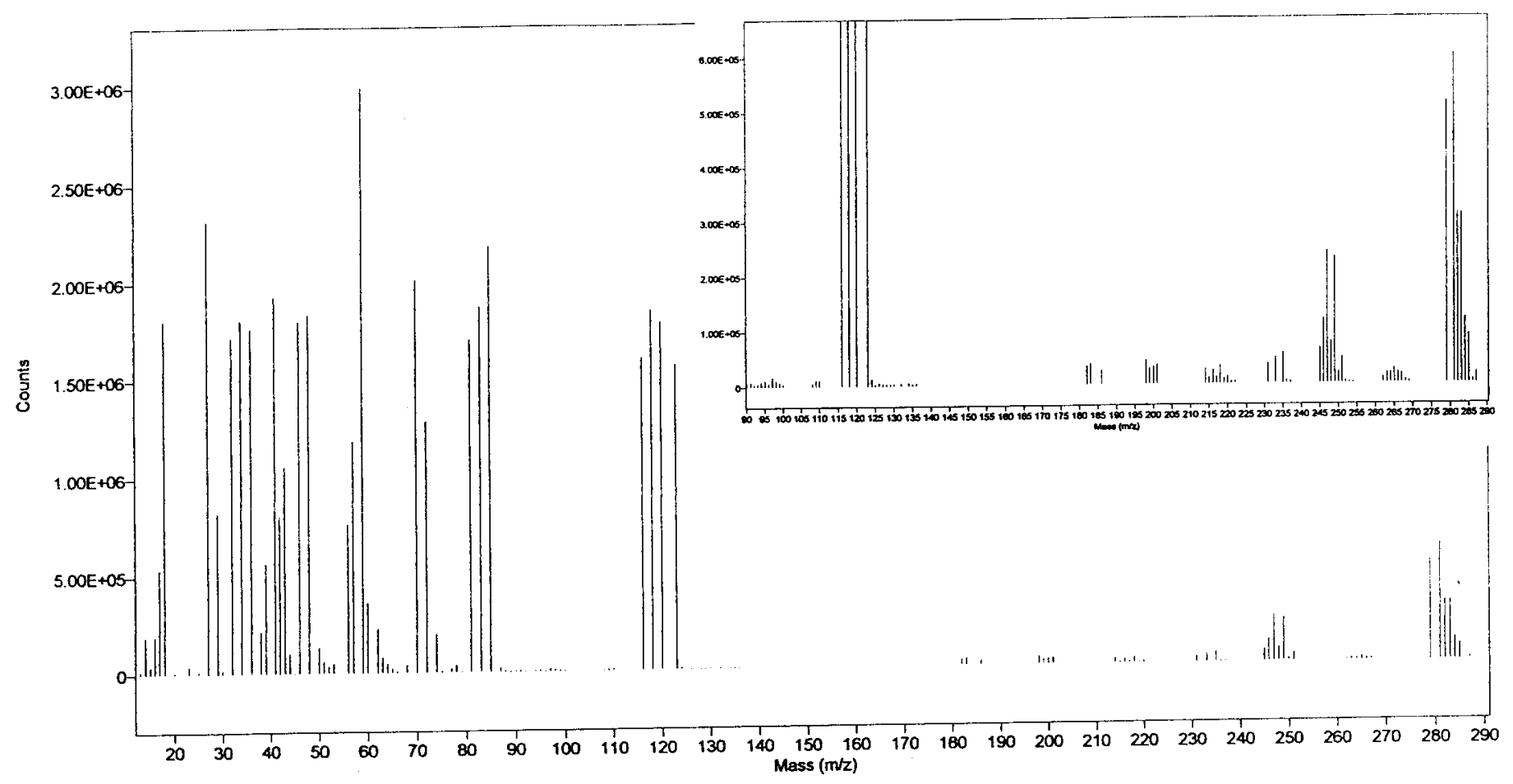

In the case of the hexane extract, the counts were very low for all mass numbers, and the peak clusters above 200 amu do not correspond well with the presence of methyl mercuric chloride. The highest peaks at mass numbers lower than 200 are as much ten times larger than the peaks above $200 \mathrm{amu}$. Based on this information, it appears that hexane is not a good solvent for extraction of the organic phase, and since the overall signal is small, it too is not readily adsorbed onto the SPME fiber.

This is in great contrast to the GC/MS trace of the $\mathrm{CCl}_{4}$ extract of Sample 103. Note that the peak counts are greater by a factor of about 100 and that there are several peak clusters at or above $200 \mathrm{amu}$. In this case too, the peaks occur at around 200, 215, 235, 248, 265, and 280 amu. This is in good agreement with the GC/MS trace from before of the just the aqueous Sample \#103. The lower mass portion of the spectrum is also in very good agreement as well with peak clusters near 120, 82, 70,59, 46, and $42 \mathrm{amu}$. Since the spectrum appeared in GC/MS traces of both the SPME fiber desorption from the $\mathrm{pH} 7$ adjusted aqueous Sample \#103, and the $\mathrm{CCl}_{4}$ extract of Sample \#103.

The $\mathrm{pH}$ was adjusted to $\mathrm{pH} 7$ before extraction to minimize acid assisted reactions with the solvent. However, at approximately $\mathrm{pH} \mathrm{4,} \mathrm{a} \mathrm{precipitation} \mathrm{occurred,} \mathrm{and} \mathrm{some} \mathrm{of} \mathrm{the} \mathrm{mercury}$ containing materials likely precipitated. Thus an extraction of Sample 103 adjusted to $\mathrm{pH} 3$ was attempted to determine if mercury material was being lost. 
SPME GC/MS of Sample \#103 extracted in $\mathrm{CCl}_{4}$ at $3.3 \mathrm{~min}$ retention time, $\mathrm{pH} 3$

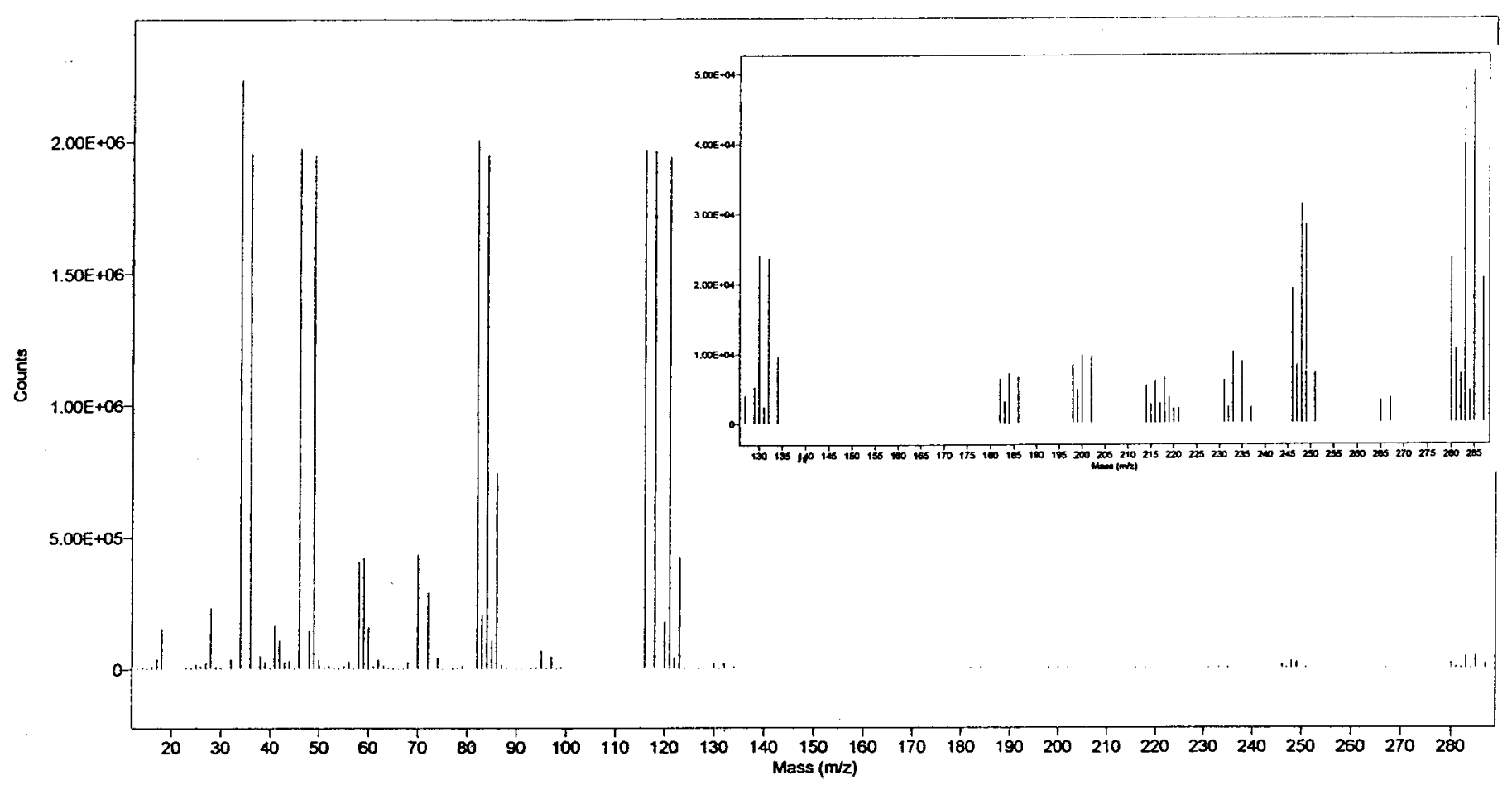

The main features are still present in the spectrum above $200 \mathrm{amu}$ as well as at lower masses. Also the signal counts has not increased but decreased slightly.

Based on the peak cluster positions, it is possible that mercuric chloride and methyl mercuric chloride are present in the sample. Samples of mercuric chloride and methyl mercuric chloride were prepared to determine if the SPME GC/MS that was obtained for Sample \#103 had a signature similar to one or both of these. A sample approximately $200 \mathrm{ppm}$ in $\mathrm{HgCl}_{2}$ and a separate sample approximately $700 \mathrm{ppm}$ in $\mathrm{CH}_{3} \mathrm{HgCl}$ were prepared, both in aqueous solution. The headspace above the aqueous mercuric chloride sample was put in contact with the SPME fiber for about 10 minutes. The $700 \mathrm{ppm} \mathrm{CH}_{3} \mathrm{HgCl}$ sample was extracted with and equal amount of $\mathrm{CCl}_{4}$ and the SPME fiber was inserted into that head space for about 10 minutes. The traces corresponding to the SPME injection for each of these samples are shown below. 
SPME GC/MS of $\sim 200 \mathrm{ppm} \mathrm{HgCl}_{2}$ aqueous solution

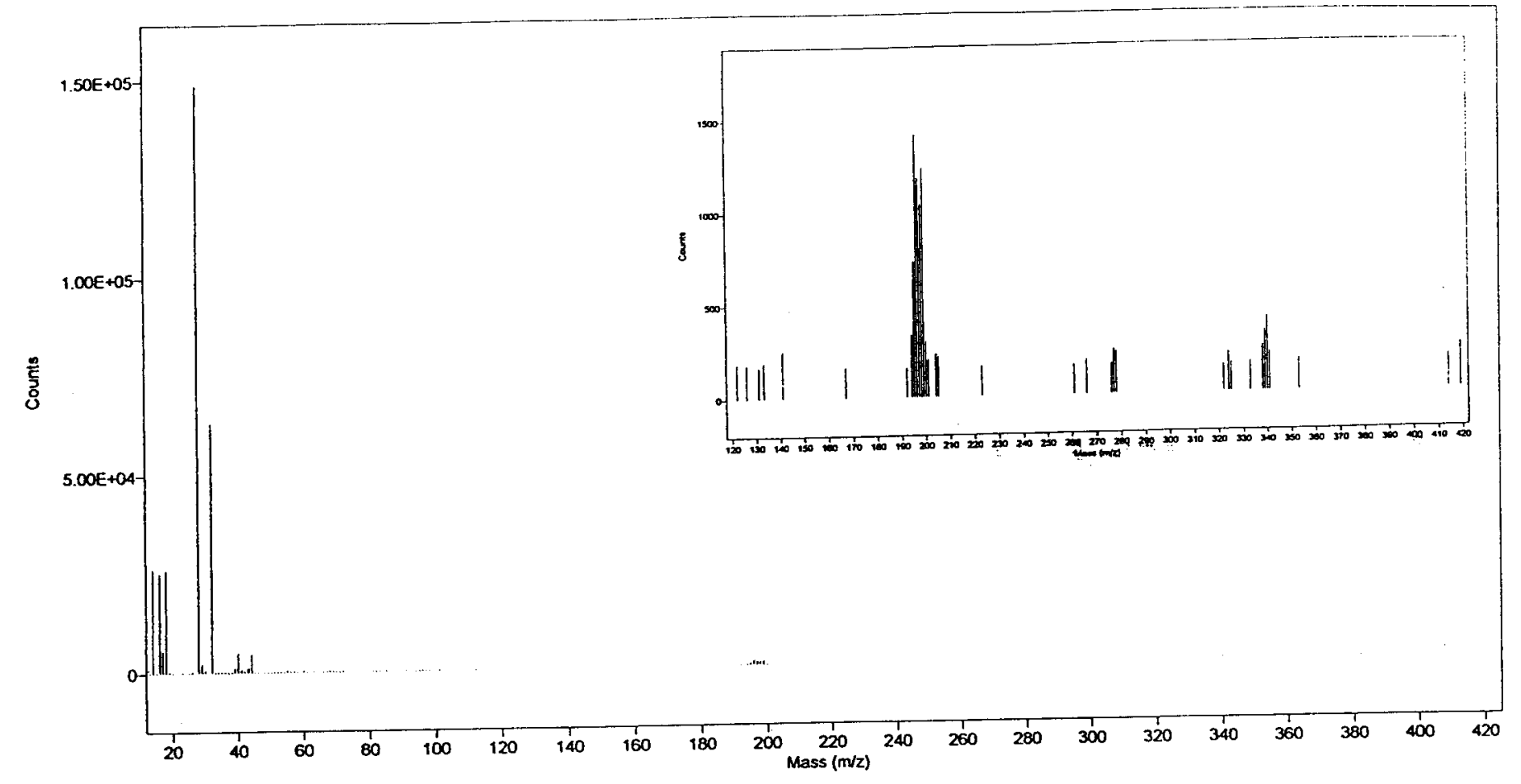

SPME GC/MS of $\mathrm{CCl}_{4}$ extract of the $\sim 700 \mathrm{ppm} \mathrm{CH}_{3} \mathrm{HgCl}$ aqueous solution

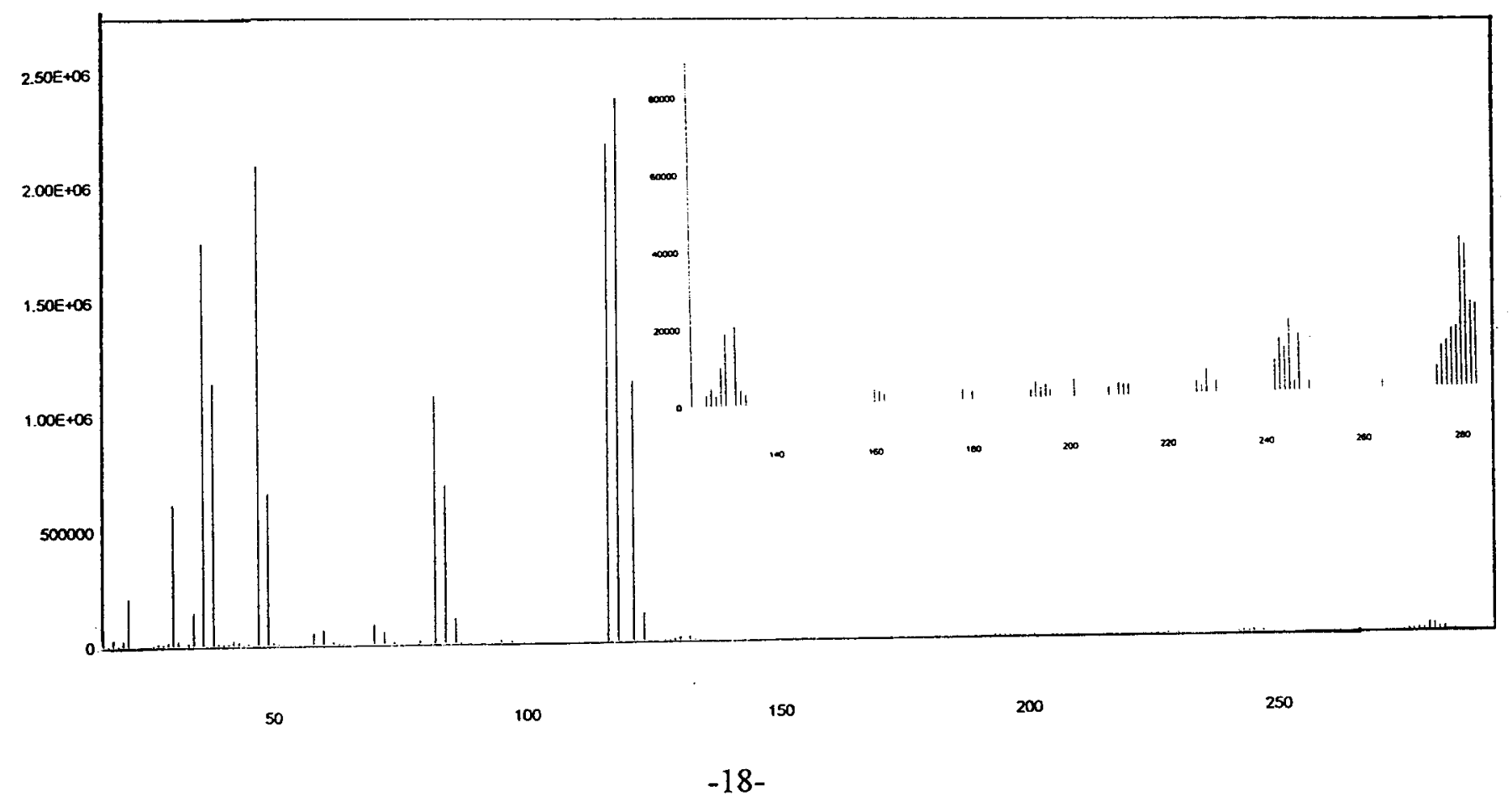


For the trace from the mercuric chloride, the largest peak appears to be in the region for elemental mercury rather than for mercuric chloride. In fact there is no peak at 270 which would correspond to mercuric chloride. This suggests that either the mercuric chloride decomposed at the injection temperature of $230^{\circ} \mathrm{C}$ or that the SPME fiber has trouble absorbing and desorbing mercuric chloride. Other researchers have reported decomposition of mercuric chloride above about $230^{\circ} \mathrm{C}$. The strength of the mercury signal is somewhat low as well, suggesting that the mercuric chloride is not readily extracted by the SPME method.

For the GC/MS from the methyl mercuric chloride, the highest peaks are for those corresponding to $\mathrm{CCl}_{4}$, but there are smaller peak clusters in similar ranges as the unknown. Peaks at about 245,229,211, and 196 appear to be 2 or 3 amu below there expected values, and the pattern is not very consistent with the NIST spectrum given in Appendix 1. We were experiencing problems with the GC/MS throughout the runs, and it is possible that the calibration could be off. We had hoped to be able to say something about the concentration of organic mercury present in the material, but this seems premature given the differences in the mass spectra of the SPME of the extracted Sample 103 and the 700 ppm solution of methyl mercuric chloride.

\section{$\underline{\mathrm{LCMS}}$}

We also had access to the LCMS in the Pharmacy Dept. for a limited amount of time. The thermospray LC/MS has excellent detectability for materials that are easily protenated To determine if organo-mercury compounds were easily protentated, a solution of $20 \mathrm{ppm}$ methyl mercuric chloride in water was prepared. A 10-1 dilution of it in a methanol/water mixture was injected into the LC/MS. No signal due to the methyl mercury chloride was detected leading to the conclusion that organo-mercury compounds would not be detectable in the solution. This was very unfortunate since the detection limits of that system are very low.

We decided to run Sample 103 through the LC/MS any way to see if any peaks were present. Again no peaks assignable to mercury-containing species were present. These spectra are attached in Appendix 2. Attempts were made to take these peaks and determine the organic species that gave the correct pattern using a BioRad ${ }^{\mathrm{TM}}$ mass spectral library. Initial attempts at this failed to produce a single structure consistent with the presence of sugar or it pyrolized products. However, time was limited since the LC/MS runs were performed at the very end of the grant period.

\section{Conclusions}

We have attempted to determine the amount and identity of organic mercury species present in the scrub solutions from the treatment of off-gas from pilot-scale waste vitrification tests. Several analytical techniques and instruments were employed including: UV-Absorption (in a Mercury Analyzer), FTIR, Raman, GC/MS, and LC/MS. Originally we had also intended to use NMR if the concentrations of the extracted materials proved to be in an acceptable range for NMR, but the amount in the extract and the volatility of organic mercury compounds precluded the use of NMR. NMR has detection limits in a similar to Raman or in a slightly higher concentration range. Since attempts to obtain a Raman Spectrum proved futile, we determined that time would be better spent focusing on the FTIR and Mass Spectal techniques.

During the course of the work we developed methodology to handle the materials and to 
get them in a form acceptable for the instrumentation. In the case of the GC/MS studies methods developed required determining the correct column temperature, injector temperature, flow rates, split rates, and SPME fiber exposure times in order to obtain a GC/MS trace. LC/MS was also attempted, but detection of mercury containing organic materials was not possible in the system.

The most significant result of this study came from the determination of mercury content using the Mercury Analyzer. The total mercury content in Sample 103, (the sample with the highest total mercury content), and in Sample 61, (the sample with the lowest mercury content), was measured to be the same or slightly lower than the mercury in an inorganic form in the samples. With experimental error of roughly $\% 10 \%$, the amounts were the same. Thus at most, the concentration of organic mercury in the samples could be $<10 \%$ of $\sim 1000 \mathrm{ppm}$ mercury in sample 103, or $<10 \%$ of the INEEL measured $42 \mathrm{ppm}$ mercury in Sample 61.

Results from the FTIR studies were slightly more inconclusive. It was difficult to subtract out the water from the spectrum of the Sample. The organic extract in $\mathrm{CCl}_{4}$ gave a peak at around $500 \mathrm{~cm}^{-1}$ which was assigned as due to a C-Hg stretch. This assignment is tentative at best, but the peak shifted close to the correct value for the $\mathrm{CCl}_{4}$ extract of a $\sim 700 \mathrm{ppm}$ solution of methyl mercuric chloride. Based on the relative areas under those peaks, and assuming that the absorption coefficients are similar for all $\mathrm{Hg}-\mathrm{C}$ stretches, a concentration of organic mercury of less than $70 \mathrm{ppm}$ was suggested. Again there is a great deal of uncertainty associated with the assignment of the peaks and other assumptions, and further investigation is warranted.

The GC/MS was difficult to use as there were problems with daily calibration of the instrument. Direct injection of the extracted $\mathrm{pH}$ adjusted sample and a technique utilizing Solid Phase Micro-extraction fiber were attempted. In these spectra peak clusters at the mass numbers appropriate to the fragmentation pattern for methyl mercuric chloride or a combination of methyl mercuric chloride, ethyl mercuric chloride, and phenyl mercuric chloride. Mercury has about six isotopes of significant abundance and it should have a characteristic fingerprint at about $200 \mathrm{amu}$. A similar finger print should be found at the base peak and each of the fragmentation peaks of say methyl mercuric chloride. The pattern did not match the NIST values completely and so it lends doubt to the assignment of the mass spectrum, although at these low levels the signal to noise could be responsible for some missing peaks or deviations from the expected patterns.

A cause for more concern is the spectrum derived from pure $\mathrm{CCl}_{4}$ which gave peaks above $200 \mathrm{amu}$, and from the $\mathrm{GC} / \mathrm{MS}$ trace derived from the $\mathrm{CCl}_{4}$ extract of $700 \mathrm{ppm}$ methyl mercuric chloride which did not match very well with the peak positions. However there appeared to be a gross fragmentation pattern similar to the fragmentation pattern expected for methyl mercuric chloride except that the base peak was shifted about 5 amu from the expected value. This could have been a calibration problem on that day and further investigation is warranted.

Also, in searching the literature, other researchers using the SPME method for organic mercury have sometimes added tetrethylborate to ethylate species such as $\mathrm{CH}_{3} \mathrm{Hg}^{+}$and labile $\mathrm{Hg}^{2+6}$. This procedure should increase the volatility of these and similar organic mercury in the solution. The only problem is that it also ethylates the labile mercury(II) in the solution. This is not desirable if one is attempting to identify and quantify the organo-mercury species, but the procedure may be worth further investigation.

LC/MS was also tested as a possible analytical tool for organic mercury. However, the ionization scheme used for this instrument required protontation of the organo-mercury 
compound, and solutions of methyl mercuric chloride were found not to be detectable. This is likely a result of the fact that they do not protonate. LC/MS of Sample 103 was attempted anyway and no mercury containing species were detected. Some presumably organic species were detected and MS/MS or MS/MS/MS spectra were obtained for some of these species to help identify the organic present. Use of a spectral library to help in elucidation of their identity was not productive and further investigation is waranted.

\section{References}

1. L. Moens, T. DeSmaele, R. Dams, P.Van Den Broeck, and P. Sandra, "Sensitive, Simultaneous Determination of Organo mercury, -lead, and -tin Compounds with Headspace Solid Phase Microextraction Capillary Gas Cromatography Combined with ICP/MS," Anal. Chem., 69 (8) 1604 (1997).

2. Z. Mester, R. Sturgeon, and J. Pawliszyn, Review of Solid phase microextraction as a tool for trace element speciation," Spectrochim. Acta B, 56233 (2001).

3. C. Cappon and C. Smith, "Gas-Chromatographic Determination of Inorganic Mercury and Organomercurials in Biological Materials", Anal. Chem., 49(3) 365 (1977).

4. J. Kopp, M. Longbottomand L. Lobring, "Cold Vapor Method for Determining Mercury", AWWA, Vol. 64, p. 20, Jan. 1972.

5. Z. Meic, and M. Randic, "Force Constant Calculations of Methyl Mercuric Chloride and Methyl- $d_{3}$ Mercuric Chloride," J. Chem. Soc. Faraday Trans., 68(3), 444 (1972).

6. Y. Cai and J. Boyona, "Determination of methyl mercury in fish and river water samples using in situ sodium tetraethylborate derivitization following by solid-phase micro-extraction and gas chromatography-mass spectrometry", J. of Chromatography A, 696 113, (1995). 
Appendix 1

NIST Mass Spectra of Several Compounds 


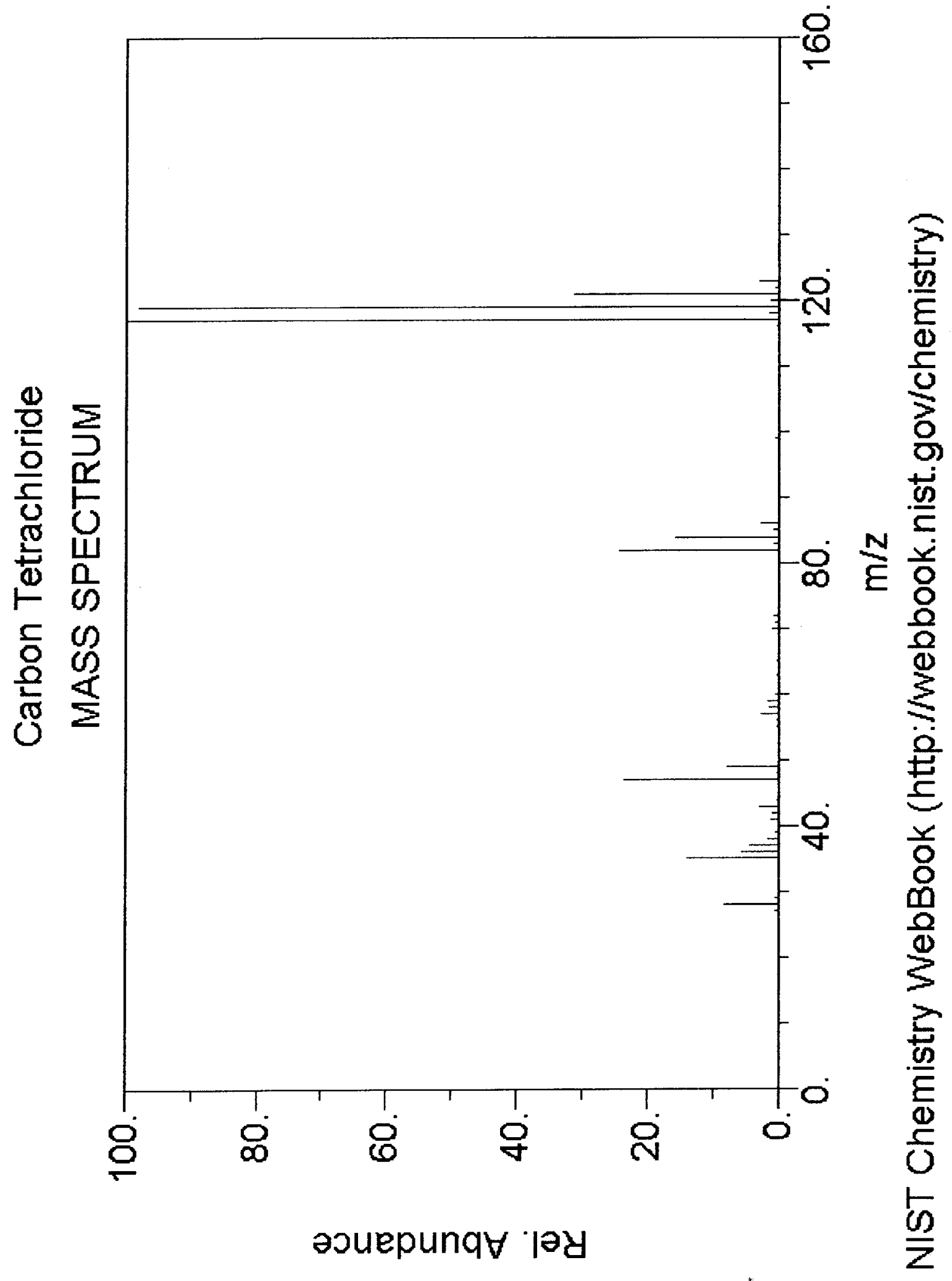


4
0
0
0
0
0

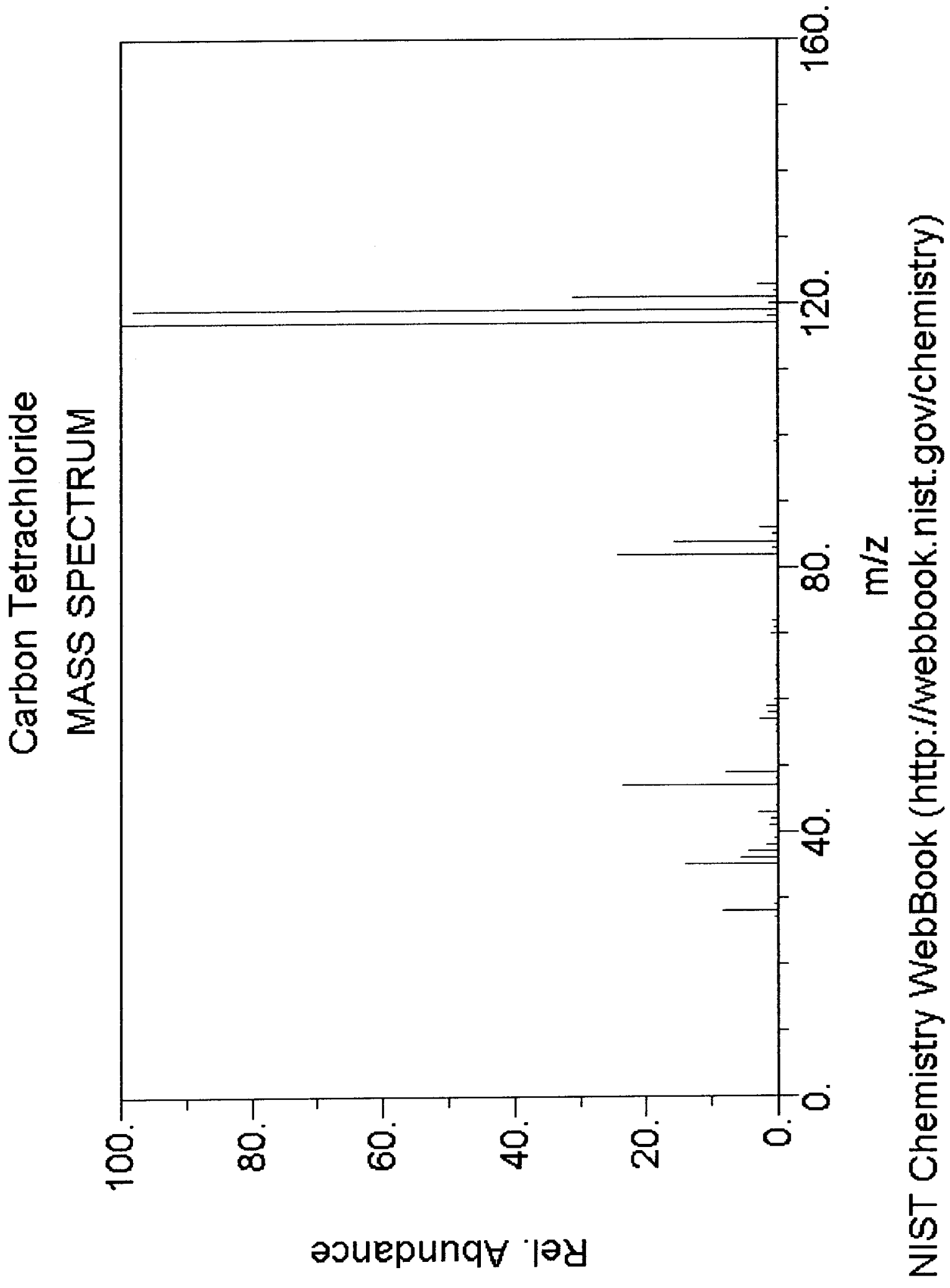


-1
0
0
0
0
0

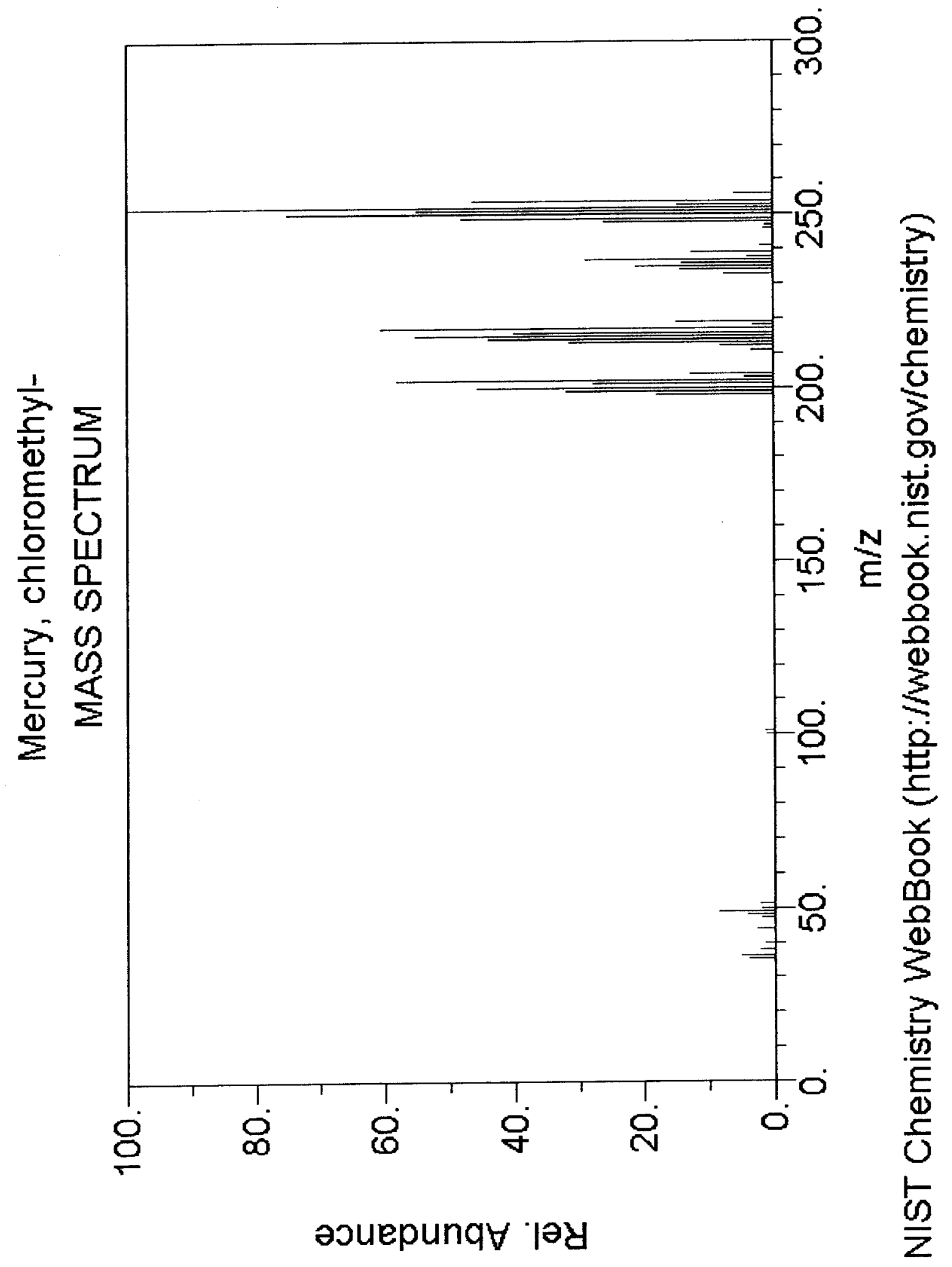


4
4
0
0
0
0
0

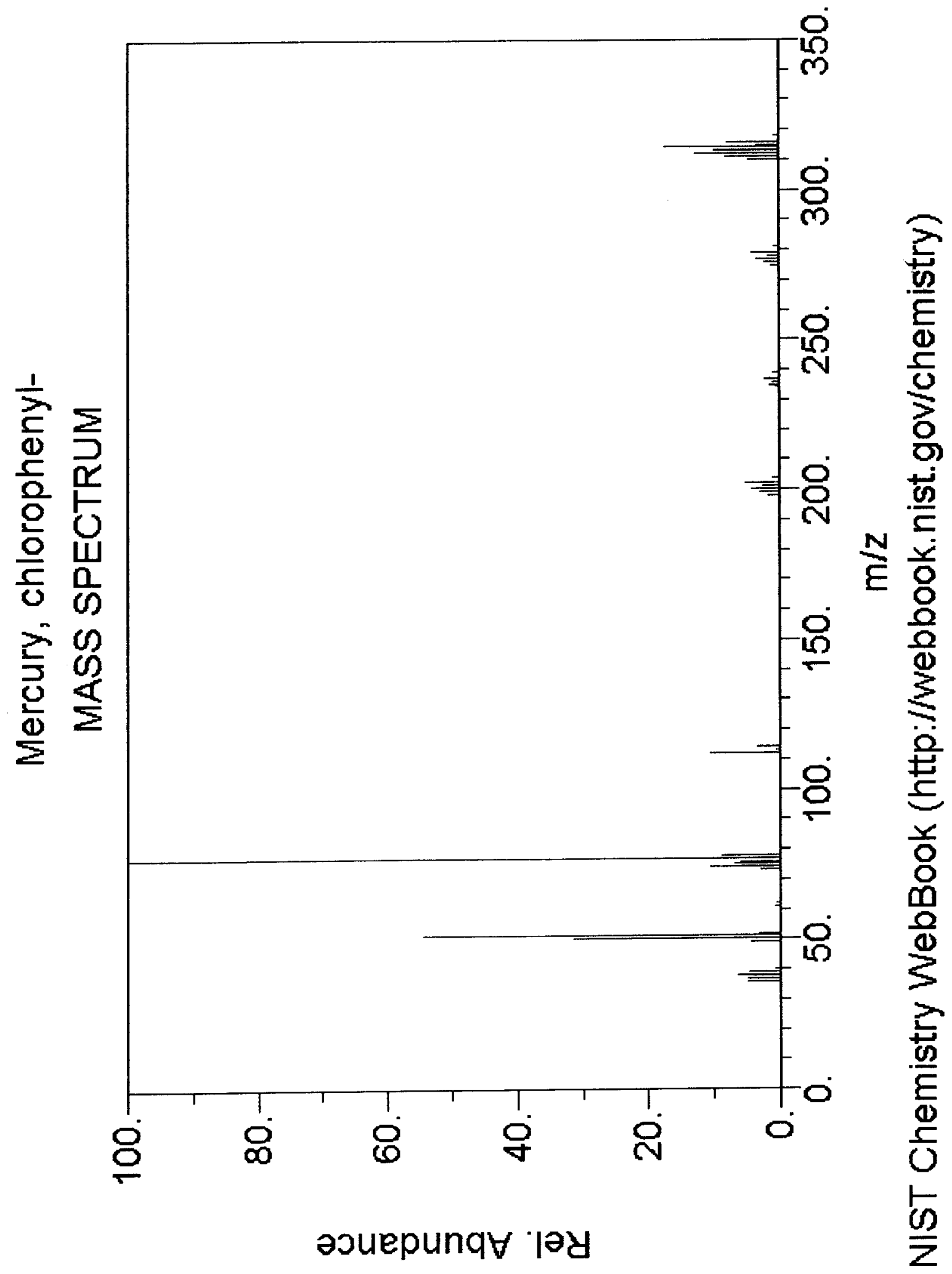




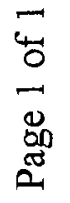

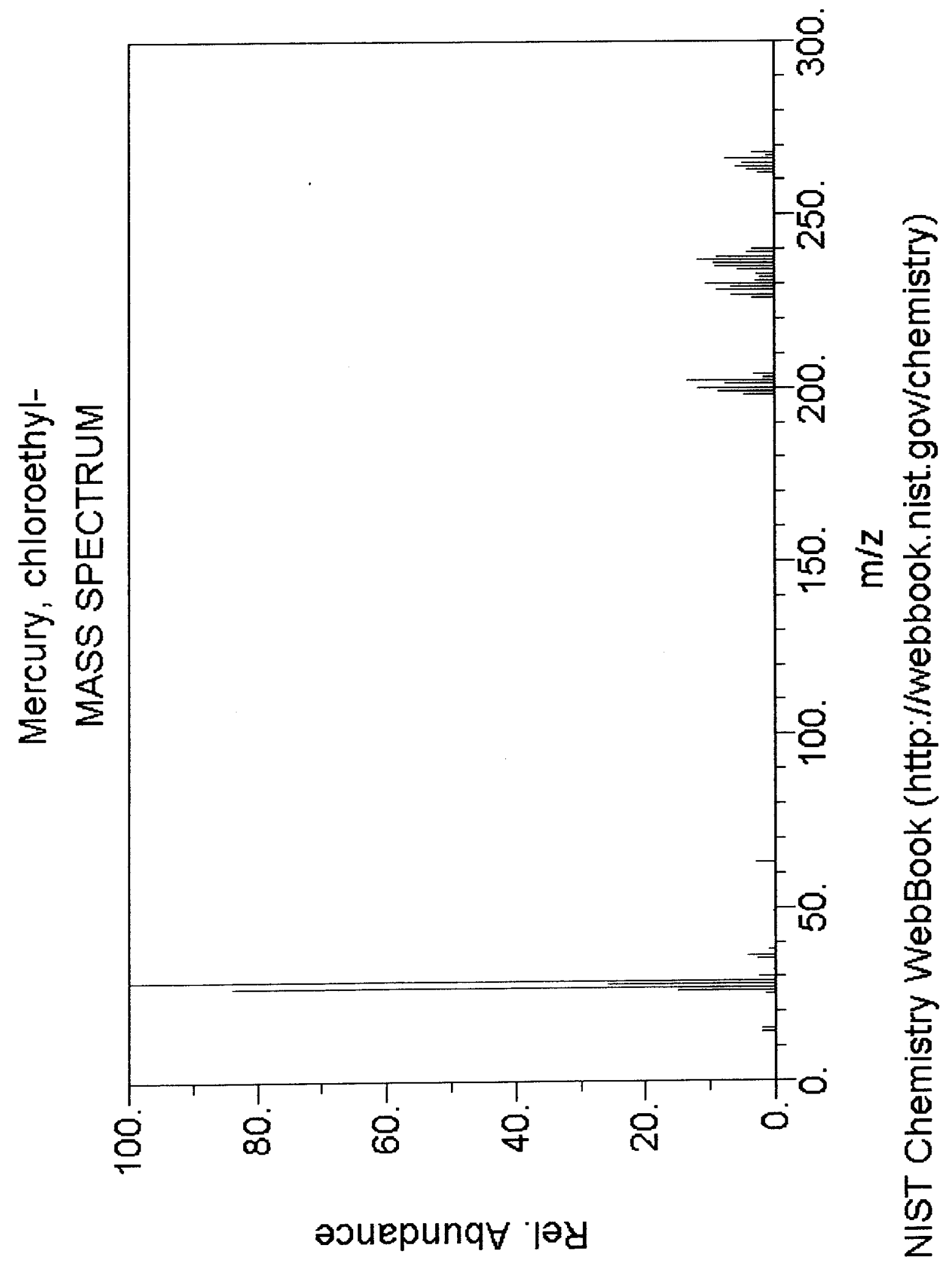




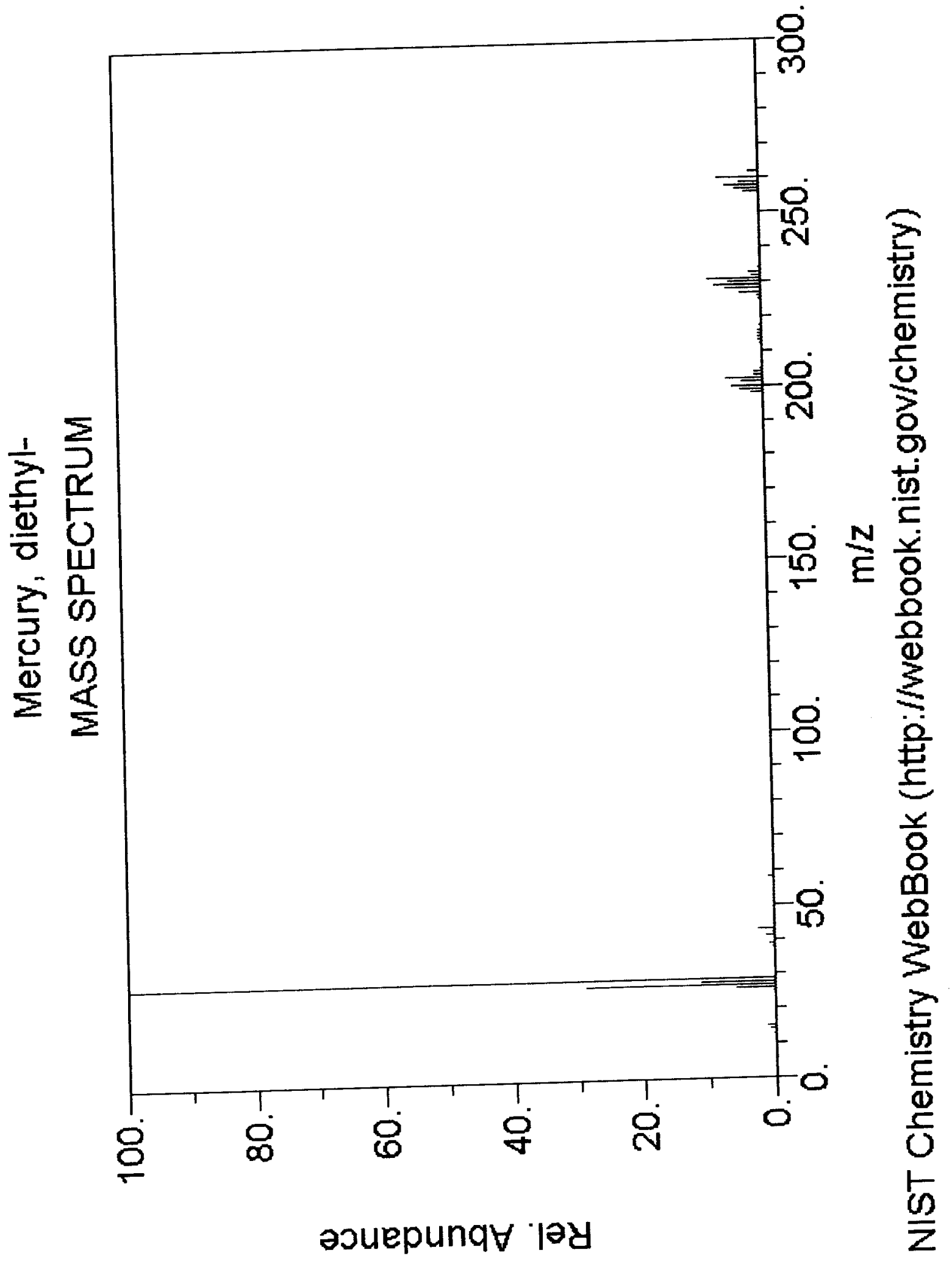


$\overrightarrow{4}$
0
0
0
0
0
0

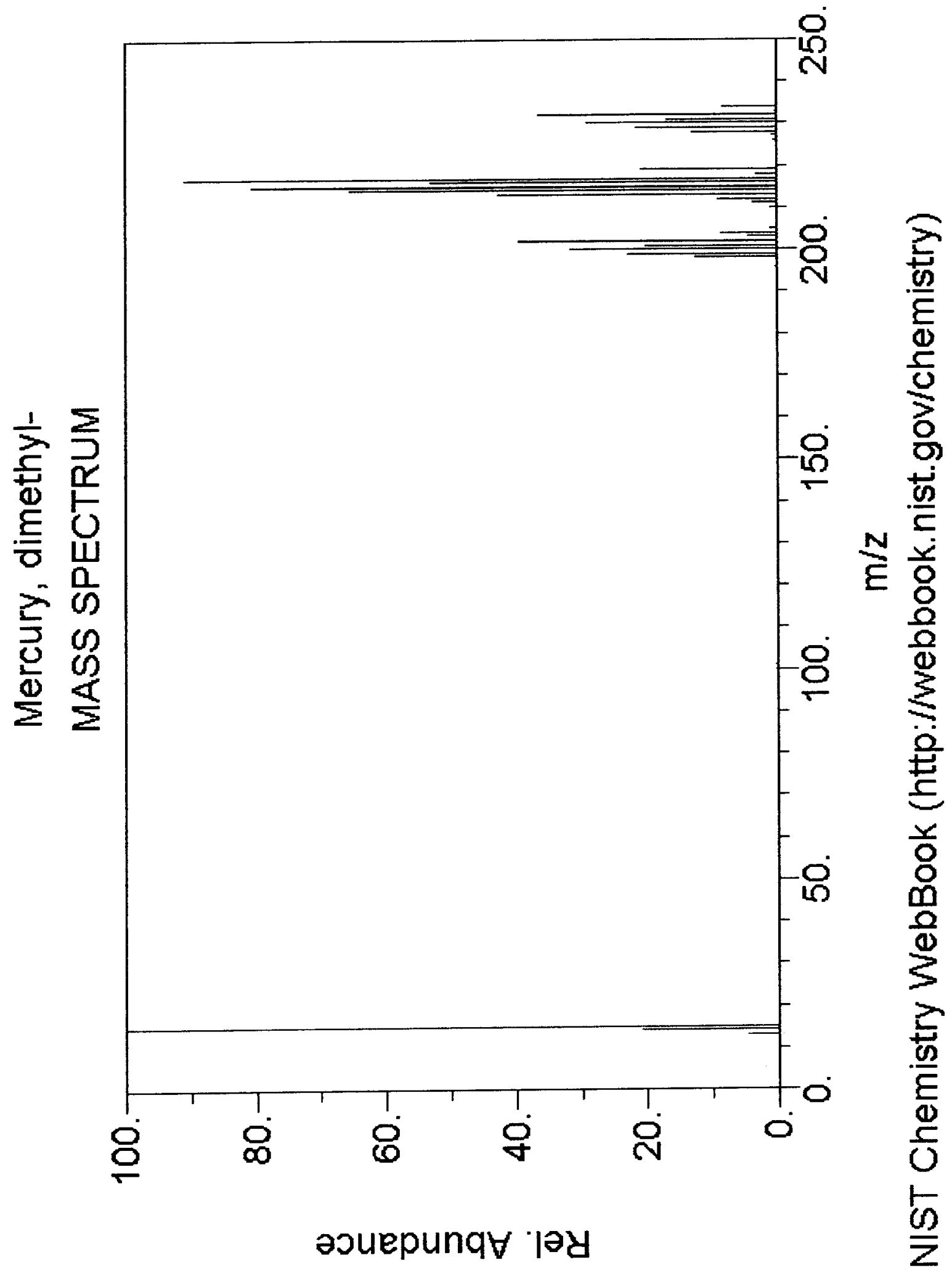


$\overrightarrow{0}$
$\overrightarrow{0}$
0
0
0
0

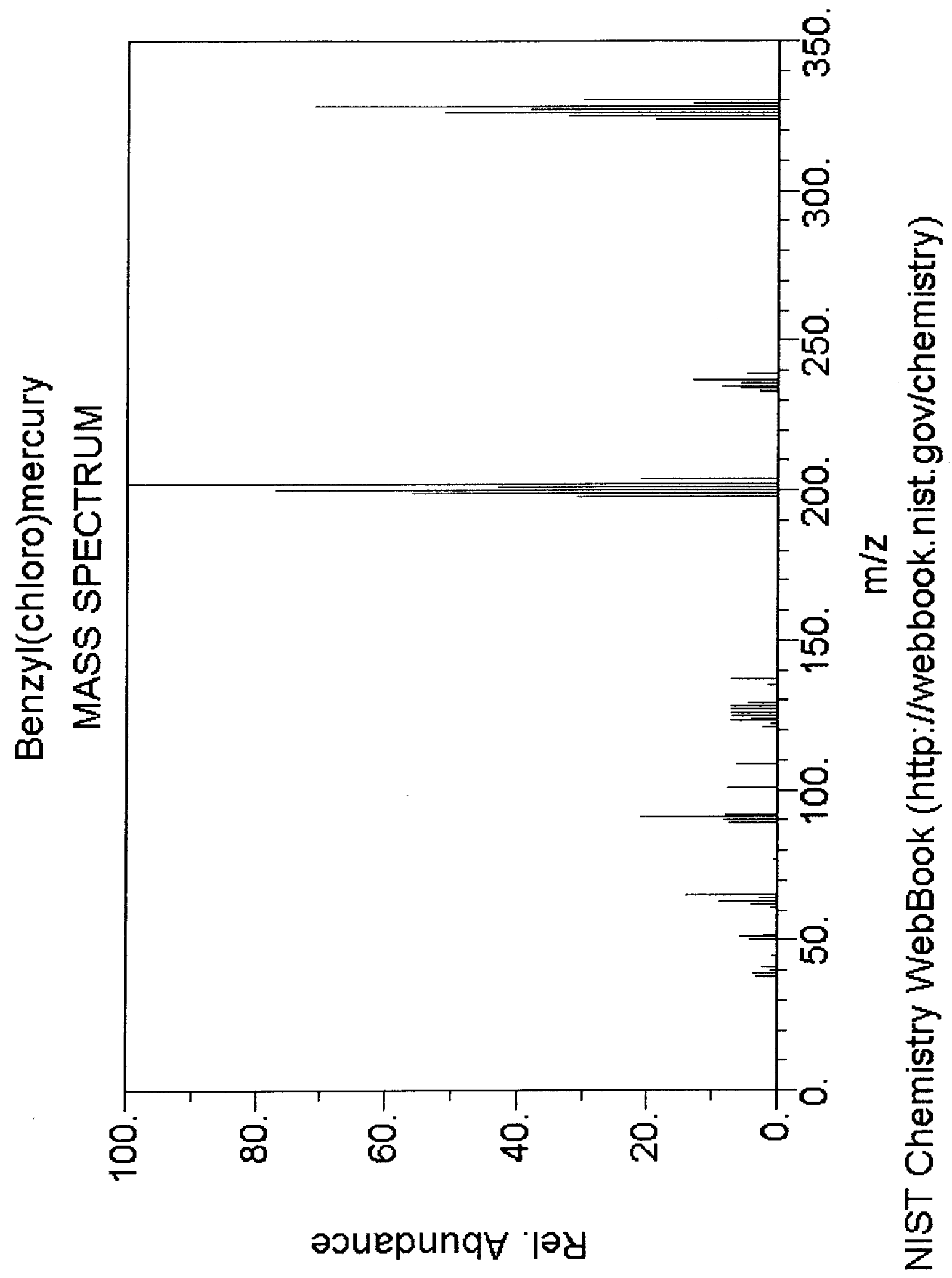


4
0
0
0
0
0

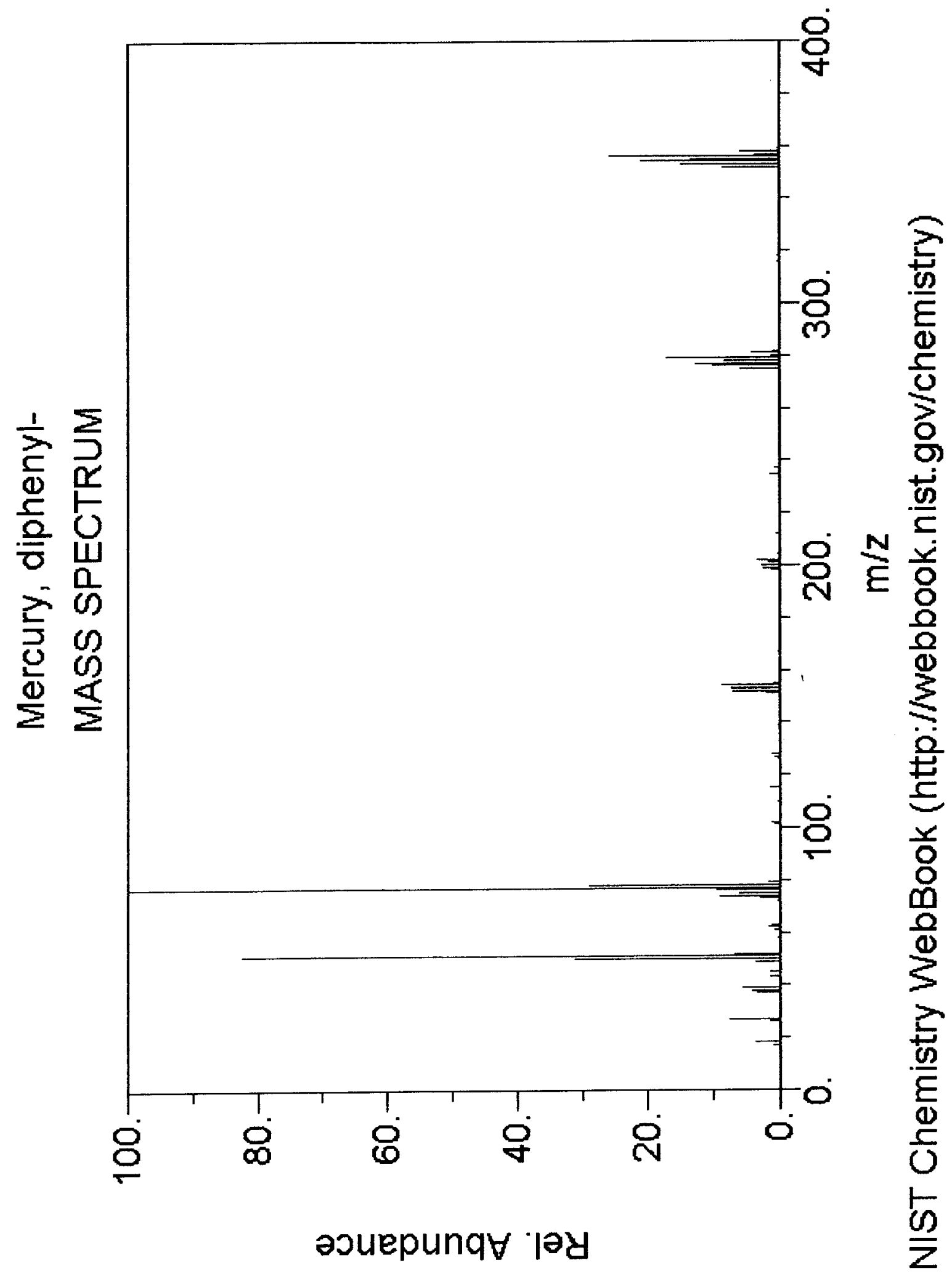


Appendix 2

Mass Spectral Traces from LC/MS of Sample 103 
LCQ Instrument Control

25 Jul $2002 \quad 03: 38$ PM

S\# : 1626 IT: 41.86 ST: 0.27 \#A: 10

NL : $5.93 e+005$

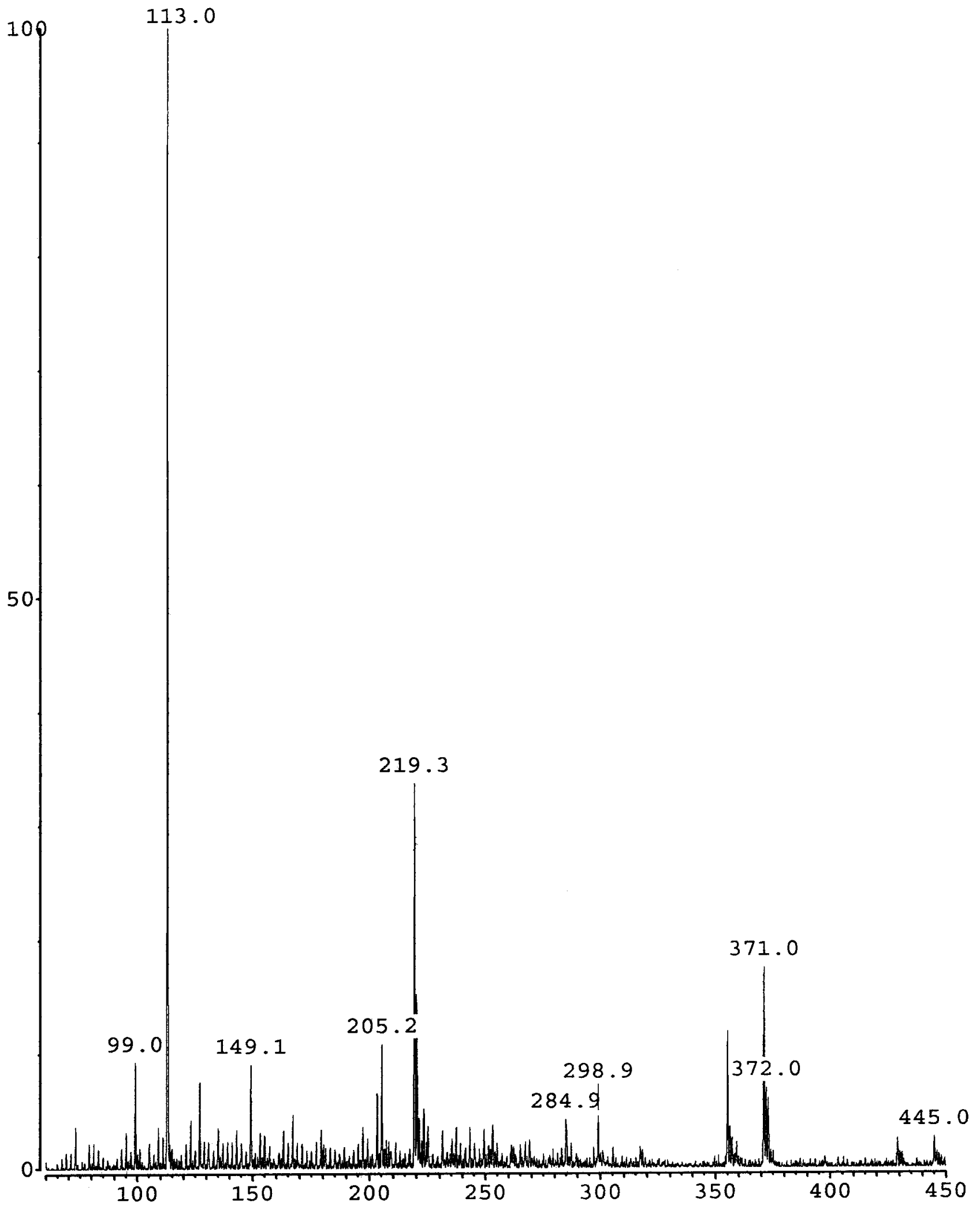

LC/MS of Sample 103 
LCQ Instrument Control

S\# : 2046

IT: 199.98

S'

109

50

$115.8 \quad 148.5 \quad 180.9207 .0$ 100
25 Jul 2002 04:12 PM

NL : $8.28 e+004$

284.9

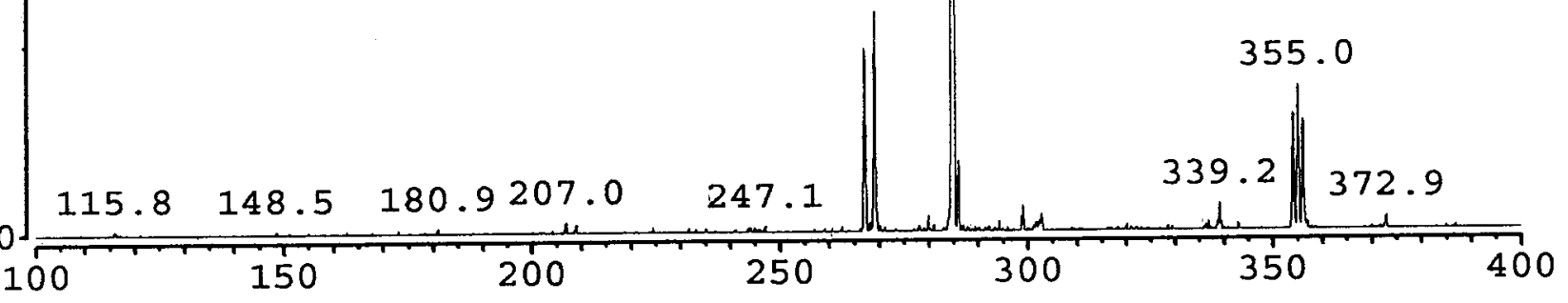

MS/MS of peak at $355 \mathrm{amu}$ in LC/MS of Sample 103 
LCQ Instrument Control

S\#： 1678 IT: 199.98

100

109

50

110.9
25 Jul 2002 04:07 PM

ST: $0.80 \quad \# A: 10$

197.1

NL: $1.09 e+004$ 
LCQ Instrument Control

25 Jul $200204: 27$ PM

S\#: 3416 IT: 194.87 ST: 0.81 \#A: 10

NL: $1.00 e+004$

00

$10 p$

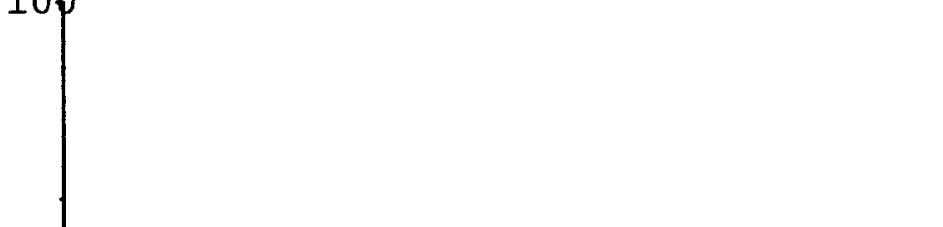

133.0

121.1

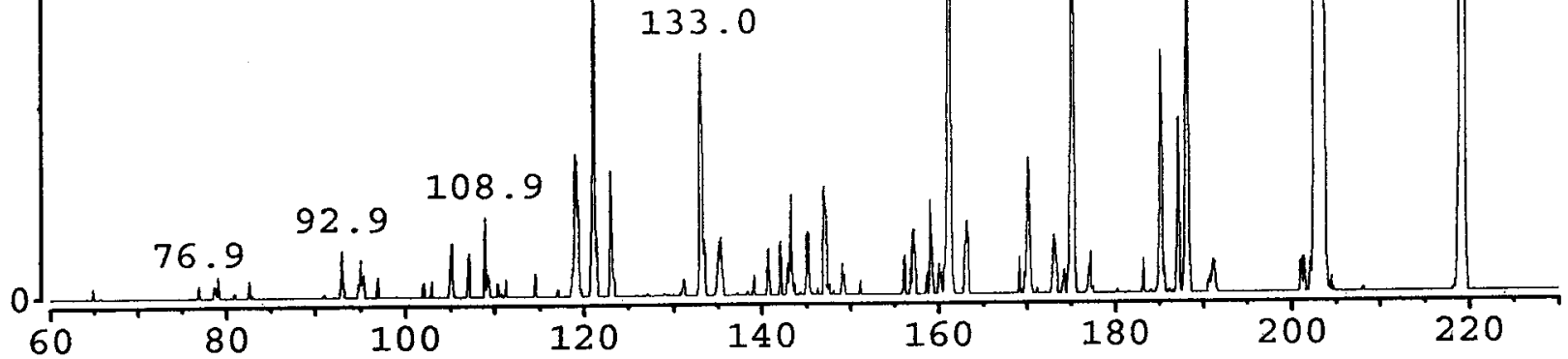

MS/MS of peak at 219 amu in LC/MS of Sample 103 
LCQ Instrument Control

S\# : 7217 IT: 199.98 ST: 0.77 \#A : 2
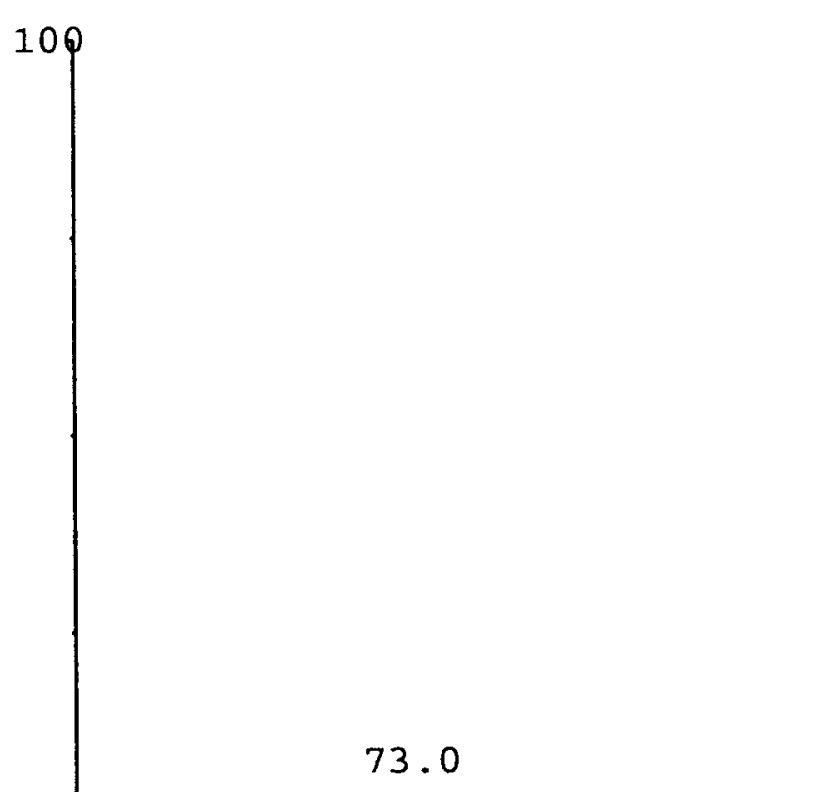

50

50

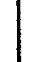
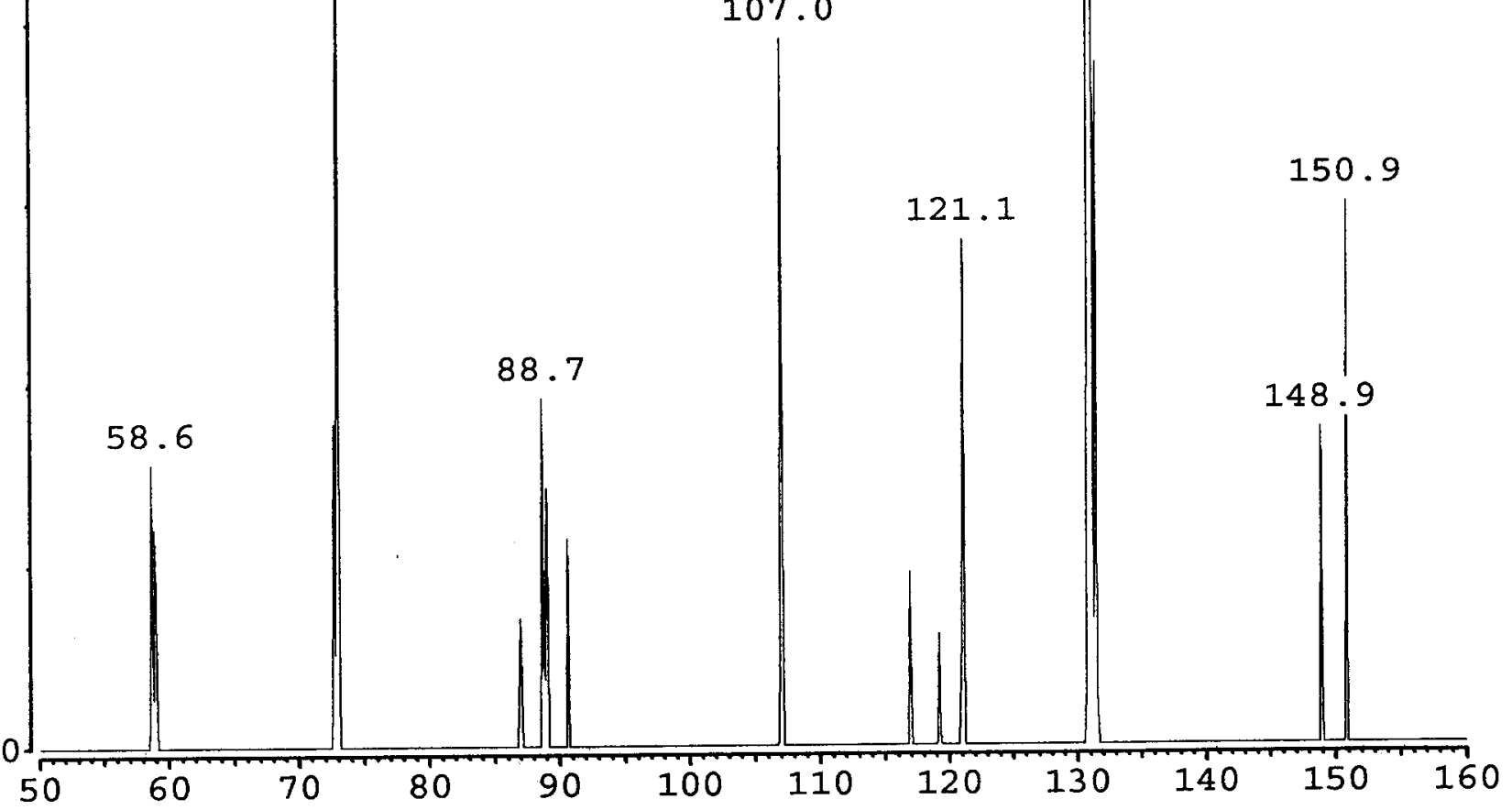

MS/MS of peak at $149 \mathrm{amu}$ in LC/MS of Sample 103 
S\# : 8884 IT: 146.20 ST: 0.60 \#A: 10

$\mathrm{NL}: 1.28 \mathrm{e}+003$

10

66.9

84.9

94.9

50

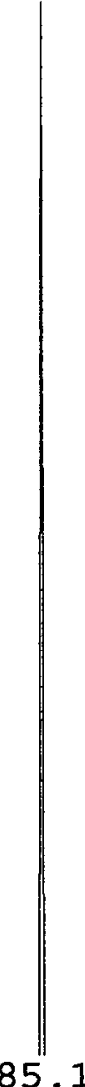

.1

112.9

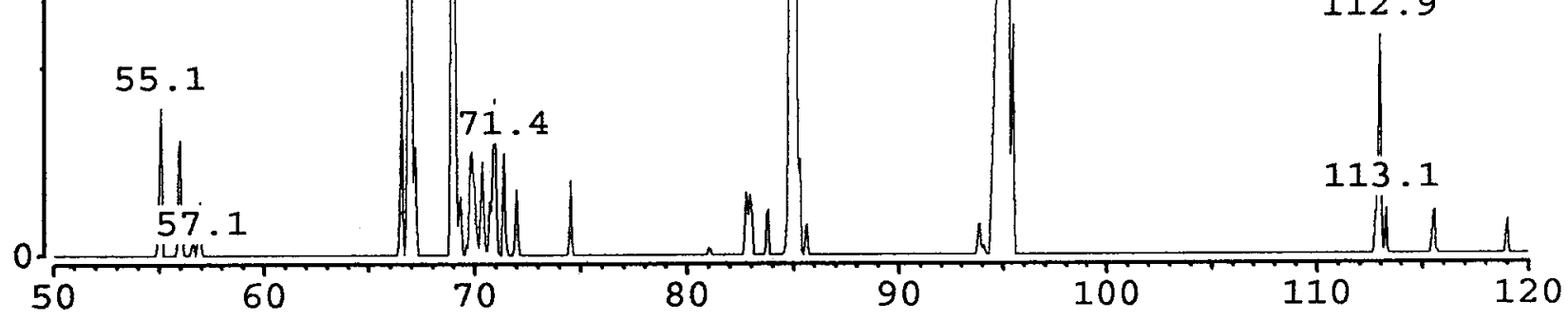

MS/MS of peak at $113 \mathrm{amu}$ in LC/MS of Sample 103 
S\# : 6151 IT: 199.98 ST: 0.98 \#A: 9

NL $: 4.47 e+004$

284.9

50
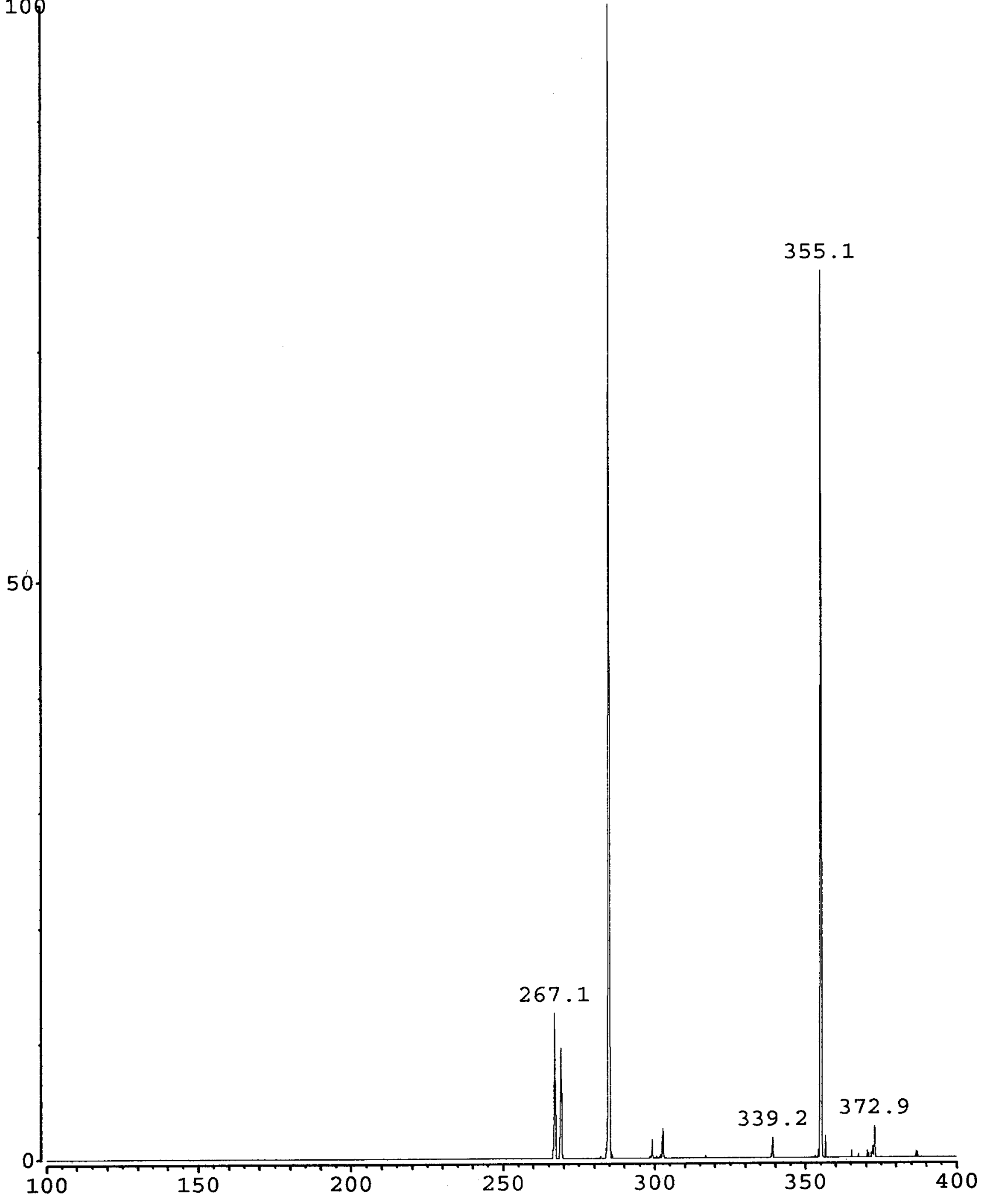

MS/MS/MS of $355 \mathrm{amu}$ of 371 peak of LC/MS of Sample 103 
LCQ Instrument Control

25 Jul 2002 05:06 PM

S\#: 8531 IT: $199.98 \quad$ ST: $0.90 \quad$ \#A: 10

NL: $7.56 e+003$

$10 p$

141.0

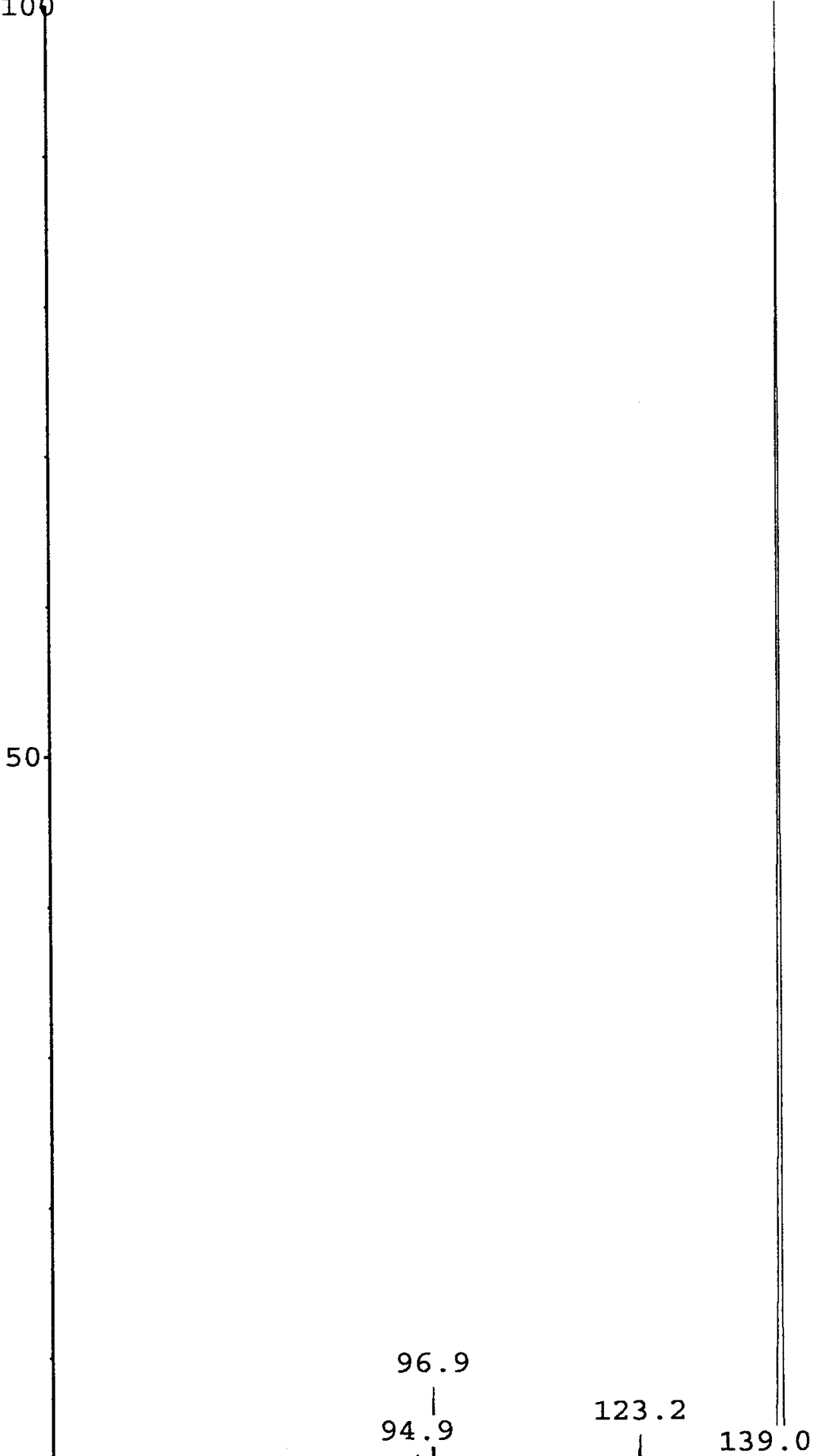

178.9

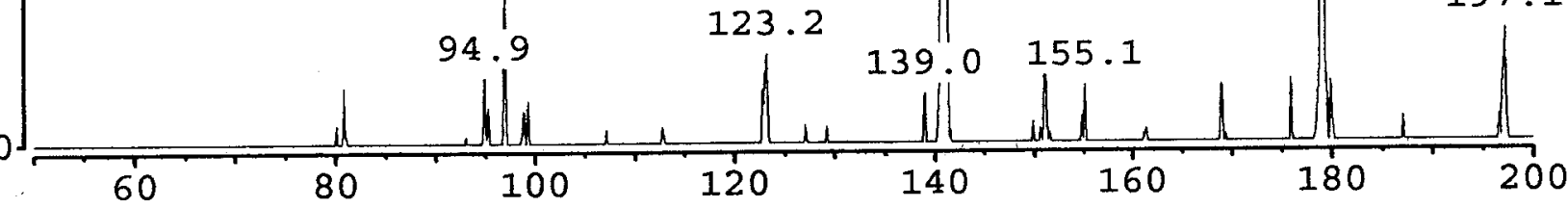

MS/MS/MS of $203 \mathrm{amu}$ of 219 peak of LC/MS of Sample 103 
$\mathrm{S \#}: 6797$ IT: 182.20 ST: 0.83 \#A: 10

$\mathrm{NL}: 1.00 e+004$

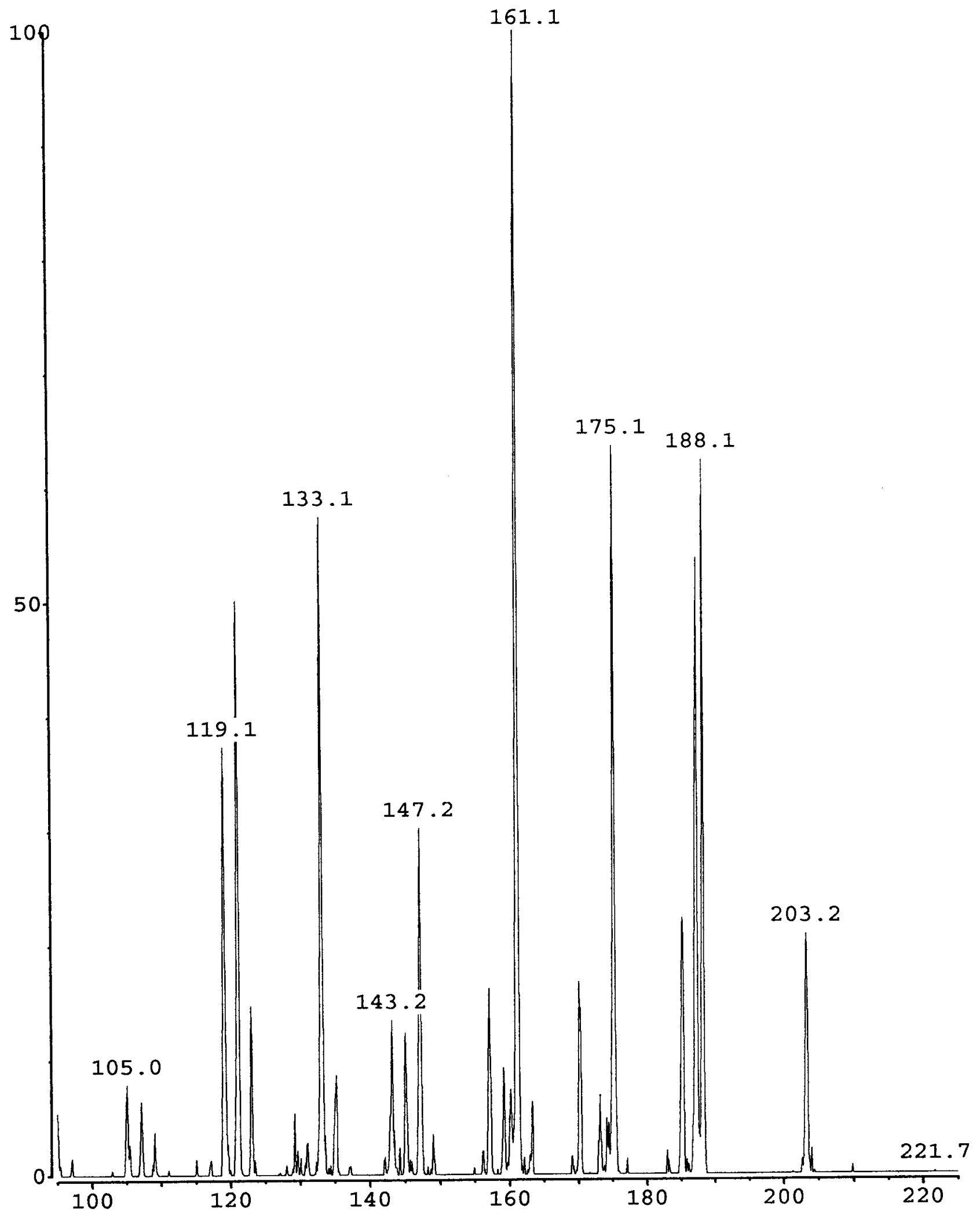

MS/MS/MS of 197 amu of 253 peak of LC/MS of Sample 103 